\title{
Misout
}

PROGRESS REPORT

TO

THE UNITED STATES DEPARTMENT. OF ENERGY

CONTRACT NO. EE-77-S-02-4268-7

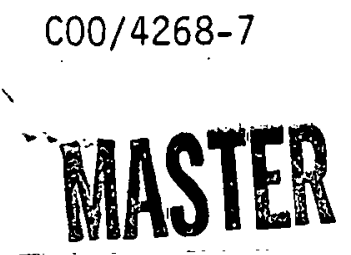
sponsored by the United States Government. Neither the United States nor the United States Department of Energy, nor any of their employees, nor any of their contractors, subcontractors, or their employees, makes any warranty, express or implied, or assumes any lega liability or responsibitity for the accuracy, completeness or use fulness of any information, apparatus, product or process disclosed, or represents that its use would no infringe privately owned rights.

\section{BIOMEDICAL RESEARCH WITH CYCLOTRON PRODUCED RADIONUCLIDES}

Contract Period:

Report Period:

8

Principal Investigator Co-Principal Investigator Co-Principal Investigator
January 1, 1979 to December: 31,1979

October 1, 1978 to July 31, 1979

John S. Laught in, Ph.D., Member

Richard S. Benua, M.D., Associate Mémber

Roy S. Tilbury, Ph.D., Associate Member

Department:

Biophysics Laboratory

5501

\section{SLOAN-KETTERING INSTITUTE FOR CANCER RESEARCH}

410 East 68 th Street

New York, New York 10021

there is no objection from the patuill

point of view to the pobiremon or

diengation of the documentiol

is and this letter.

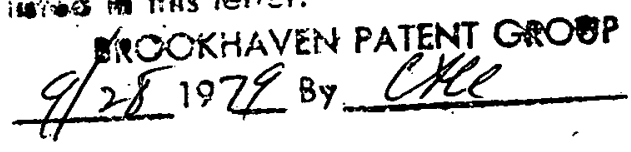

September, 1979

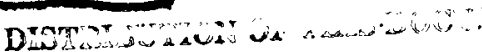




\section{DISCLAIMER}

This report was prepared as an account of work sponsored by an agency of the United States Government. Neither the United States Government nor any agency Thereof, nor any of their employees, makes any warranty, express or implied, or assumes any legal liability or responsibility for the accuracy, completeness, or usefulness of any information, apparatus, product, or process disclosed, or represents that its use would not infringe privately owned rights. Reference herein to any specific commercial product, process, or service by trade name, trademark, manufacturer, or otherwise does not necessarily constitute or imply its endorsement, recommendation, or favoring by the United States Government or any agency thereof. The views and opinions of authors expressed herein do not necessarily state or reflect those of the United States Government or any agency thereof. 


\section{DISCLAIMER}

Portions of this document may be illegible in electronic image products. Images are produced from the best available original document. 
Progress Report

Page

NOTICE

This report was prepared as an account of work sponsored by the United States Government. Neither the United States nor the United States Department of Energy, nor any of their employees, nor any of their contractors, subcontractors, or their employees, make any warranty, express or implied. or assumes any legal liability or responsibility for the accuracy, completeness, or usefulness of any information, apparatus, product or process disclosed or represents that its use would not infringe privately owned rights. 
TABLE OF CONTENTS

Page

OBJECTIVE . . . . . . . . . . . . . . . . . . . . 1

SUMMARY OF CYCLOTRON USE . . . . . . . . . . . . . . . . . . . . 1

1. METABOLIC AND TUMOR LOCALIZATION STUDIES IN MAN AND ANIMALS . 3

1.1. TUMOR DETECTION AND DIAGNOSIS. . . . . . . . . . . 3

$1.1 .1 .13 \mathrm{~N}$-Amino Acids in Patients ....... 3

1.1.2. 11 -Alpha-Aminoisobutyric Acid (AIB) and
HI Hydrogen Cyanide . . . . . . . 19

1.1.3. Metabolism of $13 \mathrm{~N}$-Amino Acids in Tumors... 30

1.2. NEUROLOGICAL STUDIES. . . . . . . . . . . . . 38

1.2.1. Cerebral $13^{N}$-Ammonia Metabolism in Normal and Hyperammonemic Rats.......... 38

1.2.2. Cerebral Metabolism and Blood Flow: Effects of Transient Ischemia.......... 44

1.3. 13N-AMMONIA METABOLISM IN RAT LUNG .......... 49

2. RADIODRUG RESEARCH AND DEVELOPMENT . . . . . . . . . . . . 58

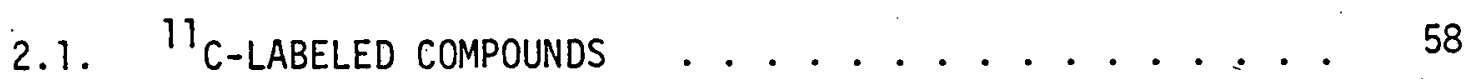

2.1.1. ${ }^{11}$ C-Amino Acids .............. 58

2.1.2. ${ }^{11} \mathrm{C}$ Precursor Compounds . . . . . . . . 67

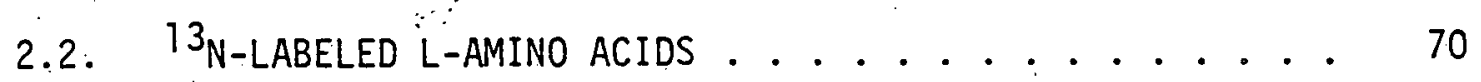

2.3. ${ }^{18}$ F-LABELED COMPOUNDS . . . . . . . . . . . 73

2.3.1. 18f-Precursor Compounds .......... . . 73

2.3.2. 18F-4-Fluoroestradiol and $18 \mathrm{~F}$-Haloperidol . . 85

2.4. STUDIES WITH POTASSTIUM-38 . . . . . . . . . . . . . 91 
Page

3. DOSIMETRY FOR INTERNALLY DEPOSITED ISOTOPES IN ANIMALS AND MAN 96

4. INSTRUMENTATION AND ANALYTICAL PROCEDURES . . . . . . 117

4.1. CYCLOTRON RESEARCH AND DEVELOPMENT .......... 117

4.2. SCANNING AND DATA HANDLING ............ 121

4.3. ELECTRONIC AND MICROPROCESSOR DEVELOPMENTS . . . . 123

4.4. EVALUATION OF MODEL 4200 POSITRON CAMERA - TOMOGRAPH . . 127

4.4.1. Summary Evaluation of PC 4200 Tomographic 127 Camera ..............

4.4.2: Tomographic Bone Scans with F-18 ..... 143

4.5. REVIEW OF POSITRON COMPUTED TRANSAXIAL TOMOGRAPHIC

INSTRUMENTS .......................... 144

5. RADIOACTIVE MATERIAL TRANSFER SYSTEM ........... 148

PUBLICATIONS . . . . . . . . . . . . . . . . . . . . . . . . . . 
BIOMEDICAL RESEARCH WITH CYCLOTRON PRODUCED RADIONUCLIDES

\section{OBJECTIVE}

The operation of the cyclotron has the following objectives:

(a) Research on nuclear reactions and target design for production of radionuclides.

(b) Research on labeling of biologically important compounds with cyclotron produced radionuclides.

(c) Production of radionuclides and labeled compounds for metabolic isotope research in patients and in animals carried out by the metabolic isotope study section.

handling technology.

(d) Development of improved cyclotron operation and beam

\section{SUMMARY OF CYCLOTRON USE}

Table 1 is a summary of runs performed with the cyclotron during this report period. A run indicates a separate request for cyclotron time, usually of several hours duration, and may include many short runs of a few minutes. Beam-on time is the time the anode or DEE voltage was on, and represents $35 \%$ of the available working hours (1848). The oscillator filament meter regestered 945 hours or $51 \%$ of the available working hours. These percentages represent a slight decrease over last year's. A beam switching magnet would probably result in a $50 \%$ increase in beam-on time. 
TABLE 1

Summary of Cýclotron Operations

October 1,1978 - July 31,1979

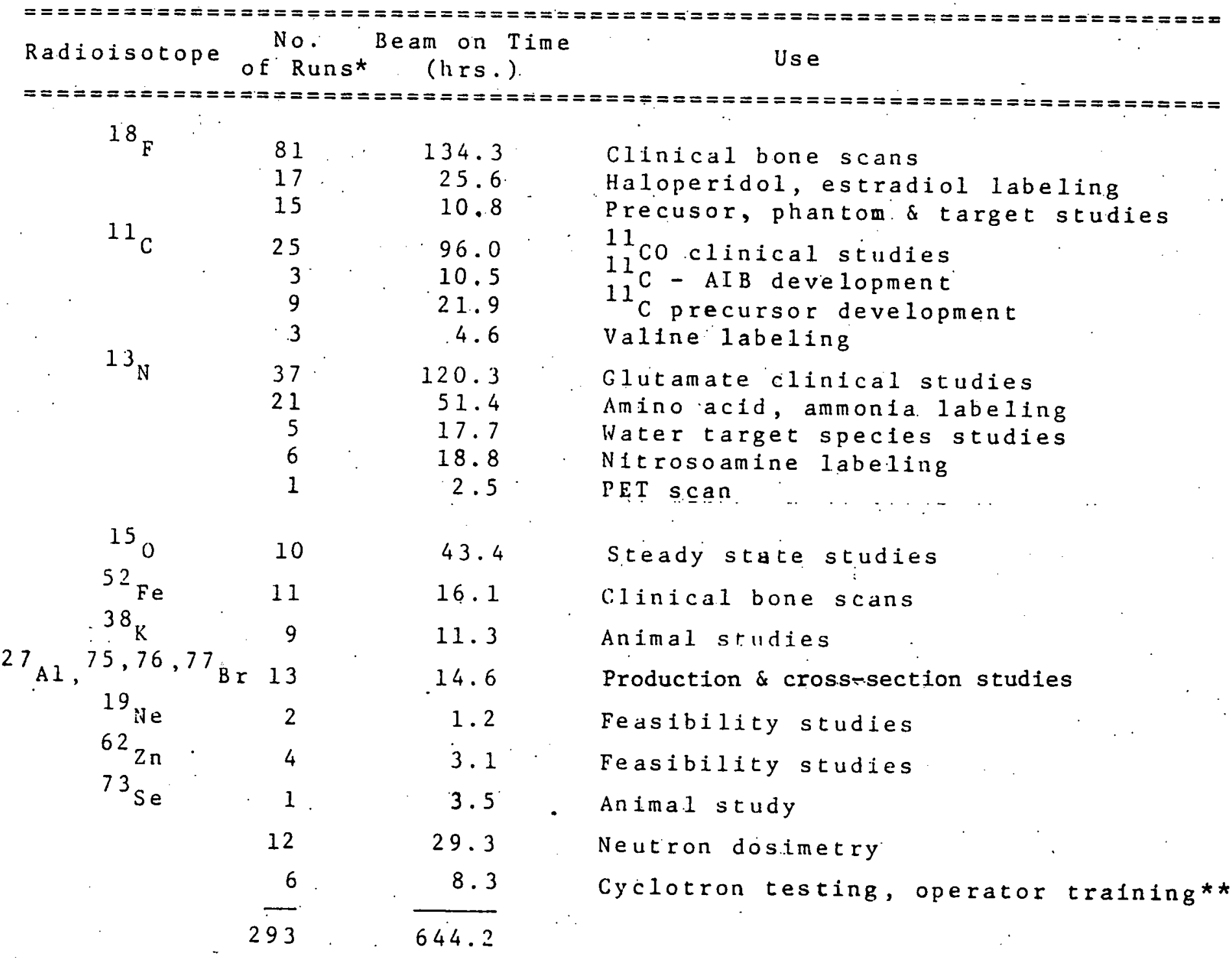

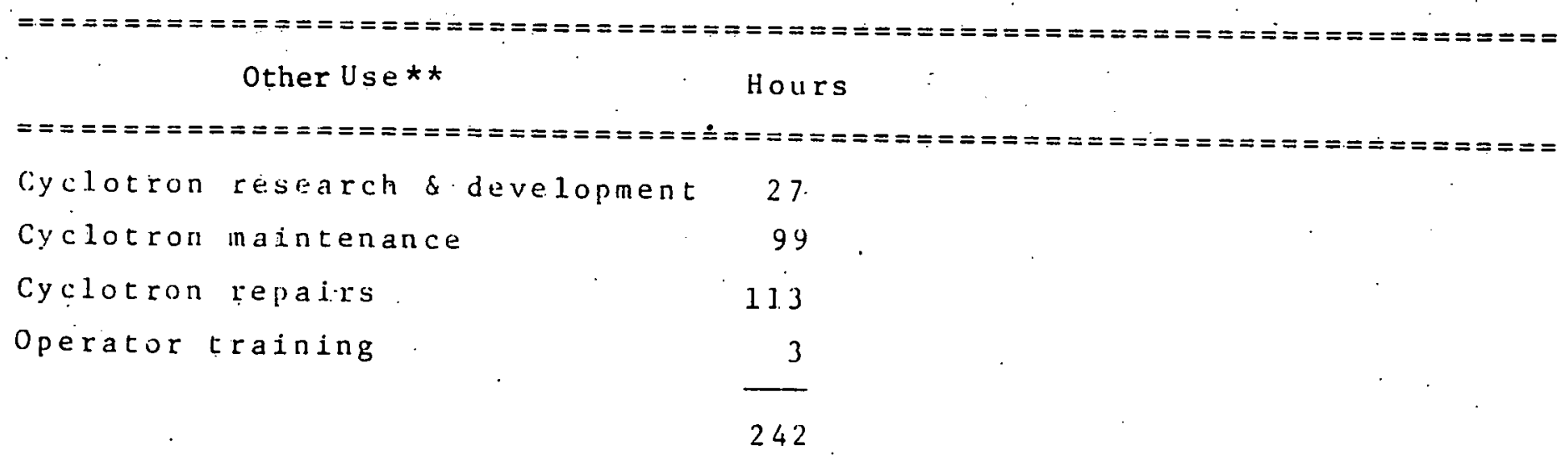

* Represents a scheduled time siot. 2-6 batches are generally made during a run.

** Not included in isotope section above.

*** Most operator training. Was cyclotron tuning and fs included in beam on time for other runs, ahove. 
1.1 TUMOR DETECTION AND DIAGNOSIS

$1.1 .1 \quad 13 \mathrm{~N}$-AMINO ACIDS IN PATIENTS

\section{OBJECTIVE:}

This project aims at detecting and staging rapidly growing maliganancies by the incorporation of $13_{N}$ labeled amino acids into tumors. Metabolism of the compounds is assessed by observing the intensity and time course of their uptake. A further objective is the development of agents which are specific for rapidly growing tumors such that they can be used to monitor the effectiveness of therapeutic agents.

\section{SCOPE OF INVESTIGATION:}

Tumor localization is logically developed by the selection of compounds or their analogues which are metabolic precursors in neoplastic cells. Amino acids as building blocks for protein may be expected to be incorporated into rapidly growing tumors. We favor the L-stereoisomers of normally occuring amino acids, and have proposed to compare several in a variety of sarcomas and cancers. Because of observed variations between species in the behavior administered compounds, evaluation is ultimately necessary by direct observations on tumors and organs in man. The sensitivity and specificity of each practically available compound needs to be evaluated in a spectrum of malignancies, especially those in which presently available radionuclides are not concentrated.

We proposed to add more osteosarcoma patients to our series, with special regard to untreated patients for the purpose of detecting distant metastases. We required further experience with $13 \mathrm{~N}$-glutamate for gauging the response of osteosarcoma to the chemotherapeutic agents, in comparison with parallel changes in tumor visualization with 99m-Tc-diphosphonate, whose uptake is determined by available active bone surface rather than tumor viability.

In Ewing's sarcoma we needed more cases, and we wished to observe the treatment response in the same fashion as osteosarcoma. We proposed to add other malignant tumors to our series to get an idea of the spectrum of tumors which would be detectable as well as how this correlated with rate of growth and with detectability using other tumor imaging agents.

\section{RESULTS AND CONCLUSIONS:}

In sarcomas other than osteogenic or Ewing's sarcoma, only isolated examples have been studies. A patient with multiple foci of untreated masenchymal chondrosarcoma was studied before therapy. Two of his 3 lesions were well visualized. The third lesion was in the spine near the liver, and may have been missed because of high liver uptake of $13 \mathrm{~N}-L$-glutamate. Serial studies showed high glutamate tumor uptake persisting when the sarcoma was not responding to chemotherapy, and decreased tumor uptake when the tumor did respond. A spindle cell sarcoma of the leg which had metastasized to lung was not seen in a glutamate scan of a treated patient, despite recent spread of the tumor.

Mixed results were found in two patients with untreated neuroblastoma. A presacral neuroblastoma in a 17 year old male had moderate uptake of $13 \mathrm{~N}$ glutamate. Multiple known sites of neuroblastoma were not visualized with 
glutamate in a 6 year old boy. Further data are needed for neuroblastoma. One large benign retroperiotneal garglioneuroma did not take up $13 \mathrm{~N} \cdot g l$ utamate.

Primary brain neoplasms were examined with $13 \mathrm{~N}$-sodium $\mathrm{L}$-glutamate with encouraging results. Two patients with recurrent pineal embryonal carcinoma had positive scans in areas confirmed as tumor on radiographic and CTT images. In the same patients $99 \mathrm{~m}$ Tc-pertechnetate images did not have as great a contrast to normal brain, suggesting that glutamate is concentrated by these tumors and not just passing the blood-brain barrier. An ependymoblastoma recurrent in an 8 year old girl had intense glutamate uptake, much higher than in the pertechnetate brain scan performed the following day. The T/B ratio was 3.50 for glutamate and 1.76 for pertechnetate, An astrocytoma of the right frontal lobe was positive in a glutamate examination of a 13 year old boy. No conventional brain scan was done. In a 6 year old, a dysgerminoma of the central nerous system was less positive in a glutamate scan than in a $99 \mathrm{~m}$ Tcglucoheptonate scan performed 2 weeks later. More patients with primary brain lesions are needed to determine patterns of $13_{N}$ glutamata concentration in brain lesions, and to define the nature of the uptake into the neoplasm.

Carcinoma of the pancreas was studied in 3 patients. In a 70 year old male the lesion in the head of the pancreas failed to collect $13 \mathrm{~N}$ glutamate while the body and tail of the pancreas were visualized by their uptake. In two other patients neither the tumor or any remaining pancreatic tissue showed uptake detectable by scanning.

A patient with an unknown source of adenocarcinoma (possibly prostate or pancreas) was imaged with the $P C-4200$ positron camera (PET) after the administration of $11.4 \mathrm{mCi}$ of $13 \mathrm{~N}-\mathrm{glutamate}$. The pancreas was not visualized but a bone metasteses in the left fifth rib had intense uptake. The same lesion was well seen in the bone scan. Further experience with carcinoma metastatic to bone will be necessary. In this instance the transaxial emission tomogram was very helpful in distinguishing the rib uptake from normal glutamate in the myocardium. A second patient with an unknown primary malignancy had a probably normal pancreas image on the PET.

We conclude that pancreas cancer fails to collect glutamate. In some patients the pancreas cancer may produce a void in the high uptake of normal pancreas tissue. Usually the extensive involvement of the pancreas by tumor or secondary inflammatory distruction of normal pancreas prevents visualization of that organ, which is undistinguishable from benign causes of pancreatic damage.

Observation of normal volunteers after the injection of $13 \mathrm{~N}$-sodiumL-glutamate early in our experience with this agent revealed high pancreas uptake. The per cent uptake was measured with the High Energy Gamma (HEG). rectilinear scanner equipped with constant-response collimation and digital data recording in 2 normal controls and measured 9.0 and $9.4 \%$ of the dose by the method of this laboratory (1). The pancreas was also visualized and separated from the liver in 3 patients with osteosarcoma (range of uptake 
$8-12 \%)$. The pancreas to liver ratio was estimated to be $9: 1$, making this one of the best agents for visualizing the pancreas of man:

Three normal volunteers also were imaged on the PET after the administration of up to $20 \mathrm{mC} i$ of $13 \mathrm{~N}$-sodium-L-glutamate. Longitudinal plane reconstruction and selected trarisaxial tomographs were made. They showed high uptake in pancreas, myocardium and liver. The resolving power of, this machine $(1.5 \mathrm{~cm}$ FWHM) may make possible the visualization of moderately early pancreas neoplasm on selected patients. More, patients need to be studied to evaluate this method. We plan to compare $13 \mathrm{~N}-\mathrm{L}-\mathrm{val}$ ine to glutamate on the PET as well as the HEG scanner. Since the PET requires a higher dose for statistically adequate measurements, the initial human studies of Li-valine may require the HEG. When higher yields of valine are produced positron transaxial tomography may become the method of choice.

The largest population of patients we have studied has consisted of children and young adults (ages 6 to 30 ) with osteogenic sarcoma. Since the ${ }^{3} \mathrm{~N}$-glutamate clinical program was begun in April 1978 we have performed a total of 69 studies on 36 individuals with osteogenic sarcoma, most of whom were seen and treated during this report period. Of these, 28 patients had tumors in peripheral limbs which could be evaluated easily by absolute quantitative techniques to yieldestimates of per cent dose in the tumor (58 studies). Twenty-two patients had one or more follow-up studies. Nineteen of that group had quantifiable peripheral tumors and pre-treatment baseline studies; between one and three follow-up studies were performed during their chemotherapeutic regimens. which generally consisted of high-dose methotrexate with citrovorum rescue factor, in some cases followed by cyclophosphamide, adriamycin or cis-platinum.

In general, the primary tumor almost always stood out from the surrounding or contralateral structures quite intensely in the scan image; a typical untreated lesion would concentrate about $2-4 \%$ of the injected $\mathrm{N}-13$ activity. Notable exceptions included two individuals with osteogenic sarcoma secondary to radiation therapy to the pelvis for neuroblastoma (13 years previously) and Hodgkin's Disease (7 years previosly); the former lesion was avascular on arteriography. A primary tumor of the mandible was poorly seen in one patient, partiy due to interfering activity in the salivary glands. A third pelvic lesion, also described as avascular on arteriography, was not well defined. All untreated primary tumors were detectable, however. Figures 1 and 2 are $13 \mathrm{~N}$-glutamate scans of patients with untreated lesions in the left distal femur; they represent the highest and lowest values of $13_{\mathrm{N}}$ uptake in tumors at that site. One individual with a large tumor in the distal femur was studied on the TOKIM gamma camera in order to observe the kinetics of uptake of label into tumor and normal tissue; in addition, stationary probes were used for the same purpose in three patients during their rectilinear scans. These results indicate that: a) tumor tissue incorporates. $13_{\mathrm{N}}$ at about the same rate as the radioactivity clears the blood and $b$ ) the $13 \mathrm{~N}$ label remains in the tumor for periods up to 35 minutes following injection, with no discernable loss.

Metastatic disease was rárely detected, even in cases where it was 
positive on radiography and 99m Tc-diphosphonate scans. This may be explained in the case of lung metastases (a common occurrence in the course of this disease) by myocardial and hepatic radioactivity which may interfere with tumor visualization. However, known metastatic disease in peripheral areas of the skeleton are also poorly seen, and the basis for this apparent difference in the affinity of primary and metastatic disease for glutamate is not clear. It is possible that differences in blood supply may be partially responsible.

In an effort to determine the factors that affect $13 \mathrm{~N}$ uptake in the primary tumor, a simple computational model of glutamate tracer uptake (see figure 3) was studied. Note that the model makes no provision for a return of labeled metabolites from the tumor cells to the blood; this is a consequence of our observation (using stationary probes or gamma camera) that the tumor radioactivity remains constant for up to 35 minutes after reaching a plateau about 2 minutes after injection. Solution of the differential equations for the total observed radioactivity in the vascular bed and tumor tissue (which are not resolvable with current instrumentation) at equilibrium yields

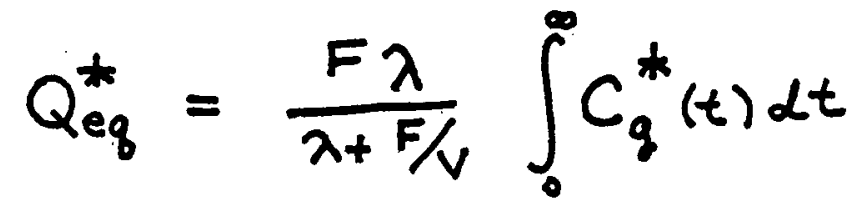

where the variables are defined in Figure 3.

Hence the observed tumor uptake (microcuries) can be expected to increase with increasing tumor extraction rate, increasing blood flow and increasing blood volume. If the tumor extraction rate is assumed to increase with increasing serum alkaline phosphatase concentration (i.e. both alkaline phosphatase and glutamate extraction are related to tumor metabolic activity), it can be shown that tumor radioactivity content is related to serum alkaline phosphatase levels (AP) by

$$
Q_{e q}^{*}=\frac{F \cdot K_{1} \cdot A P}{K_{1} \cdot A P+F / V} \int_{0}^{*} C_{g}^{(t) d t}
$$

where $K_{1}$ and $K_{2}$ are constants related to alkaline phosphatase excretion rate and total body blood volume. If it is assumed that the clearance curve, blood volume and the rate of loss of alkaline phosphatase from the serum do not vary greatiy between individuals, then a plot of tumor uptake versus AP would be linear at low AP and would increase to a plateau value $\left(=F^{\circ} C_{g} *(t) d t\right)$ for very high AP.

Our patient data tend to support these hypotheses. Table 2 shows the relationship between tumor $\mathrm{N}-13$ uptake as measured by the HEG system and tumor blood supply as measured by arteriography in fourteen studies where the patient had an arteriogram around the same time as the glutamate scan. It can be seen that poory vascularized tumors are not as well visualized in the glutamate scan as tumors that are described as hypervascular (grading system: $0=$ very poorly visualized, $4=$ very intense uptake of $(3 \mathrm{~N}$ ). Hence the equilibrium value of tumor. $\mathrm{N}-13$ content indeed appears to be related to blood supply. 
Figure 4 shows the relationship between serum alkaline phosphatase level and N-13 uptake in the primary tumor for individuals with AP below 400 Units per liter. The uptake appears to be i inearly correlated with alkaline phosphatase as predicted by the model. Individuals with AP greater than $400 \cup \wedge$ (not shown on plot) do not have proportionately larger uptake, but rather the uptake plateaus at a value of about $5-7 \%$ of the injected activity. The true shape of the uptake versus AP curve thus roughly matches that predicted by the model. Intuitively, this behavior may be explained as follows: as tumor metabolism increases (implying a concurrent increase in AP), the uptake of $13 \mathrm{~N}$ will increase proportionately. However, a point is reached where further increases in metabolism will not result in proportionate increases in uptake due to the finite amount of radioglutamate that can be delivered to the tumor by the blood; that is, the uptake in tumors that are extracting $13 \mathrm{~N}$ from the blood at very high rates will ultimately be limited by blood flow. The scatter of points about the curve is considerable and is attributable to the following sources of error: a) serum AP is age and sex-dependent in this population and no corrections for these factors have been made; b) the rates of loss of AP from the serum and the distribution space may differ between individuals and c) most importantly, tumor uptake depends on blood flow and tumor vascular yolume even in the linear portion of the curve. We can conclude, then, that $13 \mathrm{~N}$ uptake in the tumor is primarily a reflection of tumor metabolism but that factors such as blood flow and tumor blood volume also affect the equilibrium uptake. In addition, the glutamate utilization rate (umole/min) for the tumor, as measured from the tracer data, will depend upon plasma (unlabeled) glutamate concentration. If $\lambda$ is the rate of utilization and $(\mathrm{g})$. is the plasma glutamate concentration ( $\mu \mathrm{mole} / \mathrm{ml})$, then

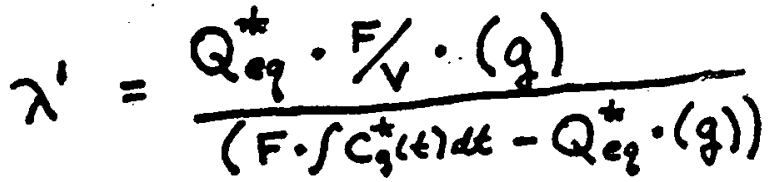

We have measured $(\mathrm{g})$ for several patients but the results are not complete at this writing.

The dependence of glutamate uptake on the metabolic state of the tumor has been exploited to monitor chemotherapy in these patients, and this venture has been quite worthwhile. In general, we have observed that the increase or decrease of the $13 \mathrm{~N}$ glutamate uptake in the primary tumor parallels changes in alkal ine phosphatase, his.tology, $99 \mathrm{mT}_{\mathrm{T}} \mathrm{c}$-diphosphonate bone scan and relevant clinical signs that are normally used to monitor the fects of pre-operative chemotherapy: Osteogenic sarcoma in peripheral sites such as the distal femur is a good "model tumor" to test the usefulness of quanti-

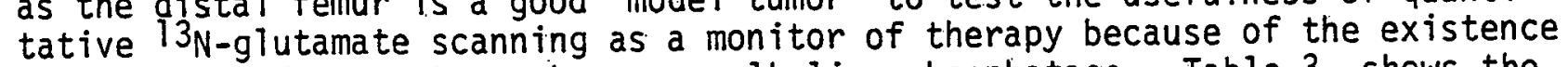
of an independent marker, the serum alkal ine phosphatase. Table 3 shows the correlation between changes in alkaline phosphatase and changes in $13 \mathrm{~N}$ uptake in the primary tumor from the basel ine values. Four individuals with normal (non-elevated) alkaline phosphatase were excluded from consideration. The correlation is quite good; the single exception was a patient with multiple sites of disease who presented with a highly elevated ( 2000 units/1) alkaline phosphatase; the major lesion in his proximal tibia showed steadily increasing degrees of $13 \mathrm{~N}$ uptake even after months of aggressive chemotherapy. 
Table 4 shows the correlation between changes in $13 \mathrm{~N}$ uptake and changes in the histologic picture for 14 individuals where both. biopsy and post-operative tumor tissue specimens were available for comparison. In general, the largest decreases in glutamate uptake show the best histological response while increases in glutamate uptake are accompanied by lesser degrees of improvement in the histologic picture. Note that there are no grade 4 histologic changes in the sample above; this is consistentwith our observation that the $13 \mathrm{~N}$ tumor uptake, even though greatly reduced, is nearly always still positive prior to surgery. This is contrast to Ewing's sarcoma, where 3 individuals with essentially negative pre-operative glutamate scans (highly positive before chemotherapy)showed total destruction of tumor at surgery or re-biopsy. In general, the changes in the $\mathrm{N}-13$ glutamate scans reflected the changes in the $99 \mathrm{mTc}$-diphosphonate scans. A detailed comparison is not available and probably is not worthwhile given the clear superiority of $99 \mathrm{~m}_{\mathrm{Tc}}$ labeled bone-seeking compounds in terms of image quality, cost and availability over $13 N-1$ abeled compounds. $13 N$-glutamate offers no advantage over the radiograph and the diphosphonate scan for evaluating the extent of tumor at the primary site. No nuclear modality has been very effective for finding metastases of osteosarcoma and the performance of $13 \mathrm{~N}$-glutamate can be considered inferior to that of $99 \mathrm{mTc}$-diphosphonate in that regard. In terms of therapy monitoring, the $13 \mathrm{~N}$-glutamate scan has proved $100 \%$ successful in predicting the effectiveness of chemotherapy; we observe that the glutamate scan tends to show somewhat larger qualitative changes: than the diphosphonate scan, due to the different mechanisms of uptake $(3 \mathrm{~N}$ tends to concentrate in the soft-tissue component of the tumor whereas $99 \mathrm{mTc}$ concentrates in regions where calicification has occurred). The glutamate scan may have only limited advantage in therapy monitoring for osteogenic sarcoma over the conventional bone scan. However, the objective of this research is not to attempt to demonstrate the superiority of glutamate over diphosphonate but rather to test the use of $13_{\mathrm{N}}$-glutamate as a measure of tumor metabolism in a model system for which distinct markers (bone scan and alkaline phosphatase) already exist, in hopes of extending this experience to other tumor types which are more difficult to follow. An example is Ewing's sarcoma, in which the bone scan is usually positive but the alkaline phosphatase is characteristically normal. Table 5 summarizes our experience with this rare tumor. Six patients were studied, 5 of whom had baseline glutamate studies and follow-up studies. All tumors were detectable and the glutamate uptake always decreased after chemotherapy.

Based on our experience with $13 \mathrm{~N}$-g]utamate in osteogenic sarcoma and Ewing's sarcoma, we conclude that a) the $13_{N}$ label enters tumor tissue rapidly at a rate similar to that at which activity leaves the blood, suggesting that the labeled glutamate itself is being transported into the tumor rather than some. labeled metabolite; b) uptake in the tumor is related to its metabolic activity, but factors such as blood flow are also important; c) changes in the glutamate scan accurately reflect the response of osteogenic sarcoma to pre-operative chemotherapy as measured by conventional means, and that it is desirable to extend this experience to other types of tumors.

$13_{N}-G$ lutamate (and other $13 \mathrm{~N}$-labeled compounds) afford several advantages over conventional tumor imaging agents, such as rapid blood clearance. and localization, low radiation exposure and the possibility of obtaining accurate, three-dimensional quantitative images via positron emission tomography. 
It is doubtful that these advantages will justify the routine use of $13 \mathrm{~N}-$ glutamate to detect tumors or to monitor therapy except in clinical situations where conventional techniques (radiography, biochemistries; $6: \mathrm{Ga}$ or $99 \mathrm{mTC}$ scanning). are unsatisfactory. The value of $13_{N}$-glutamate 7 ies not in its role as an imaging agent, but rather as: a research tool which can be used to assess the metabolic requirement of neoplastic tissue (in terms of energy-related processes or protein synthesis) in human cancer patients in-vivo. The information gained by studying many tumor types in a variety of circumstances (de novo and under the influence of chemotherapeutic drugs) will hopefully lead to an increased understanding of tumor amino acid metabolism and its implications in the design of therapeutic modalities. 


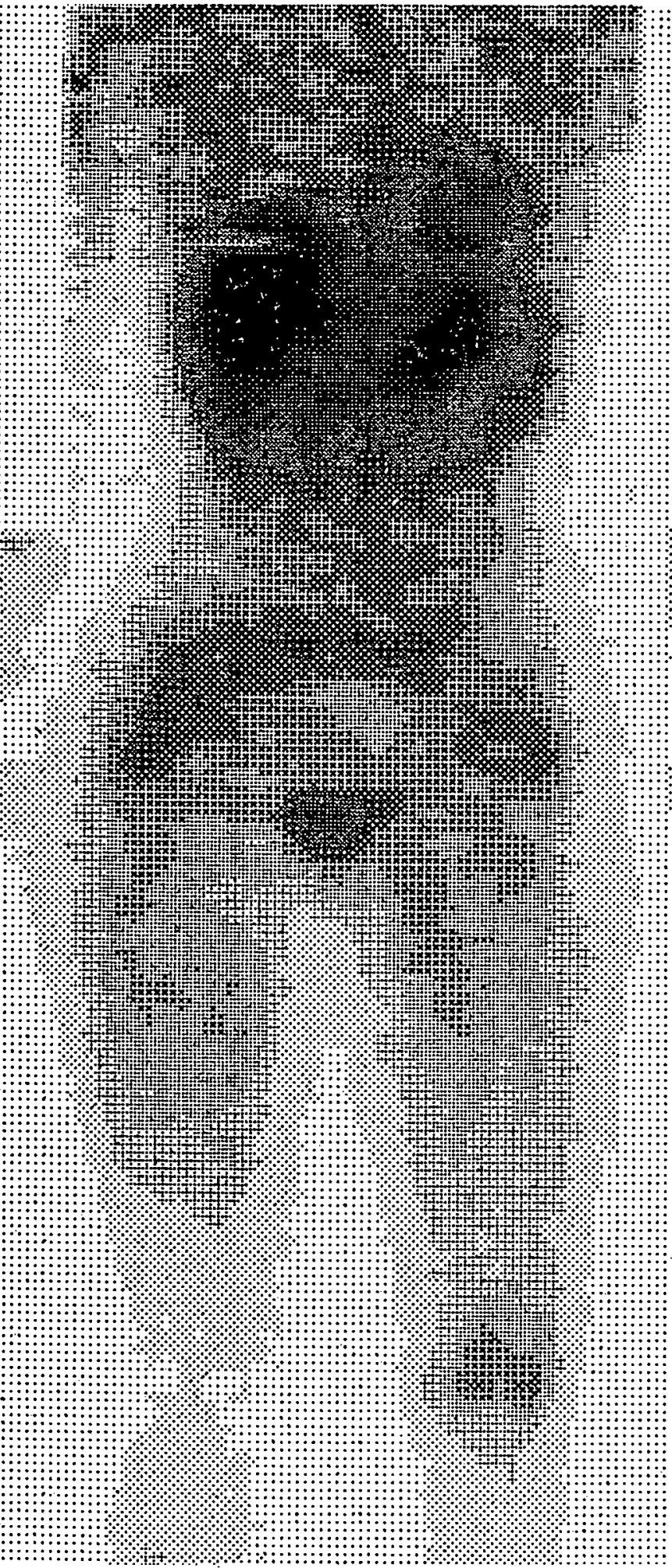

Figure 1. Total body ${ }^{13} \mathrm{~N}-\mathrm{L}-$-glutamate scan of 16 year old female with osteosarcoma in left distal femur. Tumor uptake is approximately $1.7 \%$ of dose. 


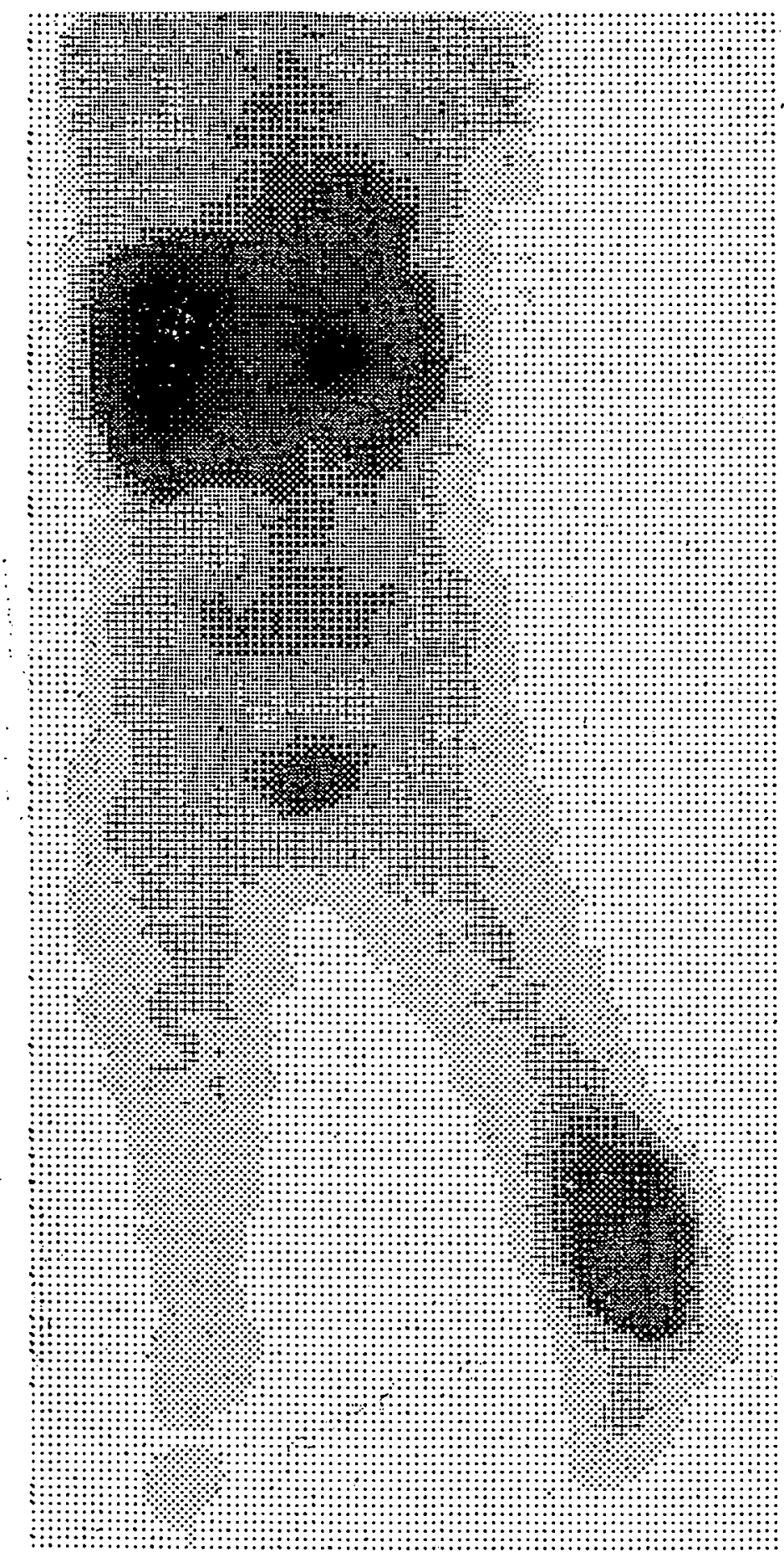

Figure 2. Total body ${ }^{13} \mathrm{~N}-\mathrm{L}-$-glutamate scan of 10 year old female with osteosarcoma in left distal femur. Tumor uptake is approximately $7.0 \%$ of dose. 


\section{N-13 GLUTAMATE TUMOR UPTAKE MODEL}

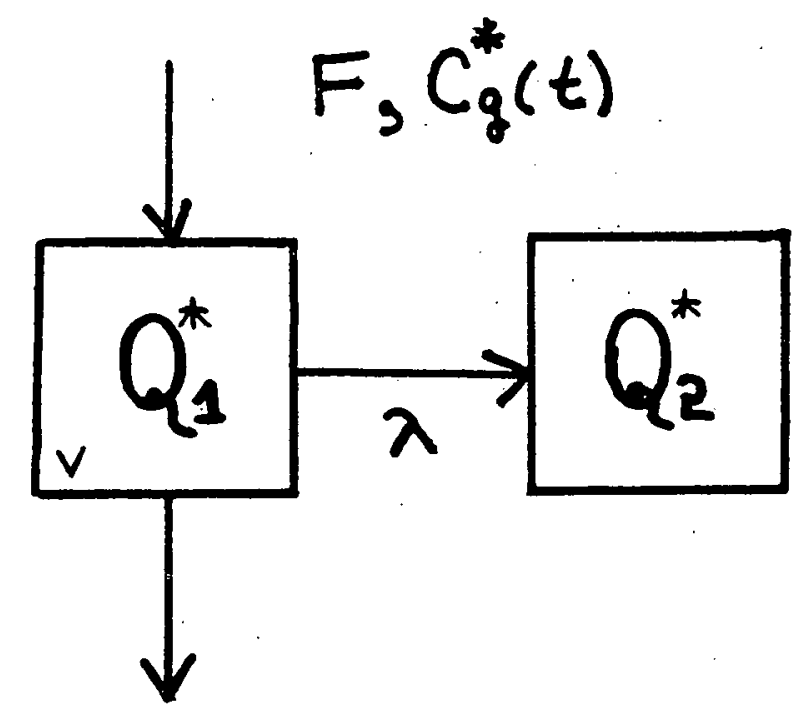

$$
\begin{aligned}
& \dot{Q}_{1}^{*}=F \cdot C_{q}(t)-\lambda Q_{1}^{*}(t)-Q_{1}^{*}(t) \cdot F / V \\
& \dot{Q}_{2}^{*}=\lambda Q_{1}^{*}(t)
\end{aligned}
$$

$Q_{1}^{*}=$ ACTIVITY IN TUMOR VASCULAR BED (MICROCURIES)

$a_{2}^{*}=$ ACTIVITY IN TUMOR CELLS (MICROCURIES)

$V=$ VOLUME OF $Q_{1}$ (MILLILITERS)

$F=$ TUMOR BLOOD FLOW (ML/MIN)

$c_{g}^{*}(t)=$ CONC. OF N-13 GLU IN. BLOOD (MICAOCURIES/ML)

$\lambda=\operatorname{EXTRACTION~RATE~(/MIN)~}$

FIGURE 3 


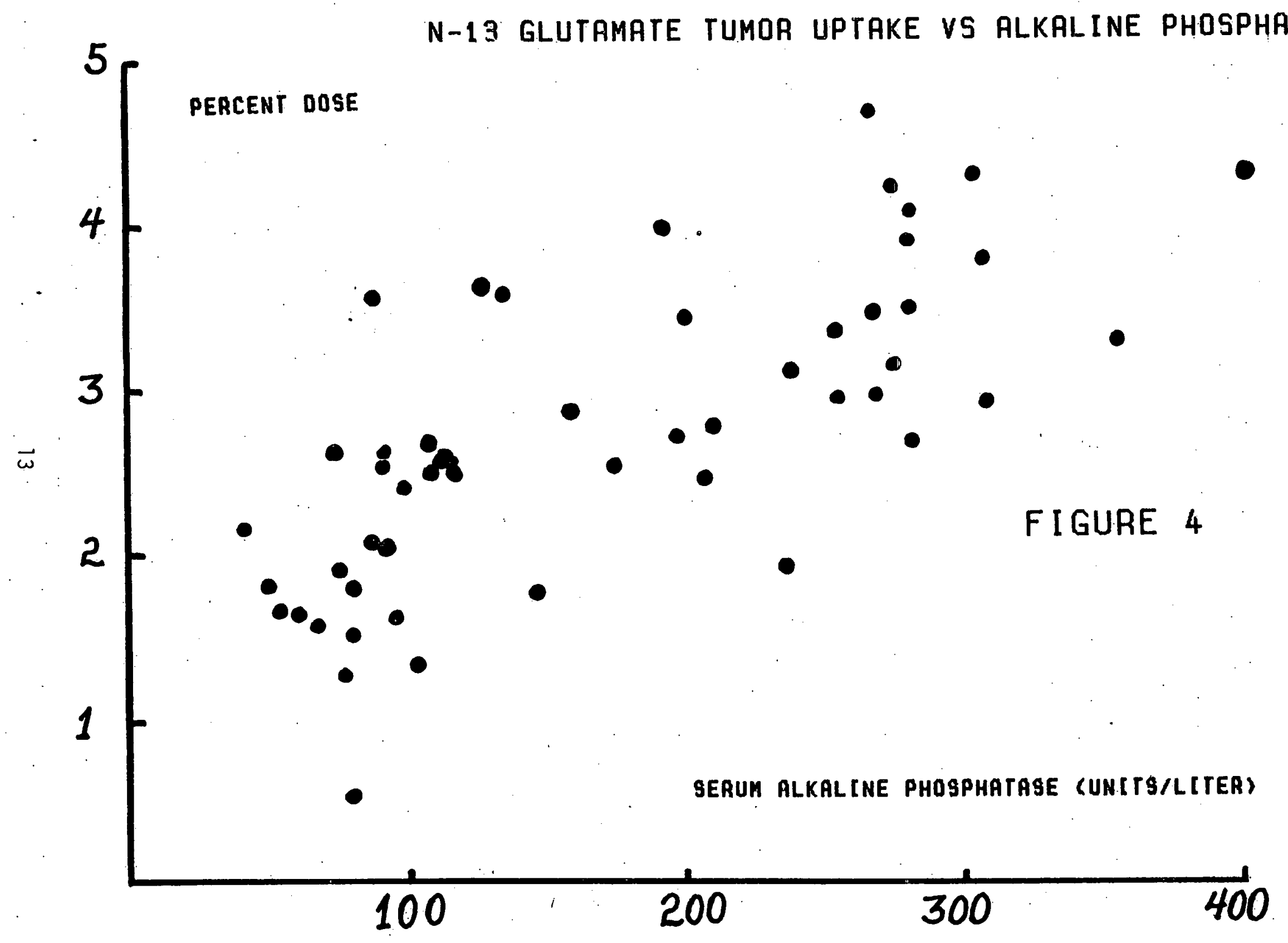


TABLE 2

N-13 GLUTAMATE UPTAKE VS ARTERIOGRAPHY

\begin{tabular}{|c|c|c|c|}
\hline SUBJECT & LESION SITE & GRADE (\% DOSE) & ARTERTOGRAM DATA \\
\hline JB & Dist. Femur & $4(3.24 \%)$ & $\begin{array}{l}\text { Faint opacification of mass } w / \text { demon- } \\
\text { stration of tumor vessels in soft } \\
\text { tissue component. }\end{array}$ \\
\hline PM & Dist. Femur & $4(3.66 \%)$ & Hypervascular lesion \\
\hline $\mathrm{CW}$ & Dist. Femur & $4(4.23 \%)$ & Hypervascular lesion \\
\hline DM & Pelvis & $0(--)$ & Avascular lesion \\
\hline MV & Pelvis & $0(---)$ & Avascular lesion \\
\hline MF & P. Humerus & $2(4.07 \%)$ & Abnormally increased vascularity \\
\hline SF & Prox. Tibia & $4(2.52 \%)$ & Diffusely incr. abnormal vascularity \\
\hline $\mathrm{FF}$ & Dist. Femur & $2(2.44 \%)$ & $\begin{array}{l}\text { Abnormally increased vasc. w/ moderate } \\
\text { tumor staining }\end{array}$ \\
\hline JK 2 & Dist. Femur & $1(1.57 \%)$ & Norma1 Arteriogram -- No tumor vasc: \\
\hline TM 1 & P. Humerus & $2(2.72 \%)$ & Small areas of abnorm, incr, vasc. \\
\hline TM 2 & P. Humerus & $2(3.12 \%)$ & $11 \times 13 \mathrm{~cm}$ mass $\mathrm{w} / \mathrm{incr}$ vascularity \\
\hline SM 2 & P. Humerus & $2(3.40 \%)$ & Mild neovascularity; some tumor stain \\
\hline SP 3 & Dist. Femur & $2(1.61 \%)$ & Very minimal vascularity in tumor \\
\hline LB 2 & Prox. Femur & $0(1.82 \%)$ & $\begin{array}{l}\text { No abnorm. vascularity; no soft tissue } \\
\text { mass del ineated }\end{array}$ \\
\hline
\end{tabular}

The grade of the $13 \mathrm{~N}$ scan is based on statistical criteria relating the uptake of $13_{\mathrm{N}}$ in the tumor to expected uptake in normal tissue at the same site. Qualitatively, the system is as follows:

0: Tumor not seen or poorly seen even under high contrast conditions in display.

1: Somewhat increased uptake under high contrast conditions.

2: Increased uptake apparent under a 17 contrast conditions.

3: Considerably increased uptake

4: Uptake very intense with count rates approaching thos in structures like. liver or pancreas. 
TABLE 3

Correlation between changes in Alkaline Phosphatase levels and

${ }^{13} \mathrm{~N}$-Glutamate Uptake after chemotherapy

Increased AP

Increased ${ }^{13} \mathrm{~N}$

Decreased ${ }^{13} \mathrm{~N}$
4

0
Decreased AP

1

11 
CORRELATION BETWEEN N-13 GLUTAMATE UPTAKE AND HISTOLOGY

\begin{tabular}{|c|c|c|}
\hline SUBJECT & CHANGES IN GLUTAMATE SCAN * & HISTOLOGY CHANGE ${ }^{* \star}$ \\
\hline JK & 55 percent decrease & 3 \\
\hline WS & 40 percent decrease & 3 \\
\hline $\mathrm{CH}$ & $\begin{array}{l}40 \text { percent decrease (post-chemo } \\
\text { scan nearly normal). }\end{array}$ & 3 \\
\hline$S P$ & 34 percent decrease & 3 \\
\hline AY & 27 percent decrease & 3 \\
\hline PM & 23 percent decrease & 1 \\
\hline LA & 20 percent decrease & 1 \\
\hline RS & 20 percent decrease & 1 \\
\hline PB & 18 percent decrease & 2 \\
\hline SM & 17 percent decrease & $2+$ \\
\hline KD & 7 percent increase & 2 \\
\hline$T M$ & 15 percent increase & 2 \\
\hline LL & 30 percent increase & 2 \\
\hline $\mathrm{CW}$ & 74 percent increase & 1. \\
\hline
\end{tabular}

1. Little or no effect identified.

2. Areas of acellular tumor osteoid, necrotic and/or fibrotic material attributable to the effect of chemotherapy, with other areas of histologically viable tumor.

3. Predominant areas of acellular tumor with osteoid, necrotic and/or fibrotic material attributable to the effects of chemotherapy with only scattered foci of histologically viable tumor cells identified.

4. No histologic evidence of viable tumor identified with the specimen. 


\section{TABLE 5}

\section{N-13 GLUTAMATE SCANNING IN EWING!S}

SARCOMA

REMARKS

LG Tumor in distal femur clearly seen w/ glutamate but not followed.

LB Tumor in prox. femur clearly detected pre-therapy; not clearly detectable 5 weeks pre-surgery; TC-DP scans showed decreased uptake. Tumor not present at surgery.

KW Tumor in prox. humerus clearly seen w/ glutamate pre-therapy; negative after 3 mos. therapy. TC-DP shows progressive decrease in uptake.

KC Tumor in posterior pelvis clearly detectable pre-therapy and negative post-chemo. Tumor destruction complete on re-biopsy,

JW Tumor in midthigh seen as a large mass $w /$ glutamate but as a more compact area of reactive bone W/ TC-DP. Both glutamate and TC-DP show progressive decrease in uptake.

EB Tumor in Midthigh clearly seen with glutamate and negative after 3 mos. chemo. TC-DP scans show decreasing uptake.

Patients LB, KW and KC showed complete tumor destruction and absence of histologically viable tumor cells at surgery or re-biopsy. 


\section{REFERENCE}

1. Clarke, L. P., Maugham, E. Z, Laughl in, J.S., Knapper, W.H., and Mayer, K. Calibration methods for measuring splenic sequestration by external scanning. Med. Phys: 3: $324-327,1976$.: 
1.1 .2

${ }^{11}$ C-ALPHA-AMINOISOEUTYRIC ACID (AIB) AND H ${ }^{11}$ HYDROGEN

CYANIDE

Distribution Studies

OBJECTIVE:

To investigate the biodistribution of ${ }^{11} \mathrm{C}$-al pha-aminoisobutyric acid and ${ }^{1} \mathrm{C}$-hydrogen cyanide in dogs with spontaneous tumors and in normal control animals in order to determine if these agents hold promise for tumor localization and/or metabolism studies.

\section{SCOPE OF INVESTIGATION:}

11. Following the development of a synthetic method for preparing ${ }^{11}$-alpha-aminoisobutyric acid in sufficient yield for studies in large animals (see Section 2.1); we have succeeded in completing three studies in dogs. One study in a normal dog included a ten minute dynamic uptake measurement over the head and shoulders with the Cyclotron Corporation Model 4200 Positron Camera. Tomograph used in its camera mode of operation and a twenty-three slice set of transaxial tomographic images taken over the following one hour period using the Model 4200 in its tomograph mode of operation. The other studies involved two dogs with spontaneous cancers, where a number of imaging procedures were carried out with each dog being killed and tissue concentrations of AIB measured. A case of 1 ymphosarcoma and one of adnexal gland adenocarcjnoma were studied. Prior to each AIB study of a tumor bearing dog a $\mathrm{H}^{1} \mathrm{CN}$ imaging study was carried out, both to show the distribution of tissues within which it concentrates and to screen tumor types for its localization properties.

RESULTS AND. CONCLUSIONS:

Carbon-11 labeled hydrogen cyanide was administered to a dog with spontaneous lymphosarcoma and a number of two dimensional images obtained. In spite of massive presence of cancer throughout the body, especially in lymph nodes ( $>5$ on diameter), an essentially normal distribution was observed; i.e. high uptake in parotid and mandibular salivary glands and in the fundus of the stomach. In contrast to this study, high uptake of ${ }^{11} C$-alpha aminobutryic acid (AIB) was seen when this agent was administered to the same dog three hours later. A head and 
shoulder image of AIB in this dog is shown in Figure 5 . Both compounds concentrate in salivary glands; whereas only the diseased lymph nodes concentrated AIB. Concentrations in tissues following the killing of the dog at 1.4 hours are given in the right hand column of Table 6 , which confirmed the tissue locations suggested by the imaging studies. The kinetic uptake measurements observed during the first 10 minutes following the IV administration of $0.4 \mathrm{mCi}$ of AIB showed an initial rapid rise of activity of less than one minute duration followed by $a$ much slower rise in tumor invaded $1 \mathrm{ymph}$ notes $(T 1 / 2=21+5 \mathrm{~min}$.$) and$ salivary glands (Til/2 = $19 \pm 3 \mathrm{~min}$.$) (See Fig. 6$ and 7 ).

A second study was done using a normal dog with AIB to provide information concerning the normal distribution of this compound. Mandibular and zygomatic salivary glands appear from the transaxial tomographic slices to concentrate AIB and as expected no brain uptake was seen (See Fig. 8-11). This dog was not killed so a tissue distribution was not obtained.

Our third study involved a $34.7 \mathrm{~kg}$ collie with an adnexal gland adenocarcinoma. Carbon-11 labeled cyanide was administered first. In contrast to the case of 1 ymphosarcoma, the adenocarcinoma concentrated $\mathrm{H}^{\mathrm{C}} \mathrm{CN}$ strongly. This result is considered very important. A lateral and an AP view of the hind-quarters of the dog are shown in Fig 12and 13. The tumor is at the base of the tail. It will be followed up with further studies to determine the value of this agent for tumor detection. Somewhat later AIB was administered to the same dog. Only a moderate concentration of AIB was observed in the tumor in the images. The dog was killed at 1.57 hours. Tissue distribution data are given in Table 6 . Al though these studies are very limited, a number of tentative conclusions appear warranted. Cyanide should be further investigated to determine its potential as a tumor specific agent, with special emphasis upon adenocarcinomas. AIB should be examined clinically for its value in lymphosarcoma and further screened various types of cancer. Because AIB does not cross the nomal blood brain barrier as verified by our studies, further exploration of the potential of this agent as a blood-brain barrier marker for brain tumor imaging is strongly indicated.. The advantage of $11 \mathrm{C}-\mathrm{AIB}$ over conventional blood-brain barríer agents (e.g., $99 \mathrm{~m}$ Tc-pertechnetate) is that AIB al so appears to be selectively concentrated by viable tumor cells, resulting in increased contrast of tumor to surrounding nomal brain.

We plan to inyestigate the properties of AIB as a pancreatic agent in comparison to $13 \mathrm{~N}$-glutamate, which is currently under study in our laboratory for this purpose. 
An abstract covering our AIB studies has been accepted for presentation at the Radiological Society of North America, 65 th

Scientific Assembly and Annual Meeting, Atlanta, November 25-30, 1979. 


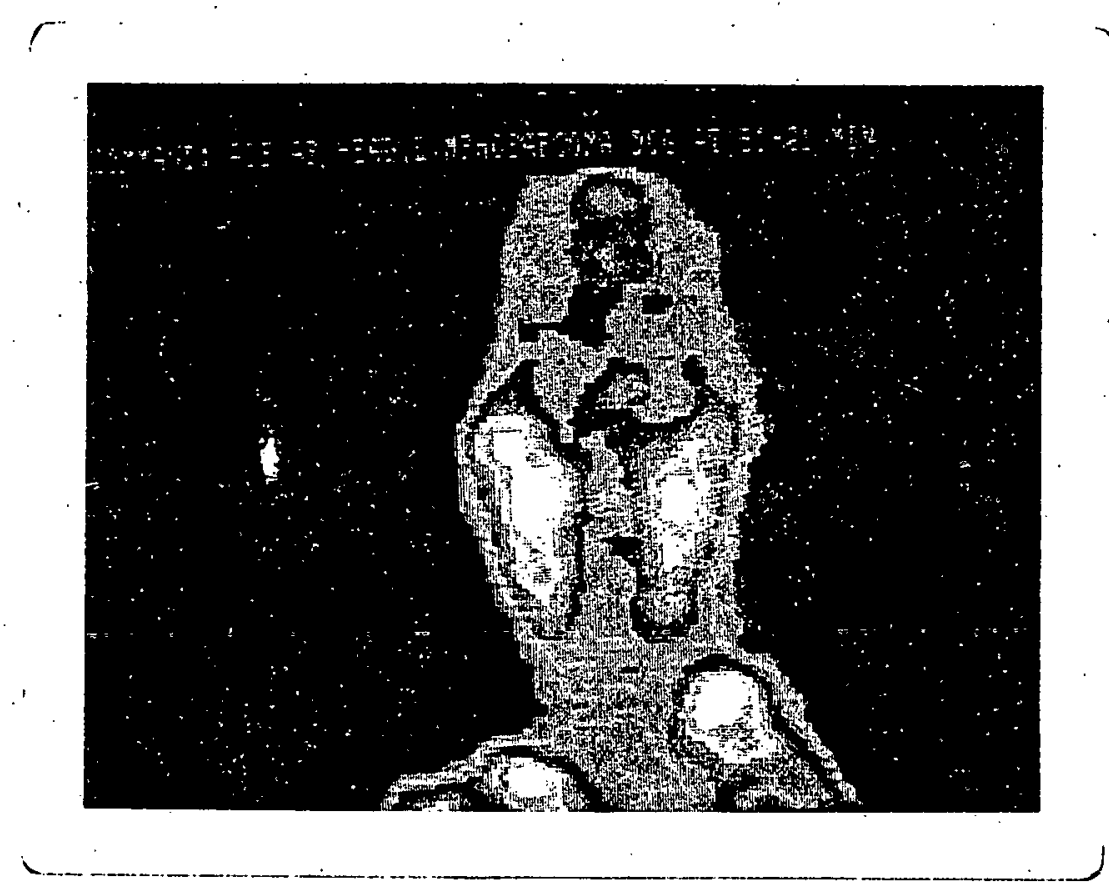

Fig. Static positron camera AP view of the distribution of $I_{C}$-AIB in the head and shoulders (at bottom) of a dog with spontaneous lymphosarcoma. High uptake is seen in the cancer invaded salivary glands and lymph nodes.

\section{rigure 5}


C-11 AIB UPTAKE IN LYMPH NODE OF DOG W/ LYMPHOSARC

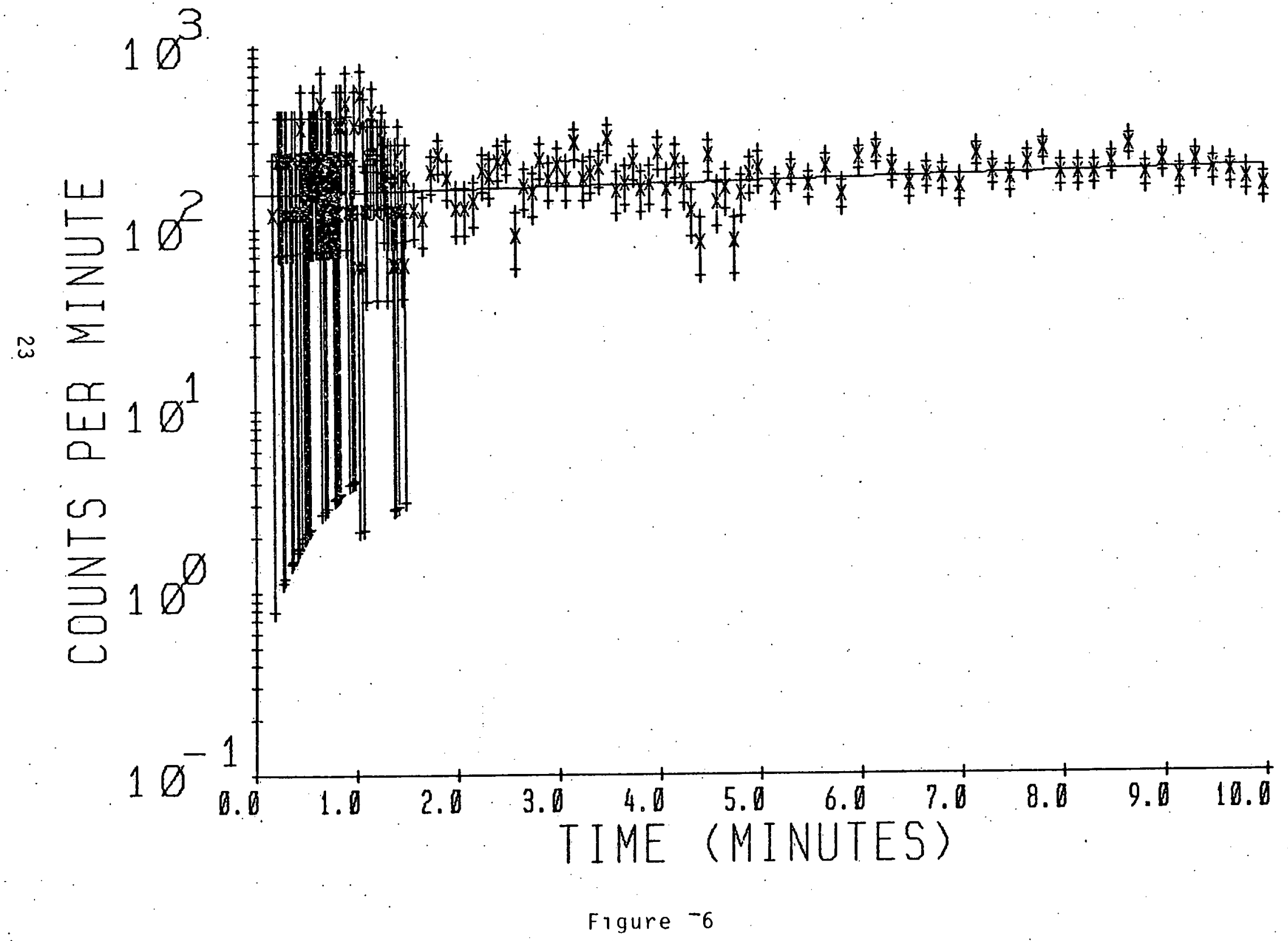


C-11 AIB UPTAKE IN PAROTID OF DOG W/ LYMPHOSARCOMA

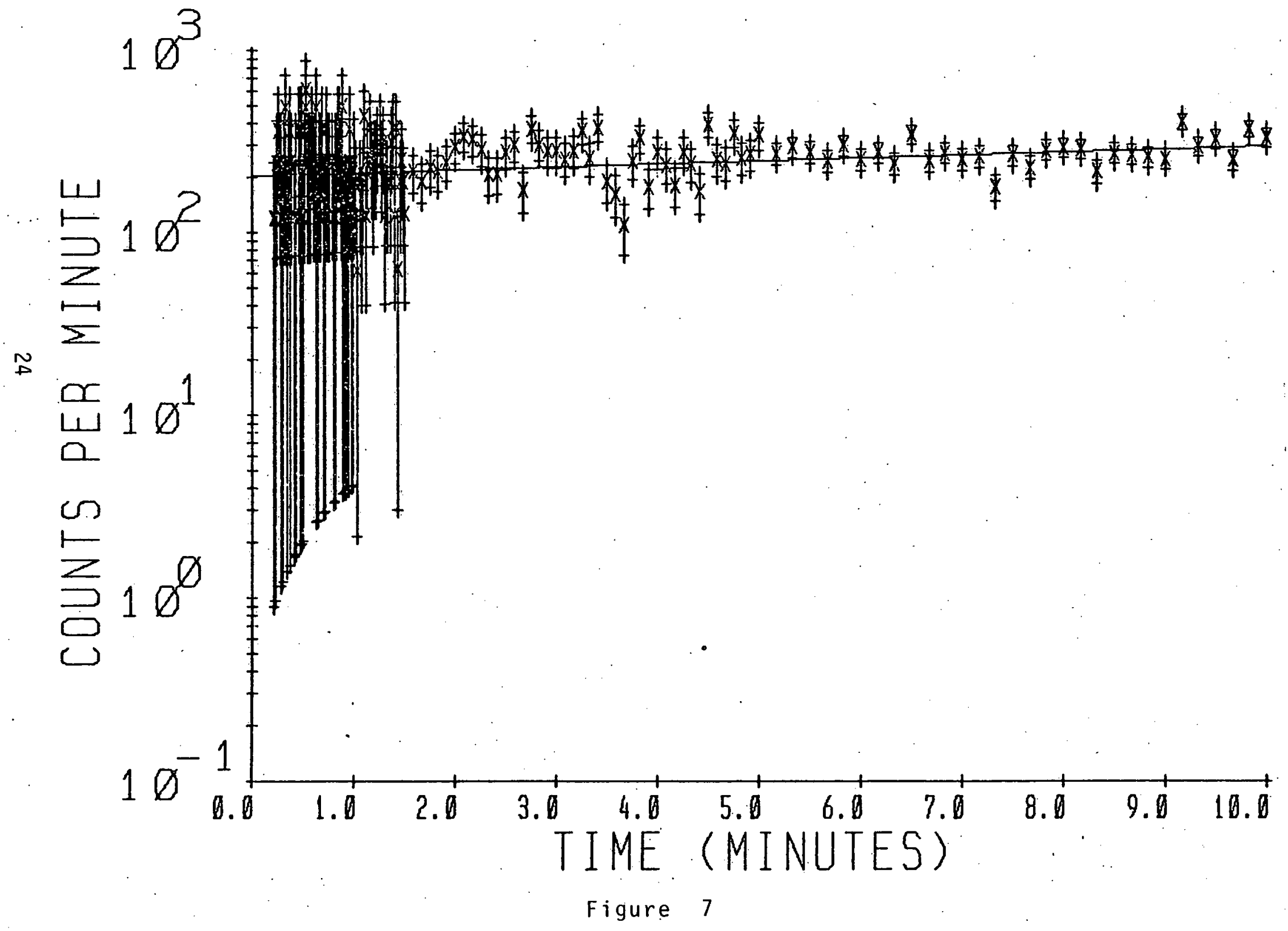



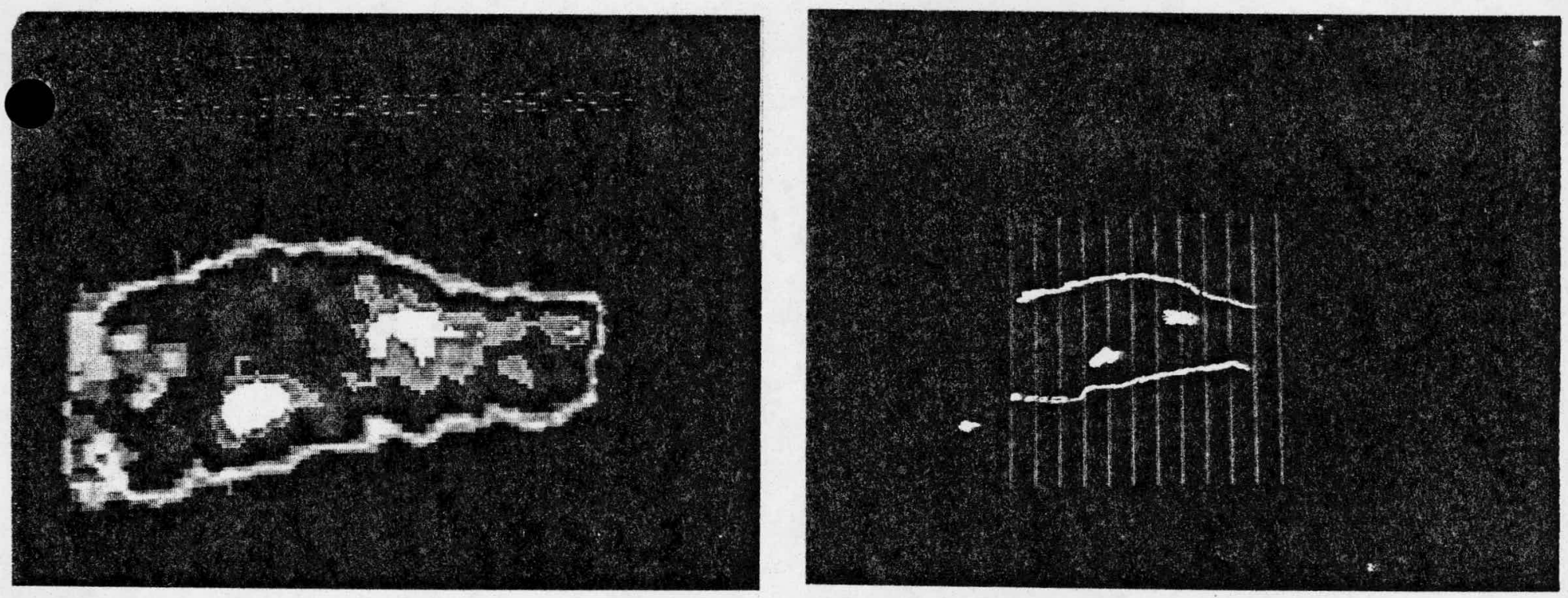

Fig. ¿

AIB $\mathrm{C}-11$ focal plane lateral view of a normal dogs head.

Fig. 9

AIB slice marker overlay vertical bars are $A-L$ from left to right.

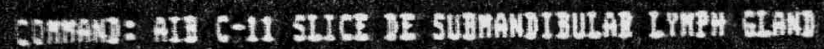

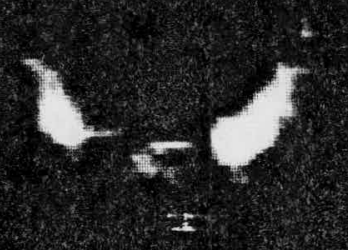

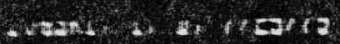

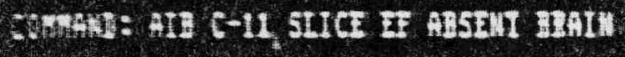

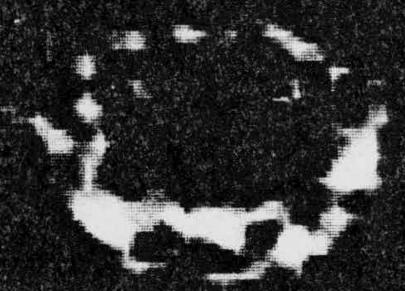

Fig. 10 .

Slice DE showing the submandibular lymph glands.

\section{Fig. 11}

Slice EF showing the absence of brain uptake. 


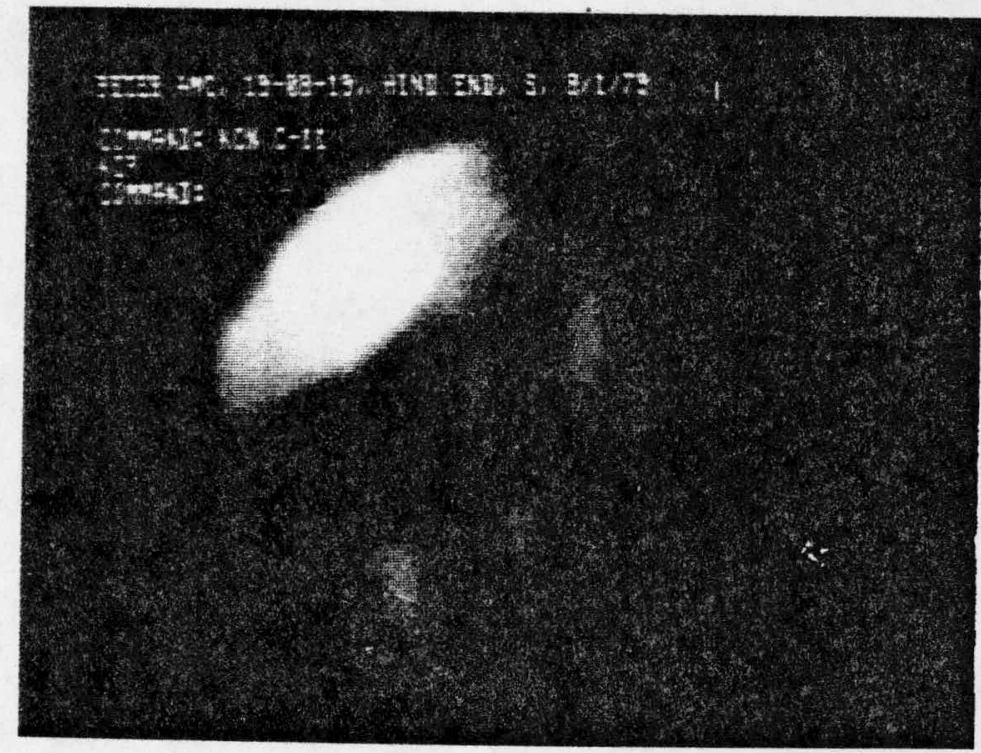

Fig. 12 Static positron camera lateral view of the distribution of $\mathrm{H}^{11} \mathrm{CN}$ in the hind end (tail to left) of a hog with adnexal gland adenosarcoma. High uptake (white area) is seen in the tumor.

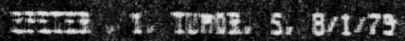

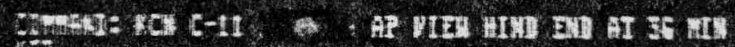

$x=$ tinev: uthron 5 nin

Fig. 13 Static positron camera $A P$ view of the distribution of $\mathrm{H}^{11} \mathrm{CN}$ in the hind end (tail to left) of a dog with adenxal gland adenosarcoma. High uptake is seen in the tumor. 
TABLE 6

TISSUE DISTRIBUTION OF ALPHA AMINOSOBUTYRIC ACID (AIB) IN DOGS

WITH SPONTANEOUS CANCER

RELATIVE CONCENTRATIONS*

TISSUE

1. Pancreas

2. Small intestine

a. Cleaned

b. Not cleaned

3. Kidney

a. Cortex

b. Medulla

4. Liver

5. Salivary glands

a. Mandibular

b. Parotid

6. Prostate

7. Colon (Clean)

8. Stomach (Clean)

9. Spleen

10. Myocardium

11. B1adder

12. Bone w/marrow

13. Testis

14. Eye

15. Lymph Nodes
a. Neck
b. Cervical
c. Left popiteal
d. Right popiteal

16. Thyroid

17. Adrenal gland

18. Brain ;...

19. Muscle

20. $\therefore$ Fat

21. Duodenum w/ contents

22. Uterus

23. Ovaries w/oviduct

24. Primary tumor

25. Lung
a. w/barely palpabie
tumor
b. $w / 70 \%$ tumor
c. $w / 90 \%$ tumor

ADNEXAL GLAND

ADENOCARCINOMA

(at 1.57 hours)

$8.8 \div 2 \%$

LYMP.HOSARCOMA

$7.5 \div 5 \%$

$2.2-3 \%$

$4.5 \div 3 \%$

$1.8 \div 5 \%$

$4.4-2 \%$

$3.0+3 \%$

$1.1 \mp 11 \%$

$2.7 \mp 5 \%$

$1.9 \div 7 \%$

$1.8+4 \%$

$1.6 \div 3 \%$

$1.2 \mp 8 \%$

$1.2 \mp 4 \%$

$0.9-12 \%$

$0.77_{\mp} 6 \%$

$0.72-16 \%$ (at 1.41 hours)

$0.72+12 \%$

$0.55 \mp 18 \%$

$0.50 \mp 18 \%$

$0.17 \mp 47 \%$

$0.70-18 \%$

$0.58 \mp 78 \%$

$0.55 \div 9 \%$

$0.35 \% 8 \%$

$0.19-11 \%$

None

None

1. $7-3 \%$

1. $8 \mp 20 \%$

$1.2-14 \%$

$0.16-42 \%$

$0.22 \div 77 \%$

$0.57+15 \%$

$2.24-7 \%$

$1.3-11 \%$

$0.89-22 \%$

2. 8 $^{\mp} 6 \%$

$1.8 \frac{+}{+} 7 \%$

$0.8 \div 76 \%$

1. 8-8\% 


\section{TISSUE}

26. Lymph Nodes with tumor
a. Mesenteric
b. Inguinal
c. Mediastinal
d. Submandibular

27. Whole blood
a. At sacrifice
b. At I hour
c. At 6 min.
d. At 1 min.

TABLE 6 (Continued)

ADNEXAL GLAND

ADENOCARCINOMA

LYMPHOSARCOMA

$0.70^{+}-9 \%$

$1.7 \mp$

$0.29-3 \%$

$3.2^{+}+5 \%$

$2.8 \mp 6 \%$

$2.3 \mp 7 \%$

2. $3-7 \%$

$0.67^{+}-9 \%$

$1.3-9 \%$

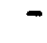

* Relative concentration=dose fraction/tissue fraction. Percent error includes the counting statistics only. 


\section{REFERENCES}

1. Myers, W.G., Lamb, J.F., James, R.W. and Winche 11, H.S., ${ }^{11} \mathrm{C}$ distribution in dogs visualized in situ after intravenous 1 C-cyanide in high specific activity. Nucl. Med. 12, 154-162, 1973. 


\section{OBJECTIVE}

Our objective has been to understand the mechanism $(s)$ of tumor incorporation of $13 \mathrm{~N}$ label following intravenous injection of $13 \mathrm{~N}$-L-amino acids, for those tumor types which have demonstrated specific concentration of $13 \mathrm{~N}$ in our human and canine studies. Such knowledge may be of value in designing improved diagnostic procedures or agents; in utilizing a labeled amino acid as a prognostic indicator to monitor tumor therapy, or in therapeutically exploiting potential tumor versus normal tissue metabolic differences.

\section{SCOPE OF INVESTIGATION}

Using nitrogen-13 produced in our cyclotron facility, a number of $13 \mathrm{~N}$-labeled L-amino acids have been enzymatically synthesized in this laboratory, e.g. glutamate, valine, methionine.

$13 \mathrm{~N}$-Amino acids, in particular $L$-glutamic acid, have shown potential as tumor scanning agents, demonstrating selective concentration in canine tumors including osteogenic and synovial cell sarcomas and mammary and colon cancers, and in human tumors, e.g, osteogenic and Ewing 's sarcomas, chondrosarcoma, neuroblastoma, pinealblastoma, and ependymoblastoma. However, until our recent studies in this area, very little has been known about the metabolic fate of the $13 \mathrm{~N}$ label in tumor and normal tissues, or even what labeled metabolites will be found in the blood and how quickly they appear in the circulation following intravenous administration of the $13 \mathrm{~N}$-compound. We had proposed, therefore, for 1978 to examine the metabolism of these compounds in animals, by analysis of biood and tissue samples, in parallel with our evaluation of the $13 \mathrm{~N}$ amino acids as tumor imaging agents.

The methods used for separating and quantitating the tumor metabolites were developed by Dr. A. J. L. Cooper of the Cornell University Medical College(Neurology Dept.) for our collaborative study of cerebral metabolism (Cooper, et al., J. Biol. Chem. 254: 4982-49.92, 1979). Briefly, the technique consists of a combination of high pressure 1 iquid chromatography (HPLC), ion exchange chromatography, and the treatment of various column fractions wjth appropriate enzymes. This method permits quantitation of the following $13_{\mathrm{N}-}$ metabolite fractions: ammonium ion, glutamic acid, $\alpha$-amino versus amide labeled glutamine, aspartate, urea, glutathione, neutral amino acids (including asparagine and alanine), $\gamma$-aminobutyrate (GABA), arginine, and $\alpha$-ketoglutaramate.

For our first tumor metabolic study, we selected the implanted murine osteogenic sarcoma ( $\mathrm{C} 3 \mathrm{H}$ mice) using $13 \mathrm{~N}-\mathrm{L}$-glutamate, because of our observation of consistently high uptake of $13 \mathrm{~N}$ label in human and spontaneous canine osteogenic sarcoma within minutes of $13 \mathrm{~N}-g$ lutamate IV injection, and because of the technical advantages in working with rodents. 
RESULTS AND CONCLUSIONS

Several preliminary measurements were made of tumor uptake of $13 \mathrm{~N}$ label after IV (femoral) injection of $13 \mathrm{~N}-\mathrm{L}$-glutamate in rats hearing transplantable tumor lines available at Sloan-Kettering. The resulting concentration of $13 \mathrm{~N}$ activity in three types of transplanted rat tumors, as well as in blood and muscle, are shown in Table 8 . Moderate to high levels of tumor selectivity, ranging from 2 to 6 times the muscle concentration, were observed, with no apparent time trend between 5 and 30 minutes after injection; this was an encouraging indication that implanted rodent tumors would take up label following $13 \mathrm{~N}$-glutamate injection in a manner similar to that observed for a number of human and spontaneous canine cancers.

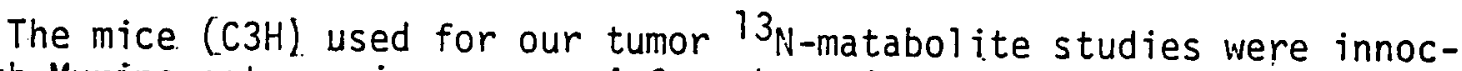
ulated with Murine osteogenic sarcoma 4-6. weeks prior to our measurements. To date we have performed six metabolite analyses with this tumor 1 ine, all at 10 minutes after. IV (jugular) injection of $13 \mathrm{~N}$-qlutamate. Each mouse was

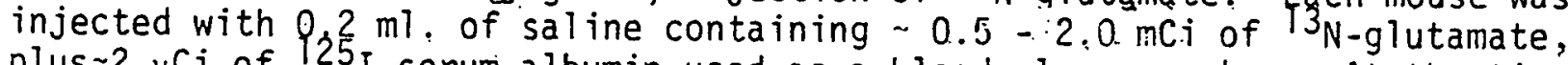
plus $\sim 2 \mathrm{Ci}$ of 125 I-serum albumin used as a blood plasma marker. At the time of sacrifice (10 MAI) approximately $1 \mathrm{~g}$ of tumor was homogenized in $2 \mathrm{ml}$. of ice cold picric acid, centrifuged for 1 minute to remove the acid precipitable fraction (i.e. proteins and nucleic acids), and $0.02 \mathrm{ml}$ of the resulting supernatant subjected to HPLC. Figure 14 shows the distribution of $13 \mathrm{~N}$-metabolites collected for the HPLC column; the activity coming off the column at approximately 2 minutes corresponds to ammonia and basic amino acids, the peak at 3 minutes represents the neutral amino acids (such as glutamine), the $13_{N}$ activity at approximately 6 minutes corresponds to glutamate and at about 9 minutes is the aspartate peak. (For one HPLC run a very acidic compound of $\sim 7 \%$ abundance was noted that eluted with an $R_{f}$ value similar to that for $r$-glutamyl amino acids and purine nucleotides ${ }_{3}$ ) The relative amounts of $3_{N}$-compunds identified in the tumors at 10 MAI of $33_{N}$-glutamate are given in Table 9 . The positions of the various peaks coming off the HPLC column were confirmed by adding unlabeled ammonia, glutamine, glutamate, and aspartate to the ficric acid supernatant and performing an amino acid analysis on the HPLC fractions collected; the resulting HPLC calibration curve indicating collection times for the four cold standards is shown in Figure 15 .

Although we have not yet broken the neutral amino acid peak down into its components, namely amide labeledglutamine versus $\alpha$-an.ino labeled glutamine versus other neutral amino. acids (this is proposed for the coming year), it is tempting to assume that most of this peak is due. to glutamine (6). However, an analysis of the free amino acid content (unlabeled) of one of these tumors, as shown in Table 10,suggest that amino acids other than glutamine (e.g. alanine) may contribute appreciably to the HPLC neutral amino acid peak. Clarification of this point must await further studies. 
The amount of $13 \mathrm{~N}$ label present in the picric acid precipitable fraction of the tumor was found to be only a few percent or less of the total present in the tumor at 10 minutes after injection, indicating minimal incorporation of the label into proteins and nucleic acids. This dermination was carried out by centrifuging a portion of the tumor-picric acid homogenate, collecting the supernatant, washing and resuspending the precipitate, and then repeating this process five times. Counting the repeatedly washed precipitate for $13 \mathrm{~N}$ found in the collected supernatant/wash yields the desired ratio.

The use of $125 \mathrm{I}$-serum albumin as a blood label also permitted us to. measure the contribution of $13 \mathrm{~N}$ in residual blood to the total $13 \mathrm{~N}$ in the. tumor at the time of its removal. This was found to be $<70 \%$ for those tumors with good uptake of label. The measurement was accomplished by obtaining a blood sample from the heart at the time of sacrifice (i.e. time of tumor removal). and assaying it for both $13 \mathrm{~N}$ and 125 I content; determining the amount of $125 \mathrm{I}$ blood label that was in a given tumor or homogenate sample and the blood $13 \mathrm{~N} / 125 \mathrm{I}$ ratio then yield the amount of $13 \mathrm{~N}$ in the tumor due to blood in the sample.

Our plans for future studies include further characterization of the $13 \mathrm{~N}$-metabolites found in the murine osteogenic sarcoma, for example by treating the neutral amino acid fraction with glutaminase to distinguish between $\alpha$-amino and amide labeled glutamine and other neutral amino acids. Injecting other $13 \mathrm{~N}$-compounds, such as $13 \mathrm{~N}$-ammonia, may prove to be of interest as a means of studying the tumor's metabolic pathways. Additional tumor metabolism studies are also contemplated for other implanted rodent tumors and for spontaneous canine cancers. 
TUMOR HPLC FOR N-13-GLU

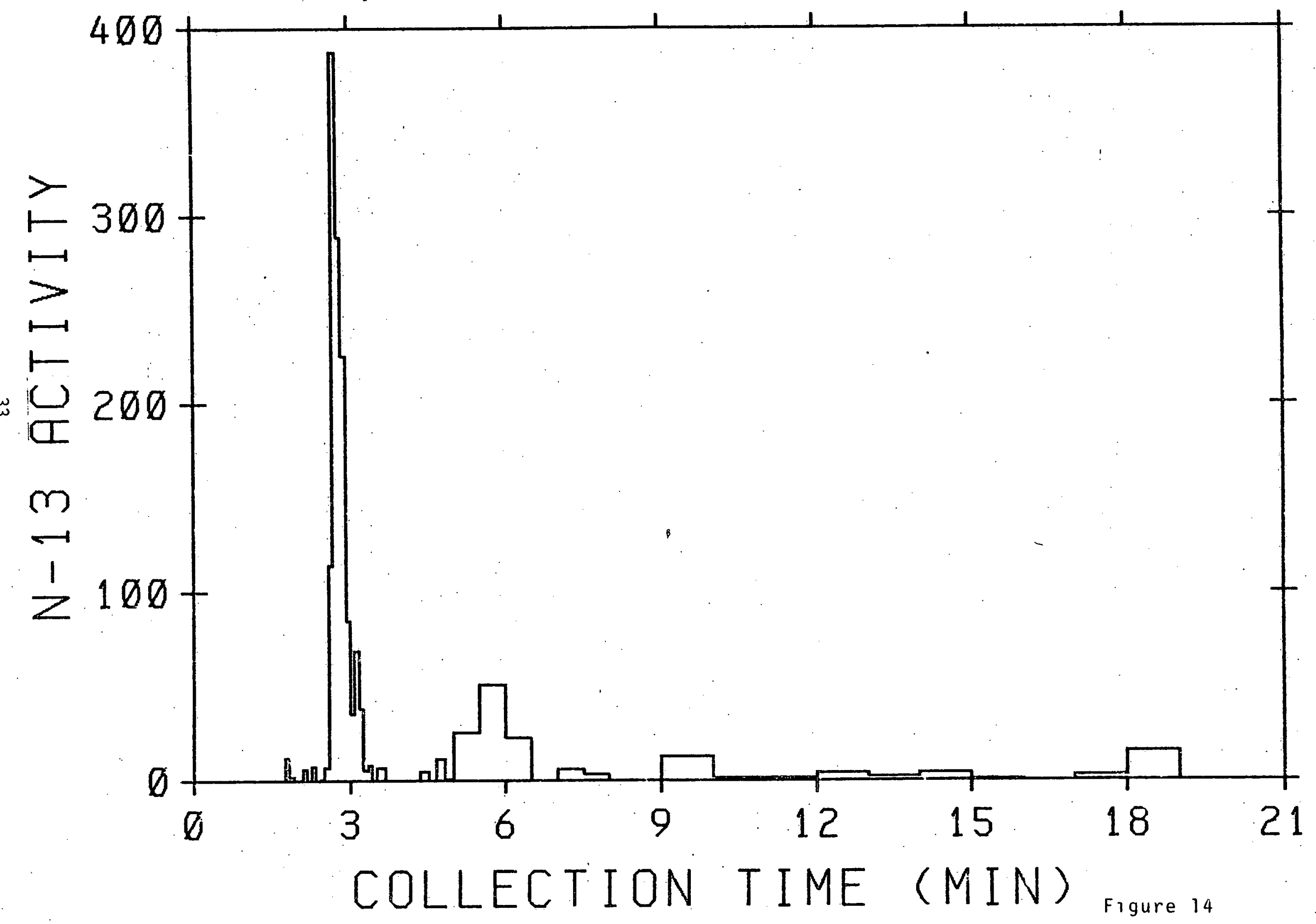




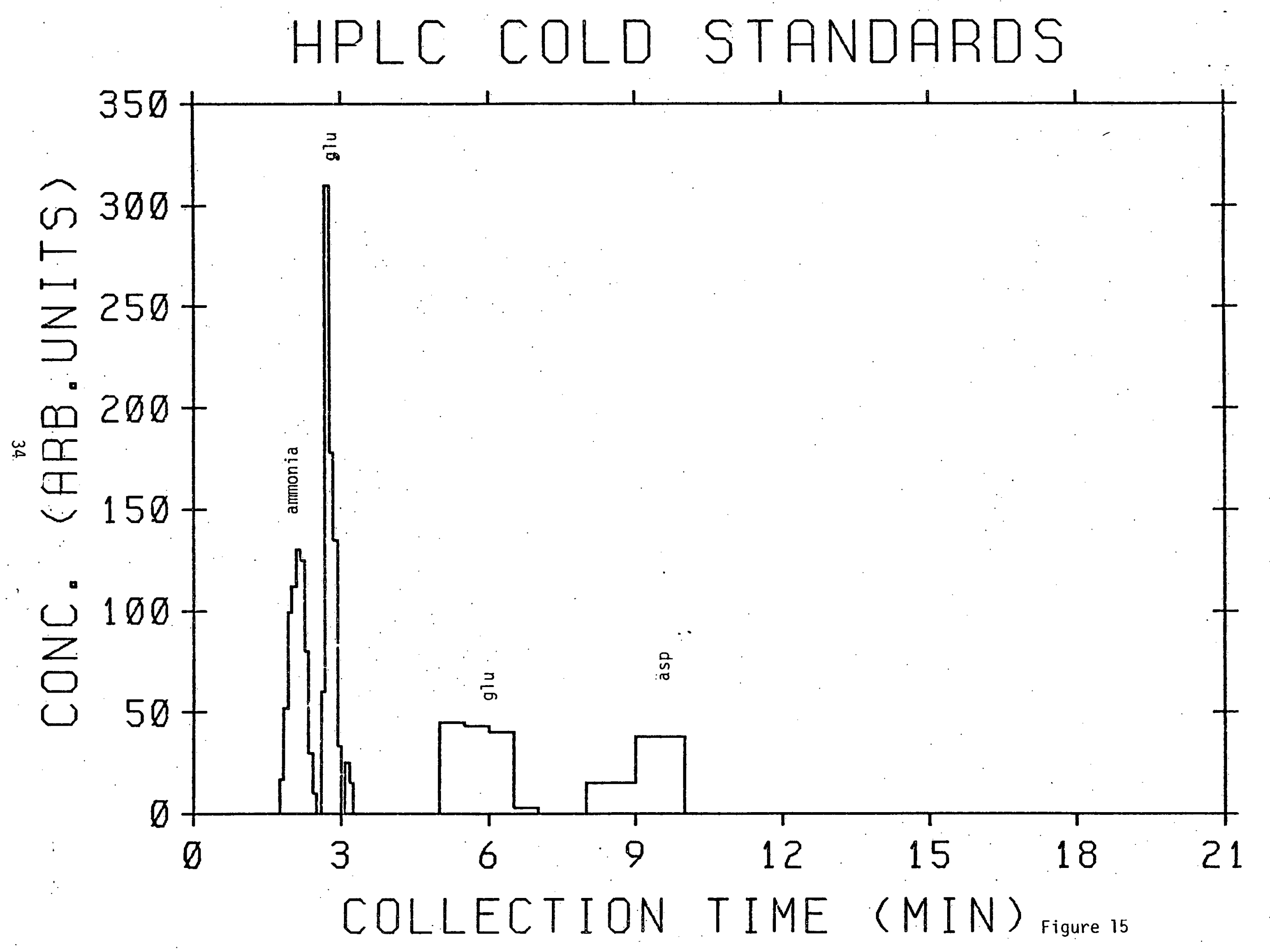


3N RELATIVE CONCENTRATION* IN BLOOD, MUSCLE AND TUMOR OF RATS AFTER INTRAVENOUS INJECTION OF $13 \mathrm{~N}-\mathrm{L}$-GLUTAMIC ACID

Tumor Line

Morris Hepatoma 7777

Morris Hepatoma 77777

Morris Hepatoma 7777

Morris Hepatoma 7777

Morris Hepatoma 5123

Walker 256 carcinosarcoma

Wa7ker 256 carcinosarcoma.

Walker 256 carcinosarcoma

Walker 256 carcinosarcoma
Rat

$\underline{\text { Strain }}$

Buffalo.

Buffalo

Buffalo

30

30

$0.59 \quad 0.55$

Buffato

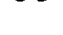

Buffalo

30

0.76

0.73

$0.59 \quad 0.55$

$0.73 \quad 0.61$

3.13 (subcutaneous)

2.37 (abdominal mass)

2.07 (subcutaneous)

3.26 (lung mass)

1.71 (intrathoracic mass)

$$
\begin{aligned}
& 1.53 \text { (subcutaneous) } \\
& 2.02 \text { (tumor rind) } \\
& 1.74 \text { (bloody nodules) } \\
& 3.42 \text { (fibrous interior } \\
& \text { of tumor) }
\end{aligned}
$$

$\begin{array}{lllll}\text { Fisher } & 5 & 0.87 & 0.43 & 1.76 \text { (intramuscular) }\end{array}$

Fisher

$0.99 \quad 0.40$

1.04 (subcutaneous)

2.28 (abdominal mass)

1.19 (abdominal mass)

Fisher $\quad 30$

0.58

0.68

2.47 (intramuscular)

$0.52 \quad 0.51$

1.78 (intromuscular)

${ }^{*}$ Relative concentration $=$ fraction of dose/fraction of body weight in sample ** All tumores were implanted subcutaneously 
TABLE 9

OSTEOGENIC SARCOMA 13 N-METABOLITES AS DETERMINES WITH HPLC, 10 MINUTES AFTER IV INJECTION OF $13 \mathrm{~N}$-GLUTAMATE

$\underline{13 N-\text { Compound }}$

ReTative Abundance

Neutral-amino acids (e.g. glutamine): $\simeq 55-60 \%$

Unmetabol ized glutamate:

$\simeq 30-35 \%$

Aspartate:

$\simeq 5-10 \%$

Ammonia and basic amino acids:

$\simeq 2-3 \%$

$\gamma$-glutamyl amino acids/purine nucleotides(?):

$\simeq \quad 7 \%$ 
FREE AMINO ACID CONTENT OF A MURINE OSTEOGENIC SARCOMA (C3H) MOUSE.

$\begin{array}{lc}\text { Amino Acid } & \frac{\text { Concentration }}{\text { (mmol/kgnet wt.) }} \\ \text { Taurine } & 9.7 \\ \text { Glutamate } & 1.04 \\ \text { Alanine } & 0.58 \\ \text { Ornithine (and ammonia) } & 0.54^{\circ} \\ \text { Glycine } & 0.44 \\ \text { Aspartate } & 0.37 \\ \text { Threonine } & 0.37 \\ \text { Lycine } & 0.19 \\ \text { Glutamine and asparagine } & 0.18 \\ \text { Serine } & 0.1 \\ \text { Leucine, isoleucine, and } & 0.12 \\ \text { methionine } & \end{array}$




\subsubsection{CEREBRAL ${ }^{13}$ N-AMMONIA METABOLISM IN NORMAL AND HYPERAMMYNEMIC RATS}

\section{OBJECTIVE}

a) To continue our studies of the metabolic fate of $\left({ }^{13} \mathrm{~N}\right)$ ammonia in rat brain and to extend the studies to a model of chronic liver disease, i.e., to the portacaval shunted (hyperammonemic) rat. b) To synthesize various $13 \mathrm{~N}$-amino acids and to determine their metabolic fate in rat brain. From such studies we will gain more insight as to the nature of the metabolic compartments in the brains of normal and chronically hyperammonemif rats. c) To continue to develop improved methods for the separation of $T 3_{\mathrm{N}}-\mathrm{labeled}$ metabolites by high pressure liquid chromatography.

\section{SCOPE OF INVESTIGATION}

Liver disease ranks as the sixth most common cause of death in the United States. A problem often associated with liver disease is blockage of the portal vein; the resulting pressure may cause ballooning of esophageal vessels (varisces) which if ruptured may cause GI hemorrhage and even death. Thus, a common surgical treatment involves the construction of a portacaval shunt whereby blood from the intestinal portal vein is diverted around the liver and drains directly into the systemic circulation. However, the long term survival rate of such patients is low, and the patients almost always develop neuropathological symptoms. Exactly why the brain is so sensitive to the effects of liver disease is not known. A number of substances that are known to be elevated in the plasma of patients with liver disease have been implicated as being toxic to the CNS and some are thought to act synergistically. Nevertheless, ammonia is widely regarded as the most neurotoxic agent in hepatic encephalopathy. Therefore, a detailed understanding of the metabolic fate of ammonia in the brain should provide a clue as to the causes of hepatic encephalopathy.

\section{RESULTS AND CONCLUSIONS}

\section{A) Background}

In the previous progress report we showed that under physiological conditions cerebral ammonia metabolism occurs in at least two compartments (1) in agreement with the previous postulate of Berl et al (2) i.e., bloodborne ammonia enters a compartment containing a small amount of the brain's glutamate that is both rapidly turning over and distinct from a larger brain glutamate pool. We further showed that 1) ammonia enters the brain from the blood largely by diffusion; 2) the glutamine sythetase reaction of the small pool is the major pathway for the detoxification of blood-borne ammonia in the brain (99\%) while the glutamate dehydrogenase reaction is negligible $(<1 \%)$; 3) ammonia entering the brain from the cerebrospinal fluid is also largely metabolized in the small pool via conversion to the glutamine; 4) the conversion of ammonia to glutamine within the small pool is extremely rapid $\left(t_{\frac{1}{2}}=1-3\right.$ secs or less); and 5 ) methionine sulfoximine, an inhibitor of glutamine synthetase destroys the integrity of the small pool (1). We have now begun to extend these studies to investigate ammonia metabolism in the brains of portacaval shunted rats. 
B) Determination of Brain Uptake Index (BUI) in Normal and 12-week

\section{Portacaval Shunted Rats}

The BUI for $\left({ }^{13} \mathrm{~N}\right)$ ammonia was determined by a modification of the technique developed by 01 dendorf (3). The technique measures the uptake of a test substance by brain, relative to that of a freely diffusible marker shortly after a bolus injection into the right common carotid artery. For our experiments we chose 14 C-butanol as a freely diffusible marker (1).

A large increase in the BUI of ammonia was noted in raising the $\mathrm{pH}$ of the injectate from 7.2 to 8.6 (Table 11). This finding is in accord with the idea that it $j$ s the free base. $\left(\mathrm{NH}_{3}\right)$ and not the ionized from $\left(\mathrm{NH}_{4}+{ }^{+}\right.$that is freely diffusable across biological membranes (4). Since the PR of ammonia is 9.2 , an incrêase in $\mathrm{pH}$ will increase $\mathrm{NH}_{3}$ and hence increase the uptake by brain. Our findings are also in accord with those of other workers in the uptake by brain of ammonia from the blood (e.g., reference 5 and references quoted therein). These changes are unlikely to be due to $\mathrm{pH}$-induced changes in $\mathrm{CBF}$; no change in CBF was noted in anesthetized and artificially ventilated dogs in which the blood pH ranged from 6.7 to $7.8(6)$.

In a second series of experiments rats were subjected to a portacaval (PC) shunt essentially according to the method of Lee and Fisher (7). Twe Tve weeks later the BUI for $\left(13_{N}\right)$ ammonia was determined. No significant difference in the BUI of $(13 \mathrm{~N})$ ammonia relative to ${ }^{4} \mathrm{C}$-butanol was noted in shunted animals either at pH 7.2 or 8.6 as compared to controls (Table 11). It is known that portacaval shunting in the rat results in an increase in blood, brain and cerebrospinal fluid concentrations of ammonia (9). Thus, it seems probable that the increase in brain ammonia in $\mathrm{PC}$-shunted rats is not due to a change in diffusibility of ammonia across the blood-brain barrier but rather to an altered steady state.

\section{c) Synthes is of ${ }^{13} \mathrm{~N}$-Amino Acids for Study of Amino Acid Metabolism}

\section{In Brain (See also Section 2.2)}

As we discussed in the last proposal our findings of overwhelming incorporation of label from blood-borne $(13 \mathrm{~N}$ ) ammonia into glutamine (amide) raises questions about the origin of precursor glutamate in the small pool of the brain (1). Transport of glutamate across the blood-brain barrier is poor (3), and the de novo synthes is of glutamate via the glutamate dehydrogenase reaction in the small pool is low as reflected by the minimal incorporation of $13 \mathrm{~N}$-ammonia into glutamate. Other possibilities for the origin of small pool glutamate include: 1) unidirectional movement of glutamate from the large pool into the smali pool, and 2) synthesis by enzymatic reactions other than the glutamate dehydrogenase reaction. At the present time there is no way to test the first possibility directly, although much indirect evidence from in vitro experiments with brain slices suggests that such movement does occur. An alternative synthetic route for glutamate in the small pool may involve transamination of a-keto glutarate with amino acids transported into the brain from the plasma: - Likely candidates as amino group donors would include those amino acids which readily pass through the blood-brain barrier such as the branched-chained amino acids, aromatic amino acids and methionine aminotransferases (9). Subsequent degradation of the corresponding $\alpha$-keto acids would 
also contribute to the carbon skeletons of glutamate, replacing carbon lost as glutamine. Indeed, Roberts and Morelos (10) have shown that after an intravenous injection of 14C-leucine, label in the brain is rapidly distributed among a number of metabolites, principally glutamate.

As a prelude to synthesizing various $13 \mathrm{~N}$-labeled neutral amino acids (so that we can investigate hypothesis \#2), we investigated the specificity of glutamate dehydrogenase toward $\alpha$-ketoglutarate. Although the specificity has been extensively studied with regard to amino acids (e.g., 11), apparently no detailed study of the $\alpha$-keto acid specificity has been reported. We determined the $\mathrm{Km}$ and $V \max$ values for eight $\alpha$-keto acids, six of which are available commercially (Table 12). It should be noted that the Vmax values are about 3 orders of magnitude lower than that for $\alpha$-ketoglutarate. Nevertheless, it was reported previously (ERDA progress report, 1977) that glutamate dehydrogenase could be utilized for the synthesis of $(I 3 N)$ valine. We have now shown that glutamate dehydrogenase immobiljzed on an inert support can be utilized to synthesize $\left(13_{N}\right)$ methionine and $\left({ }_{3}\right) \alpha$-aminobutyrate. In a preliminary experiment we have generated protein-free solutions of radiochemically pure $\left(13_{N}\right)$ valine $(2 \mathrm{mCi})$, ( $\left.13_{N}\right)$ methionine $(4 \mathrm{mCi})$ and $\left(13_{N}\right) \alpha$-aminobutyrate $(2 \mathrm{mC} i)$. The radiochemical purity of the products were monitored by high pressure liquid chromatography. In addition we have devised a method for the estimation of the specific activities of the products. The method is based on the conversion of the L-amino acid to the $\alpha$-keto acid semicarbazone in the presence of $L$-amino acid oxidase and semicarbazide (cf 12). It was found that the concentration of amino acid generated from the glutamate dehydrogenase reaction was in the range 15-25 $\mu \mathrm{M}$. The amino acid product was also further characterized by paper chromatography in three separate solvent systems. In each case only one amino acid was detected corresponding to the original $\alpha$-keto acid analog employed in the reaction.

\section{Development of a Rapid High Pressure Liquid Chromatographic}

Separation of Neutral Amino Acids

In our previous report (1) we showed that ${ }^{13} \mathrm{NH}_{\mathrm{A}^{+}},\left(^{13} \mathrm{~N}\right) \mathrm{glutamine}$, and $\left(13_{N}\right)$ aspartate could be rapidiy separated using an APLC anion exchange column. However, the system possesses one major drawback; most of the neutral amino acids (and urea) co-elute with the glutamine peak. This will be a major problem in deciding how much of the $13 \mathrm{~N}$. Tabel from e.g., (13N) valine appears in glutami Recently methods have become available for the separation of peptides and amino acids by reverse-phase HPLC (13). In these studies column separation of amino acids is affected more by the hydrophobicity of the side groups than by pK values. In a preliminary demonstration carried out at CUMC, at our request, by a representative of Waters Associates, a mixture of glutamine, glycine and alanine was resolved in 10 minutes on a $\mu$-Bondapak-c18 cojumn. Thus we apticipate that thij column should be able also to separate ( $\left.3_{N}\right)$ glutamine, ( $3 N$ ) valine and $\left(3_{N}\right)$ methionine. A $\mu$-Bondapak-C 18 column is on order and will be interfaced with our present HPLC system. 
TABLE 11

Brain Uptake Index of $\left({ }^{13} \mathrm{~N}\right)$ Ammonia Relative to $\underline{n}-\left(1-{ }^{14} \mathrm{C}\right)$ Butanol 1$)$

$$
\begin{aligned}
& \text { pH of BUI }(\%) \\
& \text { Bolus }
\end{aligned}
$$

\begin{tabular}{llll}
\hline Control & 7.2 & $23.7 \pm 4.1$ & $(6)$ \\
Portacaval Shunt & 7.2 & $21.3 \pm 3.1$ & $(6)$ \\
Control & 8.6 & $53.0 \pm 4.0$ & $(5)$ \\
Portacaval Shunt & 8.6 & $57.2 \pm 2.5$ & $(6)$ \\
\hline
\end{tabular}

1)

The bolus $(0.2 \mathrm{ml})$ contained $100 \mu \mathrm{M}$ ammonia $(20-100 \mathrm{mCi} / \mathrm{ml})$ in $10 \mathrm{mM}$ potassium phosphate buffer, $\mathrm{pH} 7.2$ or in $10 \mathrm{mM}$ HEPES-HCl buffer, $\mathrm{pH}$ 8.6. The BUI was detamined as described in ref 1 except that the In-DTPA was omitted. The va? lies given are the means- SEM. The number of determinations are giver: in parenthesis. 


\section{TABLE 12}

Specificity of Glutamate Dehydrogenase for $\alpha$-Keto acio's ${ }^{1}$ )

$\alpha$-Keto acid

Amino acid

$\mathrm{Km}(\mathrm{mPl}) \quad V \max (\mu \mathrm{mol} / \mathrm{min} / \mathrm{mg})$

Pyruvate

$\alpha$-Ketobutyrate

$\alpha$-Ketoisovalerate

$\alpha$-Ketoisocaproate

$\alpha$-Keto- $\gamma$-methiolbutyrate

$\beta$-Hidroxypyruvate

$D$ - $\alpha$-Keto- $\beta$-methyivalerate ${ }^{2)}$

$D$ - $\alpha$-Keto- $\beta$-hyroxybutyrate ${ }^{2)}$
Alanine

26

50

83

52

17

1.8

13

Isoleucine

Threonine
3
0.015

0.13

0.11

0.085

0.12

0.012

0.036

0.005

1) The reaction mixture $(1.0 \mathrm{ml})$ contained variable concentrations of $\alpha$-keto acid, $5 \mathrm{mM}$ ammonium acetate, $0.1 \mathrm{mM}$ DPNH and $0.1-1.0 \mathrm{mg}$ of enzyme in $50 \mathrm{mM}$ Tris-HCl buffer $\mathrm{pH}$ 8.5. The rate of disappearance of DPNH was determined; $25^{\circ} \mathrm{C}$.

2) Not available commercially. 


\section{REFERENCES}

1. Cooper, A.J.L., McDonald, J.M., Gelbard, A.S., Gledhill, R.F., and Duffy, T.E., The metabolic fate of $13 \mathrm{~N}-\mathrm{labeled}$ Ammonia in Rat Brain. J. Biol. Chem., 254, 4982-4992, 1979.

2. Berl, S., Takagaki, G., Clarke, D.D., and Waelsch, M.M., Metabolic Compartments in vivo: ammonia and glutamic acid metabolism in brain and liver. J. Biol. Chem., 237, 2562-2569, 1962.

3. 0ldendorf, W.H., Brain Uptake of radiolabelled amino acids, amines and hexoses after arterial injection. Am. J. Physiol., 221, 1629-1639, 1972.

4. Milne, M.D., Schribner, B.H. and Crawford, M.A., Non-ionic diffusion and the excretion of weak acids and bases. Am. J. Med., 24, 709-724, 1958.

5. Carter, C.C., Lifton, J.F., and Welch, M.J., Organ uptake and b.lood $\mathrm{pH}$ and concentration effects of ammonia in dogs determined with ammonia labeled with 10 minutes half-lived nitrogen 13. Neurology, 23, 204-213, 1973.

6. Harper, A.M., and Bell, R.A., The effect of metabolic acidosis and alkalosis in the blood flow through the cerebral cortex, J. Neurol. Neurosurg. Psychiat., 26, 341-344, 1963.

7.- Lee, S.H., and Fisher, B.; Portcaval shunt in the rat, Surgery, 50 , $668-671,9961$.

8. Hindfelt, B., Plum, F., and Duffy, T.E., Effect of acute ammonia intoxication on cerebral metabolism in rats with portacaval shunts, J. Clin. Invest., 59, 386-396, 1977.

9. Benuck, M., Stern, F., and Lajtha, Regional and subcellular distribution of aminotransferases in rat brain, J. Neurochem., 19, 949-957, 1971.

10. Roberts, S., and Morelos, B.S., Regulation of cerebral metabolism of amino acids. IV. influence of amino acid levels on leucine uptake, utilization and incorporation into protein in vivo. J. Neurochem., 12, 373-387, 1965.

11. Tomkins, G.M., Yielding, K.L., Curran, J.F., Summers, M.R. and Bitensky, M.W., The dependence of the substrate specificity on the conformation of crystaline glutamate dehydrogenase. J. Biol. Chem., 240, 3793-3798, 1965.

12. Cooper, A.J.L., Stephani, R.A. and Meister, A., Enzymatic reactions of methionine sulfoximine: conversion to the corresponding $\alpha$-imino and $\alpha$-keto acids and to $\alpha$-ketobutyrate and methane sulfinimide. J. Biol. Chem., 251, 6674-6682, 1976.

13. Hancock, W.S., Bishop, C.A., and Hearn, M.T.W., The analys is of nanogram levels of free amino acids by reverse-phase high pressure liquid chromotography. Anal. Biochem., 92, 170-173, 1979. 


\subsubsection{CEREBRAL METABOLISM AND BLOOD FLOW: EFFECTS OF TRANSIENT ISCHEMIA}

\section{OBJECTIVE}

The objectives of this project are to demonstrate the utility of the 150 steady-state method for measuring cerebral blood flow and oxygen metabol ism, through quantitative validation measurements, and to then use this technique to assess changes in brain metabolism and blood flow caused by transient cerebral ischemia. The underlying hypothes is is that transient cerebral ischemia may cause a secondary disruption of the normal coupling between brain blood flow and metabolism. Specifically, does blood flow fall at a time of increased metabolic need? This would constitute a situation that could produce additional ischemia and thus secondary brain damage. The techniques being developed for this study will ul timately be applicable to human stroke since they are minimally invasive and may prove useful in assessing the course and effects of therapy in individual patients.

\section{SCOPE OF INVESTIGATION}

Beginning with the development of the 150-gas steady state methodology in this laboratory in 1973 (1), members of our staff have performed a number of .... studies relevant to this steady-state or continuous inhalation techniques, utilizing gases labeled with short-lived isotopes of oxygen. These studies have included: total body 150 distribution studies in dogs (2), monitoring of radiation therapy effects on tumors with 150 -labeled gases (3), whole body distribution measurements with 140 -gases (4), and a theoretical analys is of the oxygen steady-state on the basis of a multicompartmental model (5).

In 1.976, Jones et. a $(6)$ suggested a model for the interpretatjon of of $15 \rho_{5}$ steady state image obtained during the continuous inhalation of ${ }^{5} \mathrm{O}_{2}$ and $\mathrm{C}^{15} \mathrm{O}_{2}$, in terms of regional cerebral blood flow and oxygen extraction; this Subramanyam et al (7). It is our goal to ultimately apply this 150 steadystate model to the measurement of cerebral blood flow and oxygen metabolism in human stroke patients and to monitor the course and effects of therapy aimed at minimizing damage due to transient cerebral ischemia. To reach this clinical application required progress through a number of steps, as follows:

(a) Develop techniques that will permit a comparison of cerebral blood flow (CBF) and oxygen metabolisim determinations, as derived from the 150 gas method, with standard results derived from Kety-Schmidt CBF and A-V oxygen difference measurements.

(b) Develop a radioactive gas de] ivery system which can supply $\mathrm{O}_{2}$, $\mathrm{CO}_{2}$, and $\mathrm{CO}$ labeled with cyclotron produced 150 . These gases must satisfy chemical and radiochemical purity requirements, and the delivery system must be capable of switching quickly from one gas to another.

(c) Validate 150 continuous inhalation model in non-human primates by performing a quantitative comparison of whole brain CBF and oxygen metabolism values obtained by 150 methodology versus standard measurement techniques. 
Posiffon emission tomography (PET) is the method of choice for performing the 150 steady-state measurements.

(d) Develop a non-human primate model of regional transient cerebral ischemia, to be introduced after the validation of the 950 blood flow and metabolism techniques.

\section{RESULTS AND CONCLUSIONS}

This investigation was planned to utilize axygen-15 to assess. regional cerebral blood flow and oxygen metabolism during and following transient cerebral ischemia in a primate model. Most of our recent activities: have concentrated on developing the methods for measuring cerebral blood flow and oxygen metabolism using oxygen-15. Although there had been a number of technical problems earlier in the study, we were able within the past year to deliver oxygen-15 labeled carbon monoxide, carbon dioxide, and molecular oxygen to a paralyzed, mechanically-ventilated baboon over a two hour period.

$\mathrm{C}^{150}$ was delivered in a concentration of $1.8 \mathrm{mCi} / \mathrm{L}$ and a flow rate of $6 \mathrm{~L} / \mathrm{min}$; there was less than $18 \mathrm{ppm}$ of cl60 and less than $0.5 \%$ total radioactivity in the form of $13 \mathrm{~N}$. Within 40 minutes of the termination of $\mathrm{C}^{150}$ delivery, the animal was receiving $\mathrm{C}^{15} \mathrm{O}_{2}$ in a concentration of $4.2 \mathrm{mCi} / \mathrm{L}$, a flow of $6 \mathrm{~L} / \mathrm{min}$; and with less than $0.15 \%$ inhaled $\mathrm{CO}_{2}$ and 1 ess than $0.1 \%$ of total radioactivity in the form of $13 \mathrm{~N}$. Within 20 minutes of the termination of $\mathrm{C}^{150}$ steady state, we were able to begin delivery of $\mathrm{I}_{2}$ in a concentration of 8.0 $\mathrm{mCi} / \mathrm{L}$, a flow of $6 \mathrm{~L} / \mathrm{min}$, and no detectable $\mathrm{CO}, \mathrm{CO}_{2}$, or $13 \mathrm{~N}$. In all instances, steady state gas delivery was maintained for at least 20 minutes. The baboon was subsequently extubated, recovered spontaneous respirations, and was returned to the Cornell Laboratory of Animal Medicine, where the same two animals have been maintained for the past several years while performing these experiments.

There has been increasing theoretical criticism of the proposed oxygen-15 methods for measuring cerebral blood flow. Therefore, within the past year Dr. Levy has begun performing whole brain cerebral blood flow and oxygen metabolism determinations in baboons utilizing 133 xenon in preparation for validating oxygen-15 methods experimentally. Baboon heads were also obtained from the Regional Primate Research Center in Seattle, and skulis were prepared in order to calibrate the scanning equipment. It has, however, become increasingly clear that the controversy developing over the use of oxygen-15 will not be settled unless validation experiments are performed using the most quantitative methods available, and this requirement has forced us to abandon our earlier plans of using the two-dimentsional HEG scanner in favor of the use of a PET scanner. The Departments of Neurology and Biophysics have therefore pooled resources in efforts to secure a PET scanner of sufficient resolution to permit the proposed studies to procede. These efforts are currently in progress.

Because questions have teen raised concerning the quantitative utility of the 150 steady-state inhalation technique, due to the nature of the formulas involved and the resulting error propagation, we als 9 performed some calculations pertinent to the quantitative validation of the 150 method and its potential in human studies. First, consider the 150 measurement of regional $\mathrm{CBF}$ using $\mathrm{Cl}^{\mathrm{O}_{2}}$ inhalation. The calculations, whose results are tabulated here, 
are based on the following sets of assumptions and conditions:

(a) Design and performance specifications for the Cyclotron Corporation PC 4600 position emission tomograph.

(b) Our measurements of arterial 150-water and oxyhemoglobin concentrations in the baboon during $\mathrm{C}^{15} \mathrm{O}_{2}$ inhalation which were found to exhibit a $\pm 2 \%$ (S.D.) variation at steady- state.

(c) Budinger's (8) PET error estimate, here increased by an additional factor of 2 to include noise introduced by attenuation and randoms corrections. $(2 \mathrm{~cm})^{3}$ for man.

(d) Region of interest (volume) equal to $(1 \mathrm{~cm})^{3}$ for the baboon and

(e) $\mathrm{C}^{15} \mathrm{O}_{2}$ gas concentration of $0.5 \mathrm{mCi} / 1$ iter for man and $5 \mathrm{mCi} / 1 \mathrm{iter}$ for the proposed baboon experiments.

(f) An imaging time of 10 minutes. $55 \mathrm{ml} / \mathrm{min} / 100 \mathrm{~g}$.

(g) Average blood flow outside region of interest was taken to be

The resulting estimates for regional $\mathrm{CBF}$ error are given in Table 13 for baboon and man. These uncertainties would appear to be quite reasonable for all but the lowest and highest flow rates.

Under the same hypothetical conditions error propagation for the $15 \mathrm{O}_{2} / \mathrm{C}^{15} \mathrm{O}_{2}$ regional oxygen extraction measurement. was also considered. For both the baboon and human cases, the expected uncertainty. was calculated to. be less than $10 \%$ at a CBF of $50 \mathrm{ml} / \mathrm{min} / 100$. g of brain.

We feel that the groundwork has been laid for final testing of the oxygen-15 methods using a PET scanner since the gas delivery system is now operational, animal handling techniques have proven reliable, and a standard Kety-Schmidt cerebral blood flow technique is available. Therefore, at this point, we are maintaining the animals while awaiting access to a PET scanner that will permit us to complete the proposed projects. 


\section{TABLE 13}

OXYGEN-15 STEADY-STATE CBF METHOD ERROR PROPAGATION CALCULATED FOR BABOON AND HUMAN MEASUREMENTS

Flow $(\mathrm{ml} / \mathrm{min} / 100 \mathrm{~g})$

1

2

5

10

30

55

100

140

\begin{tabular}{cr}
\multicolumn{2}{c}{ CBF Error } \\
In Baboon & $\frac{\text { In Man }}{21 \%}$ \\
-- & $13 \%$ \\
-- & $8 \%$ \\
- & $6 \%$
\end{tabular}

$5 \%$

$6 \%$

$6 \%$

$8 \%$

$10 \%$

$12 \%$

$13 \%$

$15 \%$ 


\section{REFERENCES}

1. Russ, G.A., Bigler R,E, Tilbury R, S: et al, Whole body scanning and organ imaging with oxygen -15 at the steady-state. [In] Proceedings of the First World Congress of Nuclear Medicine. Sept. 30-0ct. 5, 1974, Tokyo and Kyoto, Japan, World Federation of Nuclear Medicine and Biology, pp 904-9.06, 1974.

2. Russ, G. A. Bigler, R.E., Tilbury, R.S., et al. Distribution of oxygen -15 in the dog at the steady-state. Int, J. Nucl. Med. Biol, 3: 121-125, 19.76.

3. Bigler, R. E. Kostick, J.A., Davis, D.C . Russ, G.A., Hopfan S, Tilbury, R.S., and Laughl in J.S. The use of $\mathrm{C} 15 \mathrm{O}$ and $15 \mathrm{O}_{2}$ steady-state imaging to monitor radiation treatment effects. IEEE Transactions on Nuclear Science. NS - 25: 174-179, 1978.

4. Russ, G. A. Bigler, R.E. Dahl, J. R. Kostick, J.A. McDonald, J.M., Tilbury, R. S. and Laughtin, J.S. Regional imaging with oxygen-14, IEEE Transactions on Nuclear Science NS-23: 573-576, 1976.

5. Bigler, R.E., Kostick, J.A., Gillespie, J. R., and Laughlin, J.S, Compartmental analysis of the steady-state destruction of oxygen-15 labeled oxygen and water. J. Nucl. Med. 20: 606, 1979.

6. Jones, T., Chester, D., A., and Ter-Pogossian, M. M, The continuous inhalation of oxygen-15 for assessing regional oxygen extraction in the brain of man. Brit. J. Radiology 49: 339-343, 1976.

7. Subramanyam R., Alpert N.M., Hoop B. et al, A model for regional cerebral oxygen distribution during continuous inhatation of $15 \mathrm{O}_{2}, \mathrm{C}^{15} \mathrm{O}$, and $\mathrm{C}^{15} \mathrm{O}_{2}$. J. Nucl. Med. 19: 48-53, 1978.

8. Budinger, T.F., Derengo, S.E., Greenberg W. L. et al. Quantitative potentials of dynamic emission caomputed tomography. J. Nucl. Med. 19: 309-315, 1978. 


\section{OBJECTIVE}

To understand the role of the lung in the metabolism of blood-borne ammonia.

\section{SCOPE OF INVESTIGATION}

Studjes of the distribution of ${ }^{13} \mathrm{~N}$ activity following bolus injection of $13 \mathrm{~N}$-ammonia into the femoral vein of barbiturateanesthetized rats, previously undertaken at the Biophysics Laboratory, showed remarkable concentrations in the 1 ung at 2 minutes after injection. (relative concentration $=22.8+5.0 \mathrm{~s} \cdot \mathrm{e} \cdot \mathrm{m}$. , $\%$ dose $=12.6$ +2.8 s.e.m., $n=5$ ). This finding led us to suspect that the 1 ung may be a principal site of metabolism of blood-borne ammonia. The Department of Neurology, C.U.M.C, has long had an interest in understanding ammonia metabolism, particularly in relation to the known toxic effects of ammonia on the central nervous system. It was therefore decided to jointly investigate, in detail, the metabolism of ammonia in rat 1 ung.

\section{RESULTS}

A) Blood clearance of
${ }^{13} \mathrm{~N}$-ammonia.
Starting at the to 3 minutes thereafter, blood was collected dropwise from cannulae installed in the tail arteries of barbiturate-anesthetized rats, the intervals of collection recorded and relative concentration of $13 \mathrm{~N}$ in blood determined. The clearance curves obtained from 4 rats are shown in Figure 16. Following a peak observed at about 8 seconds after injection, the ${ }^{13} \mathrm{~N}$ relative concentration in the arterial blood fell with a half-time of approximately 5 seconds until about $30^{-}$seconds and subsequently fell with a half-time of 4 minutes, between 1 and 3 minutes after injection. The rel. conc. found at 2 minutes by this method ( $1.02 \pm .06$ s.e.m., $n=4)$ agreed quite closely with our earlier measurement ( $\overline{\mathrm{r} e}$ l. conc. $=1.02 \pm .13$ s.e. $m_{3}, n=5$ ) in which blood was taken directly from the heart. $\left.{ }^{B}\right)$ Lung 13 content following I.V. bolus injection of 13 -ammonia. Since the blood clearance measurements showed a rapid inifial phase ending at about 30 seconds, we decided to measure the lung $13 \mathrm{~N}$ content and metabolite profile at this time point, as well as at 2 minutes. The rel. conc. of ${ }^{13} \mathrm{~N}$ in 7 ung at 30 seconds was found to be $53.6+7.4 \mathrm{s.e.m}$. $(n=5)$. Although the fraction of injected dose in the whole organ was not directly measured (part was used for metabolite determination) we can confidently estimate that the whole lung contained a mean of $27 \%$ dose at 30 seconds, since the 1 ung represents $0.51 \%$ of body weight in rats of the size, and strain used in these experiments (unpublished measurements). C) 13 Netabolites in 
glood and lung at 0.5 and 2 minutes after I.V. bolus injection of

I N-ammonia. Lung tissues and blood samples were deproteinized in 5 volumes of $1 \%$ picric acid and the precipitate was removed by centrifugation. An aliquot of the clear supernatant was then analyzed by high pressure liquid chromatography (HPLC) as described in reference 1. Two principal peaks were observed in all samples, one containing ammonia and basic amino acids, the other containing neutral amino acids and urea. Precipitable activity was less than $0.3 \%$ of the total for blood at 0.5 and 2 minutes and for 1 ung at 0.5 minutes and was about $1.5 \%$ of total lung ${ }^{13} \mathrm{~N}$ at 2 minutes. The results of the HPLC determinations, using a separate group of 3 rats for each tissue/time point, are shown in Table 14 .

To further resolve the metabolite distribution, a technique employing small ion exchange columns was used. An al iquot of supernatant, prepared as above, was added to a column of Biorad AG-50 (TRIS form). The pass-through and $\mathrm{H}_{2} \mathrm{O}$ wash, containing neutral (and, acidic) amino acids and urea, were added to a second $A G-50$ col umn $\left(\mathrm{H}^{+}\right.$ form). The pass-through and $\mathrm{H}_{2} \mathrm{O}$ wash of the second column contained ${ }^{\mathrm{N}}$ labeled to urea. Activity remaining on this column was e] yted with $2 M K C 1$. Elution of the first column with $2 M$ ammediol removed ${ }^{3} \mathrm{~N}-$ -ammonia. The basic amino acid fractjon was then removed with $2 \mathrm{M} \mathrm{KCl}$. The separations were verified using ${ }^{14} \mathrm{C}$-labeled glutamine, urea, . arginine and glutamate and with stable ammonia (determined colorimetrically), in the presence of picric acid extracts of unlabeled tissue. It was later found that, under experimental conditions, excessive amounts of unprecipitated picrate in the extracts resulted in incomplete separation between ammonia and neutral amino acids and a slight $(\sim 0.3 \%)$ tailing of ammonia into the basic amino acid fraction. Thus, at the present stage of the work, only the urea fraction has been fully resolved and the basic amino acid results must be regarded as maximum values. Nevertheless, the latter two components may be used in conjunction with the HPLC results to yield a five-component profile of the ${ }^{3} \mathrm{~N}$ activity, as shown in Table 15 .

It may be noted that, at 30 seconds after injection, about $30 \%$ of circulating ${ }^{13} \mathrm{~N}$ is already in the form of labeled metabolites, so that the clearance half-time of ammonia from blood is even shorter than the 5 second value mentioned above. Given that the circulation time of blood appears to be of the order of 8 seconds, the first-pass extraction of ammonia by the lungs may well be $50 \%$ or more.

It is al so to be noted that the proportions of ammonia and neutral amino acids in lung and blood at 30 seconds after injection are quite similar. A quantitative comparison of the concentrations of $13 \mathrm{~N}$-labeled components in lung and blood can be obtained by multiplying the measured $13 \mathrm{~N}$ relative concentrations at the two time points by the 
fraction of total ${ }^{13} \mathrm{~N}$ in each component. (The contribution of precipitable activity is neglected). The result of this calculation for ammonia, neutral amino acids and urea are shown in Table 16.

It is seen that, between 0.5 and 2 minutes after injection, the lung maintains a more than 30-fold concentration gradient of $13 \mathrm{~N}$-ammonia with respect to blood, and this while the labeled ammonia content of both tissues decreases $7-8$ fold. A similar gradient is observed for the neutral amino acids, but with the important difference that this gradient decreases while the labeled neutral amino acid content of blood increases. Although it is conceivable that these metabolites are produced el sewhere in the body, released into the circulation and efficiently extracted by the lungs, it seens far more likely that they are synthesized in the lungs de novo and that the lungs are a principal source of these metabolites.

The early work of Duda and Handler showed glutamine synthes is to be the major fate of ammonia in the body of the rat (2). Further, it has been reported that the rat lung contains glutamine synthetase activity (3) and concentrations of glutamate and glutamine on the order of several millimolar (3-5). Thus, it seems probable that ${ }^{13} \mathrm{~N}$-glutamine is a leading constituent of the neutral amino acid. fractions of lung and blood.

Since we were unable to find any values in the literature for the ammonia content of rat lung, we have carried out our own measurements, by standard enzymatic techniques, of the concentration of ammonia and several amino acids in nomal rat 1 ung (unanesthetized animals). The results, shown in Table 17, indicate a lung ammonia concentration about 20 times that of whole rat blood (80uM).

The small gradients observed for urea (Table 16), which decrease as blood urea increases between 0.5 and 2 minutes, suggest that this metabolite is al so synthesized to some degree by the lung. Although the lung reportedly lacks the full complement of urea cycle enzymes necessary for the de novo synthesis of urea from ammonia (6), the synthesis may proceed fram- Tabeled intermediates (such as arginine) which are produced el sewhere and taken up from the circulation. D) Measurement of Expired $13 \mathrm{~N}$ in Rat Breath. Two barbiturate-anesthetized rats were separately placed in a chamber designed (Dept. of BioGigemistry, C.U.M.C) for collection of expired ${ }^{14} \mathrm{CO}_{2}$. A bolus of $13 \mathrm{~N}$-ammonia was injected via a tail vein cannula and a steady flow of air maintained through the chamber by connection to the laboratory compressed air supply. The effluent passed through a bubble-trap filled with $10 \mathrm{ml}$ iN $\mathrm{HCl}$. The $\mathrm{HCl}$ was drained and replaced every 5 minutes and the quantity of $13 \mathrm{~N}$ measured. The results are shown in 
Table 18 . In both cases, less than $10 \mathrm{ppm}$ of the injected dose were
recovered by one half hour after injection. If ${ }^{13} \mathrm{NH}_{3}$ were the principal expired species, one would expect the maximum recovery to occur in the first 5 minutes, when $13 \mathrm{~N}$-ammonia content of the lungs was at a maximum. Instead, the peak recovery was observed at later times, indicating that volatile ${ }^{\mathrm{N}} \mathrm{-l}$ labeled products other than amonia were involved, or possibly, that some ${ }^{1} \mathrm{~N}$-ammonia arises from voided urine.

It has proved difficult to measure ammonia in the expired air. of normal experimental animals. Robin et al. (7) were able to measure expired ammonia only after preloading dogs with ammonia acetate, while Jacquez et al. (8) carried out their measurements in portocaval-shunted dogs. Both groups concluded that ammonia in alveolar air is in rapid equilibrium with $\mathrm{NH}_{3}$ in blood passing through the pulmonary capillaries. Assuming that the measured uptake in rat lung arises from diffusion of the highly. permeant $\mathrm{NH}_{3}$ molecule into the lipid-rich tissue of that organ, which has been shown to be the case with brain, our results indicate that the passage of gaseous ammonia into lung tissue is favored over passage into alveolar air by a factor of at least $10^{\circ}$.

\section{RESULTS AND CONCLUSIONS}

The results obtained so far demonstrate substantial pulmonary extraction of blood-borne ammonia in the rat. and strongly suggest that a. large portion of the extracted ammonia is metabolized by the 1 ung, in the form of de novo synthesis of neutral aming acid(s). Since our earlier measurements showed that most of the ${ }^{13} \mathrm{~N}$ activity present in the lungs at 2 minutes is lost by 10 minutes after injection, and since the present experiments show that about $75 \%$ of 1 ung ${ }^{19} \mathrm{~N}$ at 2 minutes is in the form of labeled metabolites, the lung appears to be a significant contributor of systemically recirculated ammonia metabolites. Thus, our data indicate that the lung may be far more important in the metabolism of blood-borne ammonia than had heretofore been realized.. 


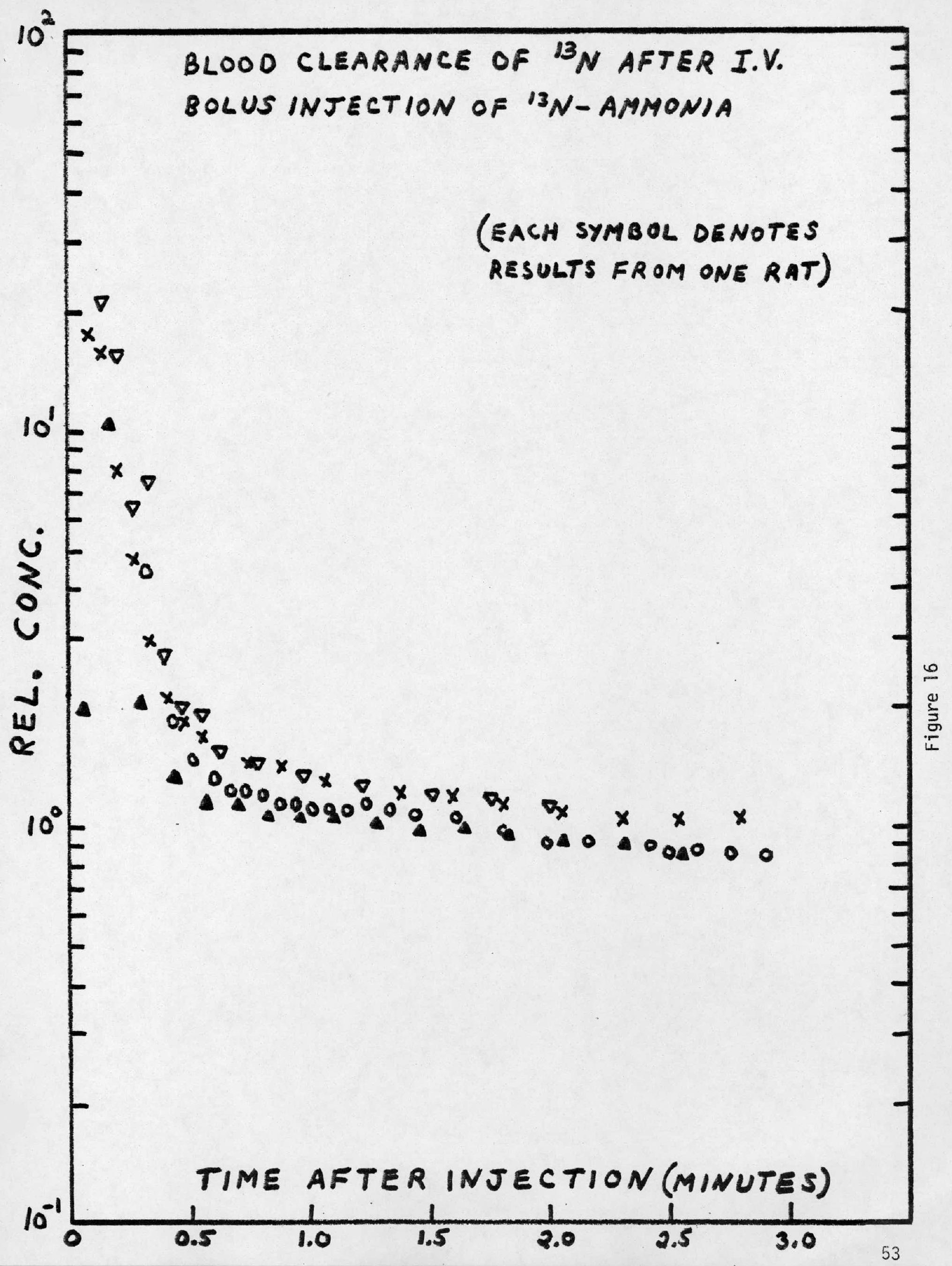




\section{TABLE 14}

Distribtuion of ${ }^{13} \mathrm{~N}$-Labeled Species in Rat Lung and Blood Following I.V. Bolus Injection of $13 \mathrm{~N}$-Ammonia, as Determined by HPLC. (\% of Non-Precipitable Activity, Mean \pm S.E.M., $n=3$ )

\begin{tabular}{|c|c|c|c|c|}
\hline Tissue & Time & $\begin{array}{l}\text { Ammonia + Basic } \\
\text { Amino Acids }\end{array}$ & $\begin{array}{l}\text { Neutral Amino } \\
\text { Acids + Urea }\end{array}$ & $\begin{array}{c}\text { Acidic Components } \\
\text { (GLU,ASP,etc.) }\end{array}$ \\
\hline Lung & $30 \mathrm{sec}$ & $69.2 \pm 5.9$ & $30.3 \pm 5.9$ & $0.47 \pm .02$ \\
\hline & $2 \min$ & $24.5 \pm 2.2$ & $74.4 \pm 2.2$ & $1.05 \pm .43$ \\
\hline Blood & $30 \mathrm{sec}$ & $72.2 \pm 3.3$ & $26.3 \pm 1.9$ & $1.6 \pm 1.5$ \\
\hline & $2 \mathrm{~min}$ & $15.2+0.4$ & $80.2 \pm 2.7$ & $4.7 \pm 2.3$ \\
\hline
\end{tabular}

TABLE 15

13 N-Metabolite Profile for Rat Lung and Blood Following

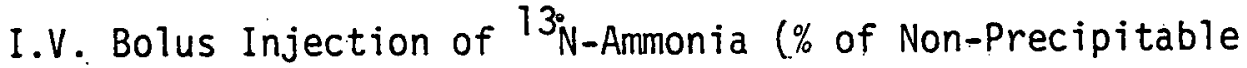
Activity, Mean \pm S.E.M.)

\begin{tabular}{|c|c|c|c|c|c|c|}
\hline Tissue & Time & $\begin{array}{c}\text { Basic* } \\
\text { A.A. } \\
\text { (maximum) }\end{array}$ & $\begin{array}{l}\text { Ammonia** } \\
\text { (minimum) }\end{array}$ & $\begin{array}{l}\text { Neutral** } \\
\text { A.A. }\end{array}$ & Urea* & $\begin{array}{l}\text { Acidic } \\
\text { Components } \\
\text { (HPLC) }\end{array}$ \\
\hline
\end{tabular}

\begin{tabular}{|c|c|c|c|c|c|c|}
\hline Lung & $30 \mathrm{sec}$ & $\begin{array}{l}1.60 \\
+.64 \\
(5)\end{array}$ & $\begin{array}{r}67.6 \\
+5.9\end{array}$ & $\begin{array}{r}29.9 \\
+5.9\end{array}$ & $\begin{array}{l}0.36 \\
+.10 \\
(5)\end{array}$ & $\begin{array}{l}0.47 \\
+.02 \\
(3)\end{array}$ \\
\hline & $2 \mathrm{~min}$ & $\begin{array}{r}1.86 \\
+.97 \\
(5)\end{array}$ & $\begin{array}{r}22.6 \\
+2.4\end{array}$ & $\begin{array}{r}72.7 \\
+2.2\end{array}$ & $\begin{array}{l}1.75 \\
+.43 \\
(5)\end{array}$ & $\begin{array}{l}1.05 \\
+.43 \\
(3)\end{array}$ \\
\hline Blood & $30 \mathrm{sec}$ & $\begin{array}{l}2.93 \\
+.82 \\
(5)\end{array}$ & $\begin{array}{r}69.3 \\
+3.4\end{array}$ & $\begin{array}{r}22.4 \\
+2.1\end{array}$ & $\begin{array}{l}3.90 \\
+.98 \\
(5)\end{array}$ & $\begin{aligned} & 1.6 \\
&+1.5 \\
&(3)\end{aligned}$ \\
\hline & $2 \mathrm{~min}$ & $\begin{array}{r}1.07 \\
+.42 \\
(7)\end{array}$ & $\begin{array}{l}14.1 \\
\pm .6\end{array}$ & $\begin{array}{l}52.0 \\
+5.0\end{array}$ & $\begin{array}{l}28.2 \\
+4.2 \\
(7)\end{array}$ & $\begin{array}{l}4.7 \\
+2.3 \\
(3)\end{array}$ \\
\hline
\end{tabular}

*Ion exchange column data

**Difference between HPLC (3) and ion exchange column measurements, variance of difference $=$ sum of variances 


\section{TABLE 16}

Relative Concentrations* of Total ${ }^{13} \mathrm{~N}$ and Principal ${ }^{13} \mathrm{~N}$ Labeled Species in Rat Lung and Blood Following I.V. Bolus Injection of ${ }^{13} \mathrm{~N}$-Ammonia.

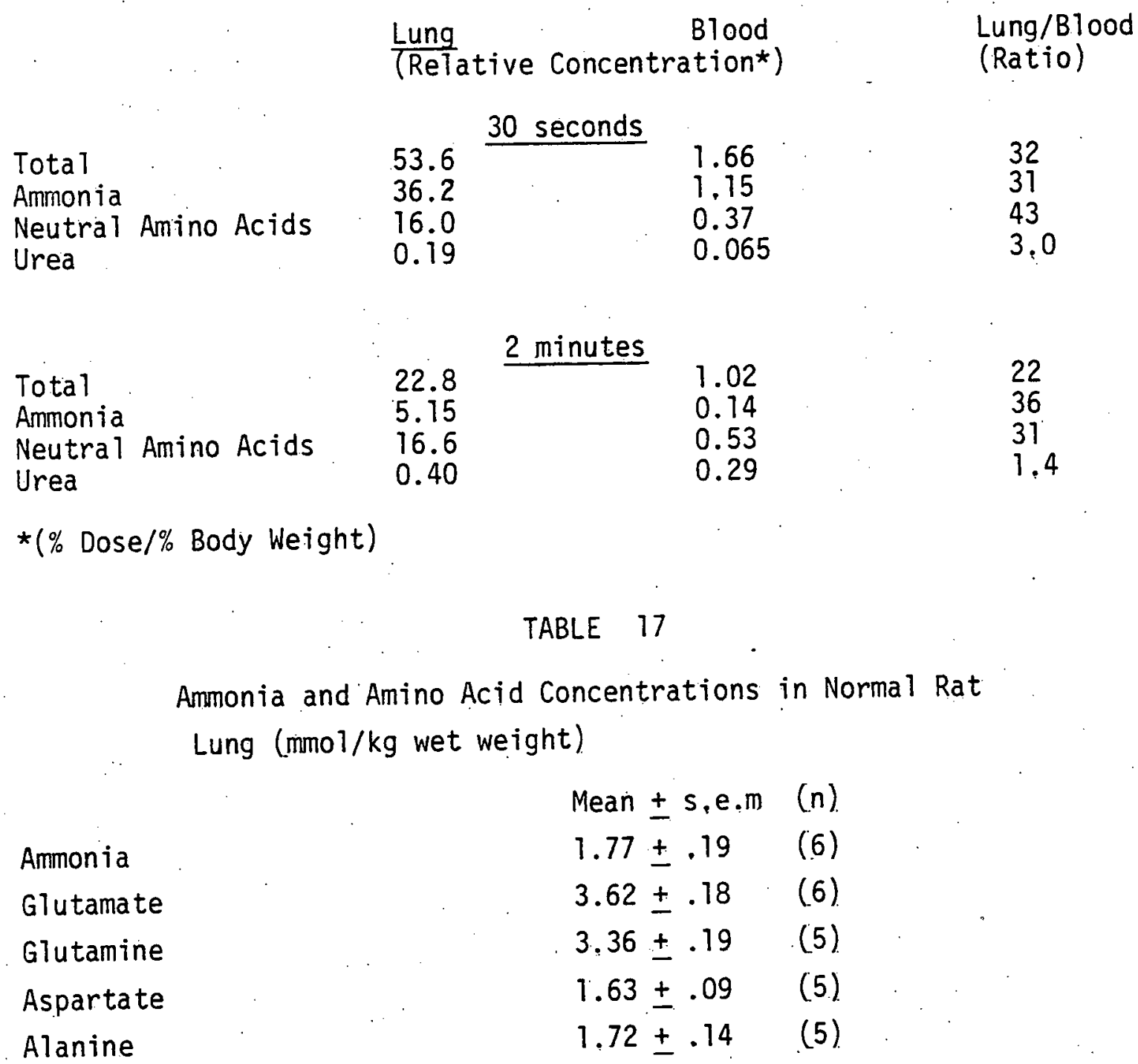




\section{TABLE 18}

\section{$1{ }^{13}$-Label Recovered in Expired Air after I.V. Bolus Injection of ${ }^{13} \mathrm{~N}$-Ammonia in Barbiturate-Anesthetized Rats}

Collection Interval

(Minutes)
Fraction of Dose Recovered ( $\mathrm{ppm}$ )

Rat \#1 Rat \#2

0.21

0.27

1.11

1.12

0.42

0.47

3.60
0.58

2.63

1.50

1.65

1.41

0.80
8.57

Total 


\section{REFERENCES}

1. Cooper, A.J.L., McDonald, J.M., Gelbard, A.S., Gledhill, R.F., and Duffy, T.E. The metabol ic fate of ${ }^{13} \mathrm{~N}-1$ abeled ammonia in rat brain. J. Biol. Chem. 254: 4982-4992, 1979.

2. Duda, G.D., and Handler, P. Kinetics of ammonia metabol ism in vivo: J. Biol. Chem. 232: 303-314, 1958.

3. Knox, W.E., Kupchik, H.Z. and Liu, L. Glutamine and glutamine synthetase in fetal, adult and neoplastic rat tissue, Enzyme. 12: 88-98, 1971.

4. Herbert, J.D., Coulson, R.A., and Hernandez, T. Free amino acids in the caiman and rat. Comp. Biochem. Physiol., 17: 583-598, 1966 .

5. Tigerman, $H_{0}$, and MacVicar, R. Glutamine, glutamic acid, ammonia administration and tissue glutamine, J. Biol. Chem., 189, 793-799, 1951.

6. Jones, M.E., Anderson, A.D., Anderson, C., and Hodes, S. Citruliine synthesis in rat tissue. Arch. Biochem. Biophys., 95: 499-507, 1961.

7. Robin, E.D., Travis, D.M., Bromberg, P.A., Forkner, C.E. and Tyler, J.M. Ammonia excretion by mammalian 1 ung. Science 129: $270-271,1959$.

8. Jacquez, J.A., Poppell, J.W., and Jeltsch, R. Partial pressure of ammonia in alveolar air. Science, 129: 269-270, 1959. 


\section{RADIODRUG RESEARCH AND DEVELOPMENT \\ $2.1 \quad{ }^{11}$ C-LABELED COMPOUNDS \\ 2.1.1 11 C-AMINO ACIDS}

\section{Objective:}

To synthesize $\mathrm{DL}-\mathrm{val}$ ine- $1-{ }^{11} \mathrm{C},\left(\right.$ carboxy $\left.1-{ }^{11} \mathrm{C}\right)$-DL-tryptophan, $\left(1-{ }^{11} C\right.$-alpha aminoisobutyric acid $\left({ }^{1} C-A I B\right),($ carboxy $1-11 C)-1$-aminocyclopentanecarboxyl ic acid ( ${ }^{C}$ - - ACPC), and related compounds in millicurie amounts, and to evaluate these compounds as potential tumor or pancreatic scanning agents.

\section{Scope of Investigation:}

Carbon-11 labeled amino acids have significant potential as agents for tumor and pancreas visualization, especially in view of recent developments in positron emission computerized axial tomography. Our laboratory (1) and the Oak Ridge Group (2-4) have shown that ${ }^{1} C_{-}$DL-val ine has a high specificity for the pancreas in rats and dogs; and recently the 0ak Ridge investigators $(5,6)$ have demonstrated the poten-

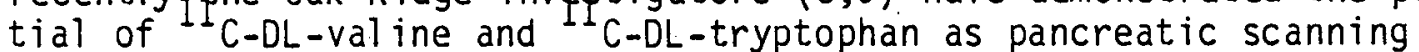
agents in humans. There is clinical indication that some neoplastic tissues may have a high turnover rate for val ine and tryptophan and therefore these $\mathrm{C}-11$ agents may be useful tumor-localizing agents in certain cases (6). There is clinical evidence al so that the synthetic amino acids ${ }^{1} C_{-}-1$-aminocyclopentanecarboxyl ic acid $\left({ }^{1} C-A C P C\right)$ and ${ }^{11} \mathrm{C}-1$-aminocyclobutanecarboxylic acid (11C-ACBC) are of value as tumor scanning agents $(5,7,8)$. We have recently synthesized (9) $\left(1-M_{C}\right)$ al pha-aminoisobutyric acid ( ${ }_{C-A I B)}$, another nonmetabolized amino acid (10) in order to investigate its potential as a tumor scanning agent for brain and other regions of the body. AIB is distinguished by its failure to cross the blood-brain barrier $(10-13)$. Since it enters and concentrates in viable cells, high tumor-to-brain concentration ratios may be anticipated. AIB is incorporated rapidly into cells, and, since it is not metabolized further, it offers the possibility of studying transport into cells without potential interference by subsequent metabolic events.

Carbon-11 has been made in our laboratory in amounts up to 1.5 Curies by proton irradiation of nitrogen either as methane- ${ }^{1} C$ when hydrogen is added to the target gas, or as carbon dioxide- ${ }^{11} \mathrm{C}$ when oxygen is present in the target gas. The methane- ${ }^{1 l_{C}} \mathrm{C}$ was converted to hydrogen cyanide- ${ }^{11} \mathrm{C}$ by reaction with ammonia on a platinum catalyst at 
$1000^{\circ} \mathrm{C}$, according to the method of Christman et at (14). We have used the $H^{11} C N$ so produced to synthesize $D L-v a l i n e-1-{ }^{11} C$, as shown in Scheme 1 , by a modification of the hydantoin procedure developed by us to produce dilantin (15) and by Hayes, Washburn and co-workers at Oak Ridge to produce a number of ${ }^{11} \mathrm{C}$-amino acids $(16,17)$. By this procedure, we have synthesized $D L-v a l$ ine-1- ${ }^{1}{ }_{C}$ in amounts up to $25 \mathrm{mC} i$ in about one hour. Specific activities up to $2.4 \mathrm{mCi} / \mathrm{mg}$ have been obtained. This compound has been administered to Sprague-Dawley rats and mongrel dogs. A positive uptake in the pancreas was observed in both species. In the rat, the relative concentrations in the pancreas and liver were about 6.0 and 1.5 , respectively. In the dog, relative concentrations of 4.0 and 2.0 were obtained. Neither species were conditioned prior to administration of DL-valine. In one experiment with an unconditioned Rhesus monkey, visualization of the pancreas was equivocable. We have synthesized $L \div$ and $D$-valine $-1-11 C$ in amounts up to 4 $\mathrm{mC} i$ from $16 \mathrm{mCi}$ of $\mathrm{DL}-\mathrm{val}$ ine-1- ${ }^{2} \mathrm{C}$ in reactions catalyzed by the specific action of $D$ - and L-amino acid oxidases (18). An equivalent amount ( $4 \mathrm{mC}$ ) of alpha-keto-isovaleric acid-1-1. C was obtained in these reactions. Our synthesis of IIC-AIB by the hydantoin method and its distribution in a dog with spontaneous 1 ymphosarcoma is described in this report.

\section{Results and Conclusions}

The preparation of unlabeled AIB by the hydantojn method has been described (19). Our sequence for the production of ${ }^{1}$ C-AIB, labeled in the carboxyl group, by the modified Bucherer-Strecker synthesis is shown in scheme 2. The reaction condjtons described below are essentially those used to produce $\mathrm{DL}-\mathrm{val}$ ine-1- ${ }^{1} \mathrm{C}$. By this procedure, ${ }^{11}$ C-AIB has been synthesized with radiochemical yields of $60 \%$. Sixteen millcuries of AIB were formed from $410 \mathrm{mCi}$ of $\mathrm{H}^{\mathrm{C}} \mathrm{CN}$ in 80 minutes (9), with specific activities of $2.1 \mathrm{mCi} / \mathrm{mg}$.

As outlined in Scheme 2, acetone, ammonium carbonate, and carbon-11 labeled cyanide are reacted at high temperature and pressure for a short time to produce the hydantoin of acetone. After cooling, the hydantoin is hydrolyzed under high temperature and pressure to AIB in $60 \%$ yield. The product was purified by ion exchange chromatography on Bio-Rad $A G-1$ and $A G-50 \mathrm{~W}$ resins. Assay of the product by thin layer chromatography showed the radiopurity to exceed $95 \%$. In a typical experiment, $\mathrm{H}^{11} \mathrm{CN}$ is bubbled into a glass gas absorption column containing $1 \mathrm{ml}$ of $0.005 \mathrm{~N} \mathrm{KOH}$. This solution (containing $\mathrm{K}^{1 \mathrm{CN}}$ ) is drained through a stopcock at the base of the column into a stainless steel pressure vessel having an internal volume of $10 \mathrm{ml}$. The reaction vessel is charged with a mixture of $23 \mathrm{mg}$ acetone, $72 \mathrm{mg}\left(\mathrm{NH}_{4}\right)_{2} \mathrm{CO}_{3}$, $6.7 \mathrm{mg} \mathrm{NH} \mathrm{NLL}_{4}$ and $8.2 \mathrm{mg}(0.13 \mathrm{mmole}) \mathrm{KCN}$ prior to introduction of the $\mathrm{K}^{11} \mathrm{CN}$. The closed vessel is heated rapidly to $210^{\circ}-230^{\circ} \mathrm{C}$ and 
maintained at that temperature for 10 minutes after which it is rapidiy cooled: One $\mathrm{ml}$ of $6 \mathrm{~N}$. $\mathrm{KOH}$ is then introduced and the vessel is again heated at $210^{\circ}-230^{\circ}$ for another period of 10 minutes. The cooled reaction mixture is filtered and then loaded directly onto a $1.5 \mathrm{~cm}$ diameter $\times 5$ cm length prewashed AG 1-X2, 100-200 mesh, anjpn exchange bed in the hydroxide form. Anionic components, including ${ }^{11} C-A I B$ are retained by the column while cationic and non-ionic components pass through. After washing repeatedly with distilled water $(50 \mathrm{ml})$ the column is then eluted with $1 \mathrm{~N} \mathrm{HCl}$, the process being monitored by means of an ion chamber. This eluate $(15 \mathrm{ml})$ is then loaded onto a prewashed $1.0 \mathrm{~cm}$ (diameter) $\times 15 \mathrm{~cm}$ (length) AG 50W-X2,50-100 pesh, cation exchange bed in the hydrogen form. Cationic material ( ${ }_{\text {C-AIB) }}$ is retained while anionic material passes through the column. After being washed repeatedly with distilled water $(50 \mathrm{ml})$, the column is slowly eluted with $0.2 \mathrm{~N} \mathrm{NaOH}$, the process again being monitored with an ion chamber to minimize the volume of eluate containing the product $(10 \mathrm{ml})$. The purified $11 \mathrm{C}-\mathrm{AIB}$ solution can then be adjusted to physiologic $\mathrm{pH}$ with $\mathrm{HCl}$ and sterilized by microfiltration for investigational use. The purity of the ${ }^{1} \mathrm{C}$-AIB product was assessed by thin layer chromatography on silica gel and paper chromatograms developed in butanol:water:acetic acid (50:25:25) and n-propanol-0.1N aq. ammonia (50:50).

We have studied the distribution of ${ }^{11} \mathrm{C}-\mathrm{AIB}$ in a $20 \mathrm{~kg}$ dog with spontaneous 1 mmphosarcoma (20). Imaging was done following $0.4 \mathrm{mCi}$ IV administration using a PET tomograph camera. (Cyclotron Corp. Model 4200). " The dog was killed at 1.5 hours and the isotope concentration measured in twenty-eight tissues. Relative concentrations were for spleen 5.7, pancreas 4.5 , lymph nodes $3.2-2.3$, salivary glands 2.2 , brain 0.2 , muscle 0.3 , and blood 0.7 . A sixfold lower uptake was observed in a second dog study for nomal 1 ymph nodes demonstrating a specificity of this agent for lymphosarcoma. As anticipated, these images revealed rapid uptake and retention of labeled AIB in extra-cerebral structures and low levels of ${ }^{11} \mathrm{C}$-activity within the brain parenchyma. Further studies of this agent in canine 1 ymphosarcoma and in other tumor types are in progress. Areas of specific interest in addition to the lymph nodes include the marmary glands and the brain.

In a prel iminary experiment, $\mathrm{DL}-\mathrm{val}$ ine- $1-{ }^{11} \mathrm{C}$ and $\mathrm{L}-\mathrm{val}$ ine$1-{ }^{14} \mathrm{C}$ were simultaneously injected into a dog with a spontaneous tumor in its thigh, and the distribution of these compgunds in tumor and tissues was determined. Uptake in the tumor of ${ }^{1}{ }_{C-D L-v a l}$ ine was 2-6 times greater than ${ }^{14} \mathrm{C}-\mathrm{L}-\mathrm{val}$ ine, possibly due to incorporation of the $D$-isomer. Further studies will be made with the $D$-isomer. 
Since the potential of ${ }^{11} \mathrm{C}$-DL-val ine as a tumor and pancreatic scanning agent has been clinically demonstrated by others (26), animal tests in our laboratory will not be extensive. Pyrogenicity tests of this agent are in progress. As described in last year's progress report (1), we have achieved optical separation of ${ }^{1}{ }_{C-D L-}$ valine in reactions catalyzed by the specific actions of $D$-and L-amino acid oxidases. Work is progressing on the development of this technique. It is anticipated that apout $10 \mathrm{mC} i$ of $L-$ and $D$-valine will be produced. We will prepare al so ${ }^{1} \mathrm{C}-\mathrm{L}$-tryptophan, because it has a higher degree of localization in the pancreas than $L-v a l$ ine $(21,22)$. Tumors studied will be lung cancer, lymphoma, recurrent breast cancer, and carcinoma of the lower abdomen. 


\section{SCHEME 1}

Synthes is of DL-Valine-1-11C<smiles>CC(C)C=O</smiles>

Isobutyraldehyde

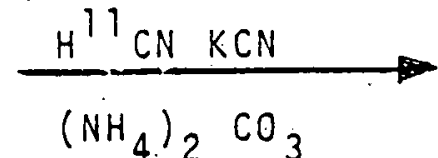
$\because$ Steel Bomb $2100 \mathrm{C}$ $10 \mathrm{~min}$.

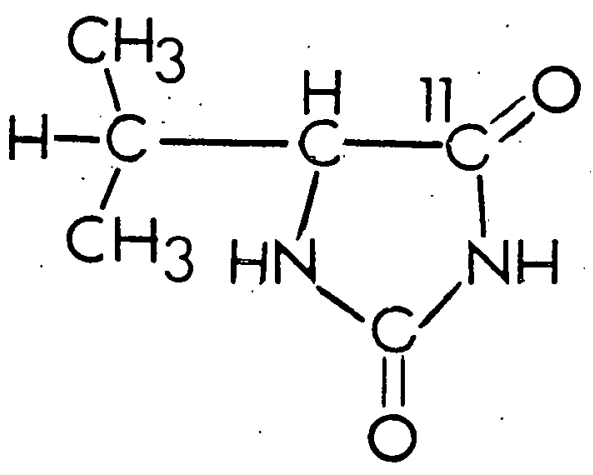

Hydantoin Intermediate

Alkaline Hydrolys is

Stee 1 Bomb $210^{\circ} \mathrm{C}$ 10 min.
Purification of DL-Valine

1) Anion Exchange $A G \quad 1-X 8$

(hydroxide form) $100-200$ mesh

2) Cation Exchange AG $50 \mathrm{~W}-\mathrm{X} 2$

(hydrogen form) 50-100 mesh

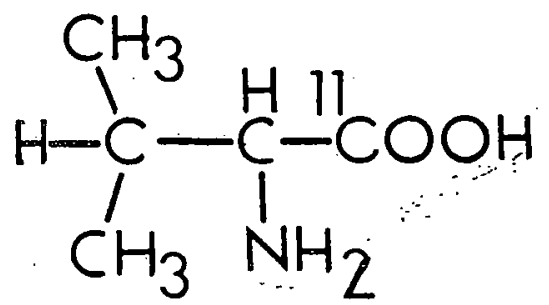

$D L-V a j$ ine

$\because 70 \%$ yield-overall 
Synthesis of $a-$ Aminoisobutyric Acid - $1-{ }^{\prime \prime} C$

$\mathrm{CH}_{3}$

Acetone

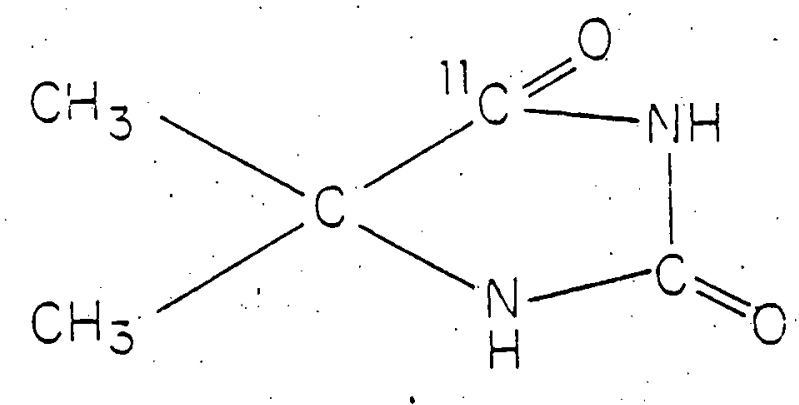

5,5 - Dimethylhydantoin $-{ }^{11} \mathrm{C}$

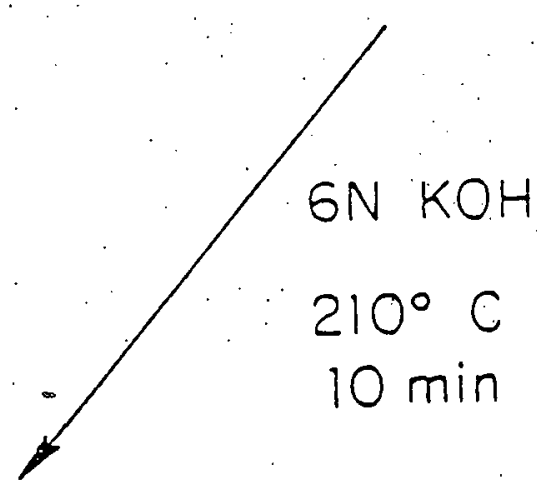

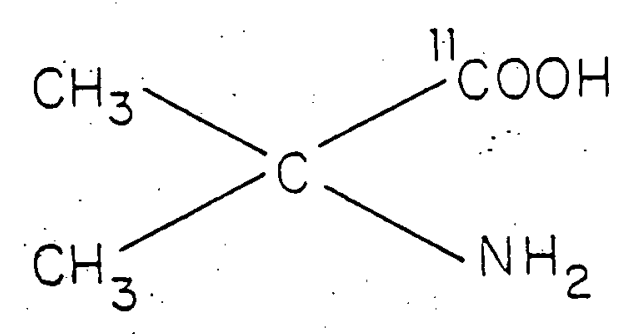

$a-$ Aminoisobutyric acid $-1-11 C(A I B)$ 


\section{References}

1. Laughl in, J.S. Biomedical research. with cyclotron produced radionuclides. DOE Progress Report, Contract No. EE-77-S-02-4268-A002, 1978.

2. Washburn, L.C., Wjel and, B.W., Sun, T.T., Hayes, R.L., and Butler, T.A. [1- $\left.{ }^{1} \mathrm{C}\right] \mathrm{DL}-\mathrm{Val}$ ine, a potential pancreas-imaging agent. J.Nucl. Med. 19:77-83, 1978

3. Washburn, L.C., Coffey, J.L., Watspn, E.E., Sun, T.T.; and Hayes, R. L. Radiation dosimetry of some ${ }^{C} C$-labeled amino acid radiopharmaceuticals. In Radiopharmaceutical Dosimetry Symposium. Cloutier, R.J., Coffey, J.L., Snyder, W.S. et al, eds. HEW (FDA) 76-8044. Rockville, Md., Bureau of Radiological Health, 1976, pp. $441-451$.

4. Washburn, L.C., Sun T.T., Byrd, B.L., Hayes, R.L., and Butler, T.A. DL-[Carboxy]- $\left.{ }^{1} \mathrm{C}\right]$ tryptophan, a potential agent for pancreatic imaging; production and preclinical investigations. J. Nucl. Med. 20:857-864, 1979.

5. Andrews, G.A., Hubner, K.F., Washburn, L.C., Wiel and, B.W., Gibbs, W.D., Hayes, R.L., and Butler, T.A. Clinical studies of C-11-labeled amino acids. J. Nucl. Med. 18:638, 1977. (Abst).

6. Hubner, K.F., Andrews, G.A., Buonocore, E., Hayes, R.L., Washburn, L.C., Collmann, I.R., and Gibbs, W.D. Carbon-11-labeled amino acids for the rectilinear and positron tomographic imaging of the human pancreas. J. Nucl. Med. 20:507-513, 1979.

7. Hubner, K.F., Buonocore, E., Gibbs, W.D., Holloway, S., and Byrd, L. Differentiation of pancreatic and other retroperitoneal tumors by positron emission computerized tomography (ECT). J. NUCL. MED. 20:631-632, 1979 (Abst).

8. Hubner, K.F., Andrews, G.A., Washburn, L.C., Wiel and, B.W., Gibbs, W.D., Hayes, R.L., Butler, T.A., and Winebrenner, J.D. Tumor location with 1 -aminocyclopentane- $\left({ }^{1}{ }_{C}\right)$-carboxyl ic acid: Preliminary clinical trials with single-photon detection. $J$. Nucl. Med. 18:1215-1221, 1977.

9. Schmall, B., Dahl, J.R., and Bigler, R.E. Synthesis of C-11 labeled al pha-aminoisobutyric acid as a potential agent for tumor visualization. 114th National Meeting of the America Chemical Society, Washington D.C. September 9-14, 1979. (Abst).

10. 0ldendorf, W.H. Brain uptake of radiolabeled amino acids, amines, and hexoses after arterial injection. Am. J. Physiol. 221:1629-1639, 1971 . 
11. Bl asberg, R.G., Patlak, C.S., Jehle, J.W., Fernstermacher, J.D. An autoradiographic technique to measure the permeability of normal and abnormal brain capillaries. Neurology 28:363, 1978. (Abst).

12. Shinohara, M., Blasberg, R., Patlak, C. and Shapiro, W. Metastatic brain tumors: local cerebral glucose utilization. Neurology 29:545, 1979 (Abst).

13. Bl asberg, R., Patlak, C., Shapiro, W., and Fenstermacher, J. Metastatic brain tumors: local blood flow and capillary permeability. Neurology 29:547, 1979. (Abst).

14. Christman, D.R. Finn, R.D., Karlstrom, K.I., and Wolf, A.P. The production of ${ }^{C} \mathrm{C}-\mathrm{HCN}$-.-. Int. J. Appl. Rad. Isotopes 26: $435-442,1975$.

15. Tilbury, R.S., Stavchansky, S., Ting, C.T., McDonald, J.M., Maugham, E., Freed, B.R., Russ, G.A., Hel son, L., Benua, R.S., Kostenbauder, H.B., and Laughl in, J.S. The preparation and evaluation of diphenylhydantoin-C-11 as a tumor scanning agent. J. Nucl. Med. 16:575, 1975. (Abst).

16. Hayes, R.L., Washburn, C.C., Wiel and, B.W., Sun, T.T., Anon, J.B., Butler, T.A., and Callahan, AP. Synthesis and purification of. ${ }^{11}$ C-carboxyl-labeled amino acids. Int. J. Appl. Radiat. and Isotopes 29:186-187, 1978 .

17. Washburn, L.C., Sun, T.T., Byrd, B.L. Hayes, R.L., Butler, T.A., and Callahan, A.P. High level production of C-11-carboxyl-labeled amino acids SNM: 2nd International Syn. on Radio-pharmaceuticals, Seattle, Wash., March 19-22, 1979.

18. Worthington Enzyme Manual, ed., L.A. Decker, Worthington Biochem. Corp., Freehold, N.J. 07728, 1977, p. 51.

19. The Merck Index, Ninth Edition, 1976, Merck \& Co., Inc., Rahway, N.J., p. 61 .

20. Bigler, R.E., Schmal 1, B, Andrews, L.K., and Kostick, J.A.. Lymphosarcoma uptake of ${ }^{11} C$-al pha-aminoi.sobutyric acid. The Radiological Society of North America, 65th Scientific Meeting, Atl anta, Georgia, November 23-30, 1979. 
21. Busch, H., Davis, J.R., Honig, G.R., Anderson, D.C., Nair, P.V., and Nyhan, W.L. The uptake of a variety of amino acids into nuclear proteins of tumors and other tissues. Cancer Res. 19:1030-1039, 1959 .

22. Washburn, L.C., Sun, T.T., Wiel and, B.W. and Hayes, R.L. C-11-DL-Tryptophan; a potential pancreas imaging agent for positron tomography. J. Nucl. Med. 18: 638, 1977. (Abst). 


\section{1 \\ $2.1 .2 \quad$ C PRECURSOR COMPOUNDS}

\section{OBJECTIVE}

To develope a versatile, reliable and easy to operate system for the production of $11 \mathrm{C}$ labeled compounds as precursors to compounds of biological interest.

\section{SCOPE OF INVESTIGATION}

The production of ${ }^{11} \mathrm{C}$ precursor compounds at this laboratory has been a continuing effort. A unified system to provide a number of $11 \mathrm{C}$ precursors was designed and constructed to permit synthes is of $H^{11} \mathrm{CN}, \mathrm{H}^{11} \mathrm{CHO}$, ${ }^{11} \mathrm{CH}_{3} \mathrm{I}$ and ${ }^{11} \mathrm{CH}_{4}$ from ${ }^{11} \mathrm{CO}_{2}$ (1). Dismantling or altering the apparatus when choosing one compound for preparation immediately following the preparation of another is unnecessary.

Carbon- $11 \mathrm{CO}_{2}$ is produced by the proton bombardment of nitrogen containing one to five percent oxygen. No difficulties are encountered with recovery of the activity and the conversion of $11 \mathrm{CO}_{2}$ to other materials such

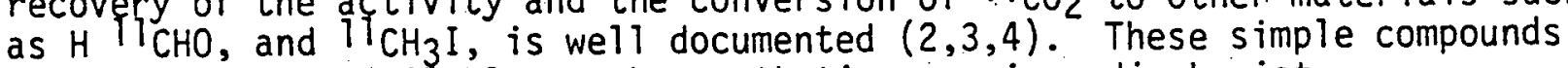
must be readily available to the synthetic organic radiochemist.

\section{RESULTS AND CONCLUSIONS}

Limitations of funding and time have resulted in priority assignments which restricted development to expand the range of $11 \mathrm{C}$ precursor compounds available. In spite of this restriction 32 experiments were performed, 28 of which involved use, repair, or improvement of $H^{11} \mathrm{CN}$ system. Only four runs were devoted to development of precursor compounds other than $\mathrm{H}^{11} \mathrm{CN}$. Three pilot studies were made to learn some of the problems which may be expected in labeling carbohydrates. Of sixteen attempts, fifteen runs successfully provided $\mathrm{H}^{\mathrm{I}} \mathrm{CN}$ for the preparation of $11 \mathrm{C}$-dilantin, $11 \mathrm{C}-\mathrm{DL}$ valine, and $11 \mathrm{C}$-AIB. The run which was not successful occured when a plug in the target began to leak. The plug closes a hole made in the target when it was modified for a previous experiment.

\section{SUMMARY OF ${ }^{11}$ C PRECURSOR COMPOUND OPERATIONS 1978-79*}

Synthesis of ${ }^{1.1}$ C-labeled compounds of biological interest 16

Apparatus testing

Pilot Studies

CN Development (chemistry) 4

${ }^{11} \mathrm{CH}_{3} \mathrm{OH}$ Development

Total ${ }^{11} \mathrm{C}$ precursor compound operations

*Exclusive of ${ }^{11}$ CO studies. 
Modifications in the $H^{11} \mathrm{CN}$ synthetic process this year have been efforts to eliminate residual $\mathrm{NH}_{3}$ in the product. For processes such as the Strecker synthesis $\mathrm{NH}_{3}$ in the product is of no importance, but labeling of certain other materials requires an ammonia free product. Previously the technique used to introduce $\mathrm{NH}_{3}$ to the feed stream was passage of the flowing gas stream through liquid ammonia. The resulting $\mathrm{NH}_{3}$ was excessive. An alternative method was developed. Molecular sieve $3 \mathrm{~A}$ as cylindical pellets $2-3 \mathrm{~mm}$ long $\times 0.9 \mathrm{~mm}$ 0.D. previously dried at $200^{\circ} \mathrm{C}$ in air for 24 hours were placed in the trap formerly used to contain the liquid. $\mathrm{NH}_{3}$. The pellets were immersed for 1 hour in liquid $\mathrm{NH}_{3}$ which was then allowed to evaporate and carried away in a stream of dry nitrogen. Excess ammonia was still present, but at a much reduced level. The residual ammonia is removed by passing the product gas through a $0.4 \mathrm{~cm}$ ID $\times 5 \mathrm{~cm}$ long column of Biorad AG $50 \mathrm{w} \times 2$ resin followed by $0.4 \mathrm{~cm} 1 \mathrm{D} \times 1 \mathrm{~cm}$ long crushed $\mathrm{CuSO} 4 \cdot 5 \mathrm{H}_{2} \mathrm{O}$. The resin is prepared by drying at $110^{\circ} \mathrm{C}$ overnight and then allowing it to regain moisture from the air. About $10 \%$ of the $1 l_{C}$ activity is retained on the resin.

The $\mathrm{H}^{11} \mathrm{CN}$ was examined to determine if any residual ${ }^{11} \mathrm{CO}_{2}$ was passing through the process without being converted to $\mathrm{H}^{11} \mathrm{CN}$ : Carrier $\mathrm{NaCN}$ and $\mathrm{Na}_{2} \mathrm{CO}_{3}$ were added to the collection flask, and a normal HllCN preparation performed. Al1 carbonate was precipitated by the addition of $\mathrm{BaCl}_{2}$. After 2 washes the precipitate obtained by centrifugation contained less than $1 \%$ of the activity.

The development of other precursor compounds depends on the preparation of $11 \mathrm{CH}_{3} \mathrm{OH}$ as an intermediate step. Although four runs were attempted, no conclusive results were obtained due to failure of counting equipment and gas chromatographs. 


\section{REFERENCES}

1. Progress Report of USDOE, Contract \#EE-77-S-02-4268-A002 (Co0/4268-2) for Oct. 1, 1977 to Sept. 30, 1978. pp 43-47.

2. Marazano, C:, Mazier, J., Berger, G., Comar, D., Synthes is of methy] iodide- $1^{i} \mathrm{C}$ and formaldehyde. $1^{\mathrm{C}} \mathrm{C}$. Int. J. App. Rad. \& Isot. 28: 49-52, 1977.

3. Christman, D., Crawford, E.J., Friedkin, J., and Wolf, A.P. Detection of DNA synthesis in intact organisms with positron-emitting (methyl-11C) thymidine. Proc. Nat. Acad. Sci. 69: 4, 988-92, 1972.

4. Palmer, A.S. The preparation of ${ }^{11} C$-methyl-labeled $1,1:$-dimethyl-4,4'dipyridinium di-iodide. J. Lab. Cmpd \& Radiopharm. XIV, 27-33, 1977. 


\section{Objective:}

To synthesize $L-(N-13)$ amino acids enzymatically and to use these compounds in metabolic studies and as tumor and/or organ scanning agents in animal model systems and in clinical studies.

\section{Scope of Investigation:}

During the preceding report period we had demonstrated that $L-(N-13)$ glutamate, prepared with an enzyme immobilized on a solid support and injected intravenously into patients, was taken up rapidly into some tumor types. This year we planned to prepare $L-(N-13)$ glutamate for use in a larger spectrum of tumors and for use in cases undergoing chemo-or radiation therapy as a measure of response to treatment. It was also planned to sunthesize $L-(N-13)$ valine in a sterile, pyrogen-free preparation, suitable for patient studies. Tissue distribution determinations in rats have indicated that $L-(N-13)$ valine has a higher concentration in the pancreas than L-(N-13) glutamate or $D L(C-11)$ valine, two compounds under clinical study as pancreas imaging agents. It was also planned to synthesize the aromatic amino acids $L-(N-13)$ tyrosine and $L-(N-13)$ phenylalalanine in a radiochemically pure state for initial animal studies.

\section{Results:}

Much of our effort during the past year has been toward the preparation of $L-(N-13)$ glutamate: for patient studies. A total of 108 studies have beer. carried out and the results will be discussed elsewhere. No undesirable side effects have been observed in patients or volunteers. Limulus tests are performed on eluates from the immobilized column before an actual run.

Our studies with other. ${ }^{13} \mathrm{~N}$-amino acids and. ${ }^{13} \mathrm{~N}$-ammonia have continued but at a lower level of priority. $13 \mathrm{~N}$-ammonia and $L-(N-13)$ glutamic acid are prepared for studies concerned with the metabolic fate of these compounds in normal and neoplastic tissues and will be discussed el sewhere.

$L(\mathrm{~N}-13)$ valine has been prepared in $2-5 \mathrm{mCi}$ batches utilizing glutamate dehydrogenase immobilized on (CN $r$ activated Sepharose. The procedure has been modified from that of the method that we use to prepare $L(N-13)$ glutamate by increasing the concentration of a-keto acid and by keeping the reaction mixture containing the labeled ammonia, $\alpha$-ketoisovaleric acid and NADH in contact with the immobilized enzyme for 5 minutes before passage through the 
column. Ten consecutive mock preparations of $L-(N-13)$ valine were found to be sterile and pyrogenic by a commercial. testing laboratory. A protocol for clinical testing of this compound as a pancreatic imaging agent has been approved by the Clinical Investigations Committee and the Committee on Radiation of Memorial Sloan-Kettering Cancer Center.

The synthesis of $L-(N-13)$ tyrosine, $L-(N-13)$ phenylalanine and $L-(N-13)$ aspartic acid by transamination of $L-(N-13)$ glutamic acid in reactions catalyzed by commercial glutamic oxalacetate transaminase has been demonstrated with the use of analytical high pressure liquid chromatography. We have not yet been able to prepare these newly labeled amino acids in radiochemically pure form suitable for metabolic studies. Attempts to separate the mixture of $N-13$ ammonia, $L-(N-13)$ glutamate and $L-(N-13)$ tyrosine in a relatively large volume of $6 \mathrm{ml}$ have not been successful to date. We have attempted.purification by ion exchange and high pressure liquid chromatography with limited success.

$L(N-1.3)$-gamma amino butric acid (GABA) has been synthesized GABA was identified by analytical high pressure liquid chromatography. $L(N-13)$-methionine and $L(N-13)$ amino butyric acid have been synthesized by the reductive amination of their respective a-keto acids in reactions. catalyzed by glutamate dehydrogenase immobilized on CNBr activated sepharose. The amino acids were purified by cation exchange chromatography and characterized by high pressure 1 iquid chromatography. 
Publications

1. Cooper, A.J.L., McDonald, J.M., Gelbard, A.S iz Gledhil1, R.F. and Duffy, T.E. The metabolic fate of $13 \mathrm{~N}-1$ abeled ammonia in rat brain. J.Biolog. Chem. 254;4982-4992 $(1979)$.

2. Gelbard, A.S., Benua, R.S., Laughlin,J.S., Rosen, G., Reiman, R.E. and McDonald, J.M. Quantitative scanning of osteogenic sarcoma with nitrogen-13 labeled L-glutamate. J. Nucl. Med. 20, $782-784$ (1979).

3. Lockwood, A.H., McDonald, J.M., Reiman, R.E., Gelbard, A.S. Laughlin, J.S., Duffy, T.E. and Plum, F. The dynamics of. ammonia metabolism in man. Effects of 1 iver disease and hyperammonemia: J.Clin Invest. 63, 449-460 (1979).

4. Tilbury, R.S., Gelbard, A.S, McDonald, J.M., Benua, R.S. and Laughlin, J.S. A compact in-house multi-particle cyclotron production of radionuclides and labeled compounds for medical use. IEEE Trans on Nuclear Sci NS-26 1729-1732 (1979).

\section{Abstracts}

1. Gelbard, A.S., Benua, R.S., McDonald, J.M., Reiman, R.E. Vomero, J.J. and Laughl in, J.S. Organ imaging with $\mathrm{N}-13$ L-glutamate. J. Nucl Med 20, 663 (1979).

2. Gelbard, A.S. and Cooper, A.J.L. Synthesis of ${ }^{13} \mathrm{~N}-1$ abeled arometic L-amino acids by enzymatic transamination of $13 \mathrm{~N}$ L-glutamic acid. J Label Compound Radiopharm 16, 92 (1979)

3. Rosen, G., Gelbard, A.S., Benua, R.S., Laughlin, J.S. Reiman R.E., and McDonald, J.M. N-13 glutamate scanning to detect the early response of primary bone tumors to chemotherapy. Am. Assoc Ca Res. Abst. 20, 189 (1979).

In Press

1. Cooper, A.J.L. MCDonald, J.M., Gelbard, A.S. and Duffy, T.E. Metabolism of $13 \mathrm{NH}_{3}$ in brain. Amer. Chem. Soc., Book of Abstracts, 178th National Meeting, Washington, D.C., Sept. $9-14,1979$.

2. Gelbard, A.S., Freed, B.R., Cooper, A.J.L., McDonald, J.M., Reiman, R.E. and Vomero J.J. $L(N-13)$ amino acids: Enzymatic syntheses and metabolic studies. Amer. Chem. Soc., Book of Abstracts, 178th National Meeting, Washington, D.C., Sept. $9-14,1979$. 
$18_{\text {F-PRECURSOR COMPOUNDS }}$

\section{OBJECTIVE:}

To devise methods and hardware for the preparation of useful amounts of carrier free ${ }_{F}$ for introduction into selected organic compounds.

\section{SCOPE OF INVESTIGATION}

The research proposed was separated into four categories: 1) target development, 2) radiation chemistry, 3) post-irradiation processing, and 4) compound characterization. Work during this report period has concentrated upon target development and post irradiation processing to remove ${ }^{10} F$ activity from the target.

Several laboratories have publ ished results of efforts to
produce $18 \mathrm{~F}$ for use as a labeling agent $(1-5)$. With the exception of a silver target (5) and a glass lined target (6), the usual material for construction has been nickel. The choice of nickel is largely based on the available data regarding the safe handling of fluorine and protection by passivation of apparatus against corrosion. Metals are passivated to fluorine attack by forming the fluoride salt on the metal surface by reaction with fluorine $(7,8)$. Availalle reports $(9,10)$ which are studies of $F$ for $F$ exchange between $H^{18} F$ and halogen f] yorides or fluoromethanes indicate the absence of exchange between $H^{18} \mathrm{~F}$ and passivated metals, but the most quantitative data states nothing other than the error to these experiment from this reaction is less than 1\%. Lambrecht et al ${ }^{2}$ (1) recognize "some confusion on the point". Nozaki et al. eluted ${ }^{P} F$ activity from the walls of a silver target by adding $H F_{8}$ to a flgwing oxygen stream. The reaction used for production of the ${ }^{18} \mathrm{~F}$ was ${ }^{10} \mathrm{O}\left({ }^{3} \mathrm{He}, \mathrm{P}\right){ }^{18} \mathrm{~F}$. A patent on the use of nickel as the material for target construction when removing ${ }^{\circ} F$ from $a$ target above $500^{\circ} \mathrm{C}$ has been granted (11). The passivation of nickel toward reaction with fluorine or its compounds is achieved by reacting fluorine with the metal being passivated until a coating of metal fluopride is formed which resists further reaction. This approach works well when there are macroscopic amounts of fluorine present. However, the preparation of materials of biologic interest frequently demands the highest possible specific activities. For example, the use of ${ }^{18} \mathrm{~F}$-fluorestradiol to study estrogen binding sites (12) requires that the material not saturate the available binding sites. It is necessary to devise means of obtaining the 18 F-labeled precursor without adding carrier. 


\section{RESULTS \& CONCLUSIONS:}

In the situation considered in this work, ${ }^{18}{ }_{50}$ is made 18 y the irradiation of neon with deuterons using the reaction ${ }^{20} \mathrm{Ne}(\mathrm{d}, \mathrm{a}) \mathrm{l}_{\mathrm{F}}$. If no fluorine is used in preparation of target or apparatus, all fluorine prodyced will be ${ }^{2}$. F. Using the data of Nozaki et al. (13) the amount of ${ }^{1} \mathrm{~F}$ produced in our system is calculated as about $\mathrm{I} \mathrm{C} i$ at the end of a 1 hour, 50uAmp bombardment. This corresponds to about $3.3 \times 10^{14}$ atoms $18 \mathrm{~F}$, about $0.5 \mathrm{n}$ moles. Since the coating on the wall s of a target passivated against fluorine corrosion involves mole quantities of fluorine, losses as small as a part per million to a purge gas cause gross isotopic dilution. The number of ${ }^{\circ} F$ atoms produced is small with respect to any detectable impurity in the gas and very small with respect to the number of sites available for reaction, absorption, absorption or other process which removes the ${ }_{F}$ from mixture with the gas phase.

18 The first task in design of a target for the production of ${ }^{18} \mathrm{~F}$ by bombarding neon 1 ith deuterons is finding the material which most readily releases ${ }^{18} \mathrm{~F}$ to a selected purge gas. The release to a purge gas depends on several factors among which the composition and surface finish of the target material and selection of the purge gas are the most important. Criteria for the selection of the purge gas were compatability of the gas with a wide range of sovlents and use of simple, safe rugged handling equipment. The gas chosen was $10 \%$ hydrogen inhelium. A target chamber consisting of a $5 \mathrm{~cm}$ ID nickel tube, 1 meter long closed with nickel plates at each end was available. This target and its arrangement with vacuum pumps and filling equipment are shown diagramatically in Figure 17 . Three runs were performed to determine if ${ }^{\circ} \mathrm{F}$ could be removed from the target at temperatures up to $500^{\circ} \mathrm{C}$. The procedure was as follows:

1) After washing with deionized water, acetone, and chloroform the target was assembled and evacuated.

2) The system yas tested for leaks with a helium leak detector (max leak $2 \times 10^{-9}$ STD $\mathrm{cc} / \mathrm{sec}$ ).

3) The target was purged with $10 \% \mathrm{H}_{2}$ in He for up to 18 hours while heating to $300^{\circ}$ to $350^{\circ} \mathrm{C}$.

4) The target was closed and allowed to cool while filled with $10 \% \mathrm{H}_{2}$ in He.

5) Immediately before irradiation the target was exacuated to $-10^{-3}$ Torr and filled with neon, which was pumped out to $-10^{-3}$ Torr and again filled with neon. 


\section{6) The taryet was irradiated.}

7) After irradiation the target gas was exhausted to atmosphere through a bubbler containing $-2 \mathrm{ml}$ of THR or DMSO. THF was used only in the first experiment. The bubbler was in an NPL ion chamber connected to a Keithley el ectrometer to allow measurement of the ${ }^{18} \mathrm{~F}$ accumulating in the bubbler.

8) The target was heated while purging with $10 \% \mathrm{H}_{2}$ in He.

The results of these runs are presented in Table 19 . During the purge process, the approximate location in the target of the peak amount of ${ }^{18} \mathrm{~F}$ activity was estimated by measuring the radiation dose rate with a hand held ionization chamber (RAD-GUN). As the purge proceeded activity accumulated in the out put valve at the back of the target about twice as fast as in the bubbler. However, most of the activity remained in the target.

At this point in the experiments it was apparent that considerable improvements in the target and handling system were required if useable quantities of ${ }^{16} \mathrm{~F}$ were to become routineiy available from this approach. Specifically, the valves are all manually operated and located within several feet of the target chamber. An unacceptably large radiation dose will result if larger integrated beam currents are applied to the target. The connecting lines are unnecessarily long. The tubing and connections have been overtightened and maintaining a leak tight system is difficult. The target chamber is assembled without gaskets using long rods which extend the entire length of the larget to secure the end plates. These rods expand and stretch during heating and the retightening required ultimately leads to failure of the rod.

Due to the lack of data regarding the retention of $18 \mathrm{~F}$ by metals and the difficulty of removing ${ }_{F}$ from the existing nickel target, experiments were undertaken to find what metals would most readily release ${ }^{18} \mathrm{~F}$ to the purge gas.

A frame to hold foil samples was constructed. The frame, shown diagramatically in Figure 18 was constructed so the foils were held in the neon out of the path of the beam. The initial experiments . used samples of several readily available foil materials. The foils, cut in $1 \times 12$ on strips were arranged on the frame so their major surface paralled the beam axis, and surrounded the beam axis. The pre-irradiation treatment was the same as the first runs with the target. Post-irradiation processing in this case was simply purging at 
the ambient temperature $\left(23^{\circ} \mathrm{C}\right)$. Aluminum was found to retain more activity than any other material and as expected, the distribution of activity along the target axis was not constant. The foils were examined with a Ge( $L i)$ detector $y$ spectrometer and no peak other than the $511 \mathrm{~B}^{+}$annihilation peak was observed, demonstrating that no activation of the foils occured by direct contact with the beam. For subsequent experiments, the foils were wrapped around only $50 \%$ of the frame and an aluminum monitor strip installed on the remaining frame member to monitor the distribution of ${ }^{18} F$ along the axis of the target. The arrangement is shown in Figure $19 \mathrm{a}$.

To derive a value for activity retained per unit area of foil, a correction was empirically developed. Selected copper and al uminum foils were cut as shown in Figure $19 \mathrm{~b}$ in to the inner and outer sections, after irradiation and removal from the target. Using the activity ratio between the inner surface and the outer surface, a correction was developed to account for the fact than any ${ }^{2} \mathrm{~F}$ absorbed by the outer surface was reflected back through collision with target gas or the target wall. Because the correction is the same for each foil and the sample geometry is constant with respect to the beam axis, the error introduced is systematic and does not affect the comparison of one foil to another.

The distribution of activity along the target axis was monitored by folding a $2 \mathrm{~cm}$ wide strip of $0.25 \mathrm{~mm}$ thick al uminum around one frame member as shown in Figure 19 a.

The procedure for these experiments was to mount the foils and secure them in place using $0.03 \mathrm{~mm}$ bare copper wire. The assembly was then rinsed with acetone and chloroform and placed inside the target chamber. After closing, the target was made leak-tight and evacuated, back fjlled with purge gas and then, with purge gas flowing, was heated to $300^{\circ} \mathrm{C}$. for at least one hour before being allowed to cool. Irradiations were perfomed as described previously. Following irradiation, the target gas was blown out by purge gas and the target chamber heated. As soon as the maximum planned temperature was reached, the heat was turned off and the target insulation removed. The target was opened as rapidly as possible and the foils removed to individual containers for measurement of the radioactivity retained. The al uminum monitor strip was removed and cut to $2 \mathrm{~cm}$ lengths which were individually assayed for radioactivity. The distribution of activity along the target chamber axis was not the same from one experiment to the next, al though the form the distribution was similar. Figure 20 shows the distribution in a typical run. In each the activity measured in individual foil samples was normalized to the maximum activity of the distribution obtained from the al uminum monitor strip in that particular run. A series of runs were made at final 
purge temperatures of $100^{\circ}, 200^{\circ}$, and $300^{\circ} \mathrm{C}$ as well as ambient temperature. The activity remaining on the foil was measured and corrected for decay from. EOB. From this value of. Activity. Per Effective Area (APEA) was calculated for 5 different elements. These results are shown in Table 20 .

Based on these experiments, copper appears as good or better than nickel as $\delta_{F}$ material for makjig a target chamber for the
production of $18_{F}$ by the $20 \mathrm{Ne}(d, \alpha)$ reaction and recovering the $18_{F}$ without adding any carrjer. "It is interesting that tungsten does not retain "carrier-free" ${ }^{\circ} F$ very well either.

New targets are being built. Very simple in design, they will be all-copper cylinders with welded or high temperature brazed joints. The question of nickel vs copper may be settled by making several chambers; one of which can be plated with nickel after construction. Chromium was not tested for ${ }^{18} F$ retention, but its similarity to tungsten and the APEA values obtained for tungsten indicate it may be useful.

18 It is anticipated that, within calendar 1980, useful amounts of ${ }^{18} \mathrm{~F}$ precursor compounds accomplished.

This work has been accepted for presentation to the 31st Soutneastern Regional ACs Meeting, Koanoke, VA. Oct. 24-2\%, 1y79. A copy of the abstract is attached (14). 
TABLE 19

RUN\#

s

I

$\Delta t i$

Neon Press

Calc'd Total Yield

$\mathrm{mC} 18 \mathrm{~F}$ in Bubbler

$\%$ Recovery

Highest Temp. \begin{tabular}{l}
1.3 \\
\hline
\end{tabular}

$1 \mu \mathrm{Amp} . \mathrm{Hr}$. 3uAmp.Hr. 3.0uAmp.Hrs.

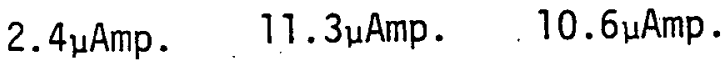

25 min. 16 min. 17 min.

1 ATM 0.87 AIM 1 ATM

$11.8 \mathrm{mCi} \cdot 29.3 \mathrm{mCi} \quad 27 \mathrm{mT}$.

0.84 EOB 6 mCIEOB 3 G EOB

$7 \% \quad 21 \% \quad 11 \%$

$420^{\circ} \mathrm{C}$

$500^{\circ} \mathrm{C}$

$450^{\circ} \mathrm{C}$ 
TABLE. 20

VALUES OF APEA FOR DIFFERENT PURGE TEMPERATURE

\begin{tabular}{|c|c|c|c|c|c|}
\hline Final Purge Temperature & Cu & $\mathrm{Ni}$ & W & Mo & Ar \\
\hline Ambient $\left(\sim 20^{\circ} \mathrm{C}\right)$ & 64 & 89 & 60 & 71 & 94 \\
\hline $100^{\circ} \mathrm{C}$ & 53 & 68 & 55 & 64 & 88 \\
\hline $200^{\circ} \mathrm{C}$ & 51 & 56 & 45 & 83 & 183 \\
\hline $300^{\circ} \mathrm{C}$ & 14 & 22 & 14 & 21 & 90 \\
\hline
\end{tabular}


EVALUATION OF MATERIALS FOR FABRICATION OF A FLUORINE-18 TARGET.

\section{J. Robert Dahl Sloan-Kettering Institute for Cancer Research, \\ $\begin{array}{ll}\text { R.S. Tilbury } & \text { Biophysics Laboratory } \\ & 1275 \text { York Avenue } \\ & \text { New York, N.Y. 10021 }\end{array}$ \\ $\begin{array}{ll}\text { R.S. Tilbury } & \text { Biophysics Laboratory } \\ & 1275 \text { York Avenue } \\ & \text { New York, N.Y. 10021 }\end{array}$ \\ $\begin{array}{ll}\text { R.S. Tilbury } & \text { Biophysics Laboratory } \\ & 1275 \text { York Avenue } \\ & \text { New York, N.Y. 10021 }\end{array}$}

$\mathrm{X}$

$x$ or

not selected

EVALUATION OF MATERIALS FOR FABRICATION OF A FLUORINE-18 TARGET. J. Robert Dahl and R.S. Tilbury. Sloan-Kettering Institute for Cancer Research, Biophysics Laboratory, 1275 York Avenue, New York, N.Y. 10021

Fluorine-18 (96.9\% positron decay, 3.1\% electron capture) is a radioisotope of fluorine with a sufficiently long half life $(110 \mathrm{~min}$.) for convenient use as a label. in compounds of biological interest. Increasing use of Positron Emission Tomography, a scanning technique utilizing the positron-electron annihilation radiation, adds to its utility. Fluorine-18 can be produced by deuteron bombardment of neon in a suitable chamber. If no fluorine is added to the target or used to passivate the target chamber, only undetectable trace amounts of fluorine present as natural contaminants. will dilute the $210^{14}$ atoms of $18 \mathrm{~F}$ produced. This permits preparation of very high specific activity Tabeled compounds. The target chamber material influences the ${ }^{18} \mathrm{~F}$ recovery. Nickel has been used for ${ }^{18} \mathrm{~F}$ targets on the bas is of flunrine data concerned with corrosive effects or process contamination. Retention of ${ }^{1.8} \mathrm{~F}$ by various metallic elements was measured by placing foil samples in the neon target gas so the foils were exposed only to recoiling or thermally diffusing ${ }^{13} \mathrm{~F}$ and not struck by the deuteron beam. Following irradiation the neon gas was exhausted and the target purged with $10 \% \mathrm{H}_{2}$ in. He at ambient temp., $100^{\circ}, 200^{\circ} \mathrm{C}, 300^{\circ} \mathrm{C}$. The ${ }^{18} \mathrm{~F}$ remaining on each foil was measured. Of the 19 metals studied copper and tungsten retained less $18 \mathrm{~F}$ than $\mathrm{Ni}$ at all temperatures and molybdenum retained about the same amount. These studies suggest that copper is the best material for fabrication of ${ }^{18} \mathrm{~F}$ target chamkers. 


\section{REFERENCES}

1. Lambrecht, R.M., Neirinckx, R., Wolf, A.P., Cyclotron isotopes and radiopharmaceuticals-XXIII novel anhydrous $18 \mathrm{~F}$-fluorinating intermediates.

Int. J. App. Rad \& Isot. 29: 175-81, 1978.

2. Neirincki, R.D., Lambrect, R.M., Wolf, A.P., Cyclotron isotopes and radiopharmaceuticals' XXV-an anhydrous 18F-fluorinating intermediate-tribluoromethyl hypofluorite. Int. J. App. Rad. \& Isot. 29: 323-7, 1978

3. Bakker, C.N.M., Kaspersen, F.M. Production of ${ }^{18}$ F by -particle bombardment of $\mathrm{SiO}_{2}$. Int. J. App. Rad. \& Isot. 30: 61-2, 1979.

4. Frouzel, C., Comar, D. Production of Carrier-gree ${ }^{18}$ F-hydrofluoric acid. Int. J. App1. Rad. \& Isot. 29: 407-8, 1978.

5. Nozaki, T., Tanaka, Y., Shimamura, A., Karasaua, T. The preparation of anhydrous HFl8. Int. J. App. Rad. \& Isot. 19: 27-32, 1968.

6. Guillaume, M. Production en routine par cyclotron de fluor-18 et pottasium-43, A usage medical au moyen D'une cible gazeuse télécommandée. Nuc 1. Inst. Meth. 136: 185-95, 1976.

7. Braker, W., Mossman, A.L., "Matheson Gas Data Book". 5th Ed. 1971 Matheson Gas Products, East Rutherford, N.J. 261-5.

8. Cannon, W.A., Asunmaa, S.K., English, W.D. and Tiner, N.A. Passivation reactions of nickel and copper alloys with fluorine. Trans. Met. Soc. Ame. 242: 1635-43, 1968.

9. Boggs, J.E., Van Artsdalen, E.R., and Brosi, A.R. Ion exchange of ${ }^{18} \mathrm{~F}$ between HF and fluorinated methanes. J. Am. Chem. Soc. 77: 6505, 1955.

10. Rogers, M.T. and Katz, J.J., Fluorine exchance reactions between hydrogen fluoride and the halogen fiuorides. J. Am. Chem. Soc. 74: 1375, 1952.

11. Winche11, H.S., Wells, D.K., Lamb, J.F., Beaudry, S.B, Process for preparing fiuorine-18. US Pat 3 : $981,769,1976$.

12. Proposal to U.S. DOE, contract\#EE-77-S-02-4268-A002, Jan 1979-Dec.1979, Sloan-Kettering Institute, Biophysics Laboratory.

13. Nozaki, T., Iwamoto, M., Loo, T. Yield of ${ }^{18} \mathrm{~F}$ for various reactions from oxygen and neon. Int. J. App. Rad. \& Isot. 25: 393-9, 1974.

14. Danl, J.R., Tilbury, R.S. Evaluation of materials for faprication of a fluorine-18 target. To be presented to 31st.S.E. Regional ACS Meeting Symposium on kadiopnarmaceuticals. Koanoke, Va. Oct. $\angle 4-\angle 7,1979$. 


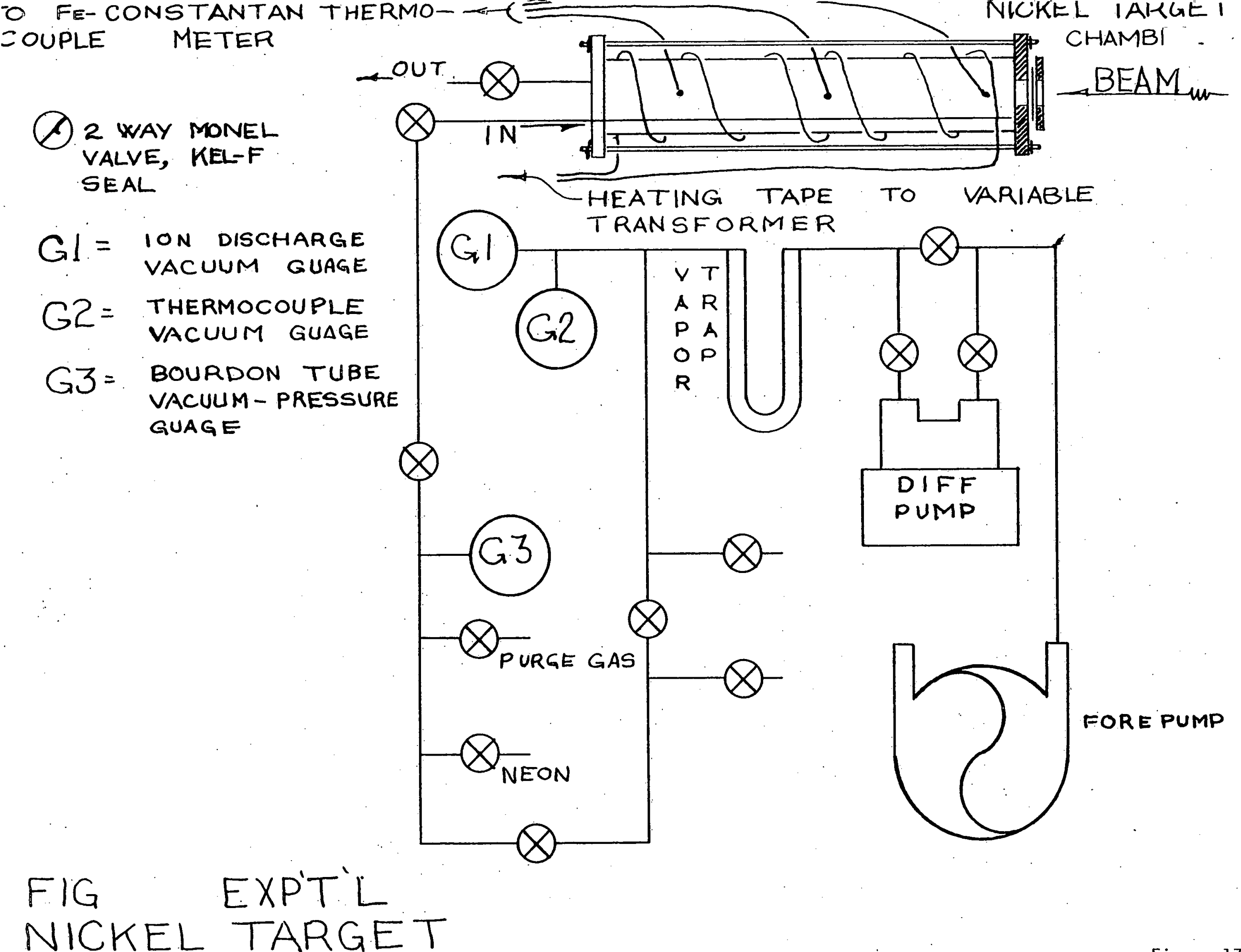




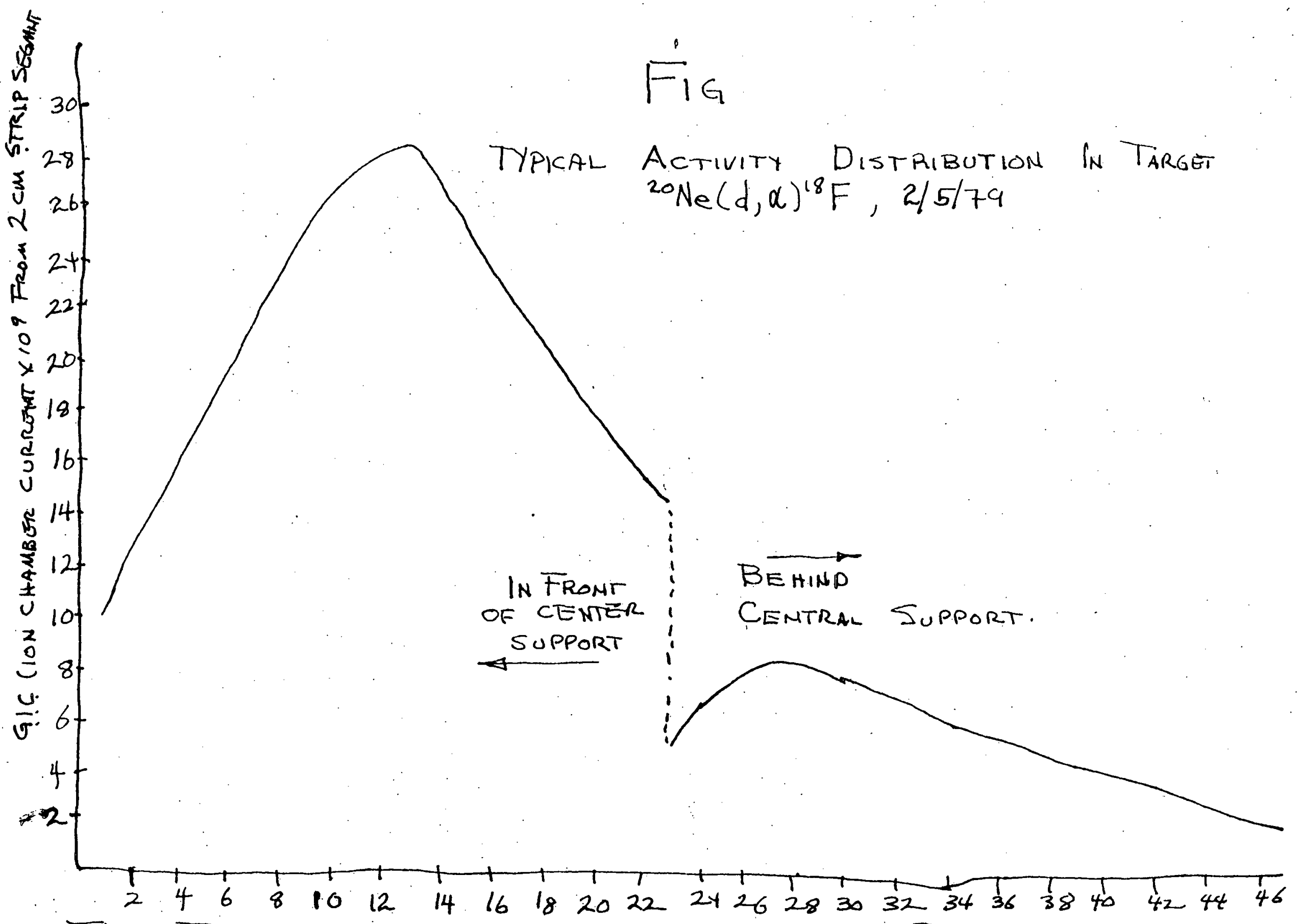
TARge Fol $=0 \mathrm{~cm}$. Distance From From of Rack, Cm.

Figure 20 


\subsection{2. $18_{\text {F-4-FLUOROESTRADIOL AND }{ }^{18} \text { F-HALOPERIDOL }}$}

\section{OBJECTIVE}

One goal of this project is to synthesize ${ }^{18} \mathrm{~F}-4-\mathrm{fluoroestradiol}$ as a possible agent for the detection of hormone dependent tumors. Another goal is to synthesize 18F-haloperidol as a possible brain tumor localizing agent and as an agent to measure neurotransmitter receptors in the brain by a noninvasive and low hazard method.

\section{SCOPE OF INVESTIGATION}

Many mammary tumors are known to be estrogen receptor positive and this has prognostic significance in humans. The development of an estrogen derivative containing a gamma-emitting nuclide will provide a diagnostic agent for the management of patients with breast cancer and other endocrine related cancers. Experiments by us at the Estrogen Receptor Protein Laboratory in Memorial Hospital (1), and by Utne et al (2) have shown 4-fluoroestradiol to have comparable physiological activity to estradiol itself. There is currently considerable interest in the possibility of measuring the number and distribution of neurotransmitter receptors in the brain by positron emission tomography. The possibility exists that changes in the functioning of these receptor sites may occur in many psychiatric and neurological diseases and be central in their etiology and symptomatology (3). Haloperidol is an antipsychotic drug with a high specificity for the dopamine receptor and may be useful as an indicator in mental illness.

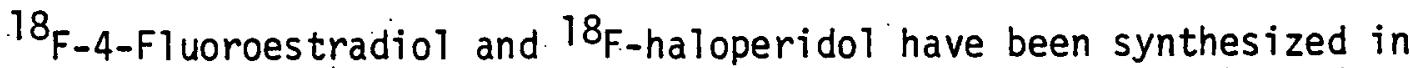
our laboratory by an adaptation of the Schiemann reaction, Scheme 3 and 4 . We (4) and others (5) have produced 18F-4-fluoroestradiol with specific activities up $\neq 0.5 \mathrm{mCi} / \mathrm{mg}$. By a modification of Kook's synthesis (6), we have produced $8 \mathrm{~F}$-haloperidol with a specific activity of $0.8 \mathrm{mCi} / \mathrm{mg}$, and carried out transaxial tomographic imaging of its distribution in the head of a dog as described below (7).

Labeling efficiency in the Schiemann reaction is low, and since the number of receptor sites in brain and in hormone dependent tissue is small, labeling these sites requires tracer quantities of drugs with sufficiently high specific activity to allow detection by scanning. We have been working on a method for producing 18F-haloperidol with ultra-high specific activity. A number of aromatic flourides have been prepared $(8,9)$ through diazotization of the corresponding amines in anhydrous hydrogen fluoride, and we have synthesized unlabeled haloperidol by an adaptation of this procedure. We are presently working gut the details of this reaction with $H^{18} \mathrm{~F}$. Another method for synthesizing $18 \mathrm{~F}$-haloperidol was recently reported by Tewson and Welch (10) for a no-carrier-added synthesis. Briefly, replacement of the amino group is through stabilization of the diazonium salt by its reaction with piperidine, followed by decomposition of the diazoamino-compound (triazine) formed $(9,17-13)$. Thus, reaction of 2-N-piperidy1-p-diaza-4-(4(p-chlorophenyl)-4-hydroxypiperidyl) butyrophenone in refluxing 1,2dimethoxyethane gave a $22 \%$ yield of $18 \mathrm{~F}$-haloperidol in a 4 minute reaction time (10). 


\section{RESULTS AND CONCLUSIONS:}

We have administered $0.2 \mathrm{~m} \mathrm{Ci}$ of haloperidol labeled with fluorine-18 (specific activity $0.8 \mathrm{mCi} / \mathrm{mg}$ ) and carried out transaxial tomographic imaging of its distribution in the head of a dog, using a Model 4200 Positron Camera Tomograph (Cyclotron Corporation). Uptake kinetics were observed during the first 70 minutes after IV administration, Figure 21. Brain showed a 2.4 min uptake halftime that reached a plateau at 20 minutes with a much slower 25 hours clearance halftime (7).

In a preliminary experiment, outlined in Scheme 5 , unlabeled haloperidol was produced by diazotization of 4-(4-p-chloropheny 1$)-4$-hydroxypiperidino) $-4^{\top}$-aminobutyrophenone in concentrated hydrogen fluoride and decomposition of the diazonium fluoride at 145 degrees for 4 minutes. We are presently working out the details of this reaction with $\mathrm{H}^{18 \mathrm{~F}}$. While we're exploring the potential of this reaction to labeling haloperidol and 4fluoroestradiol, we have begun adapting the no-carrier-added method of Tewson and Welch (10) for use in our laboratory. 
FIGURE 21

\section{F-18 HALOPERIDOL DOG UPTAKE - BRAIN}

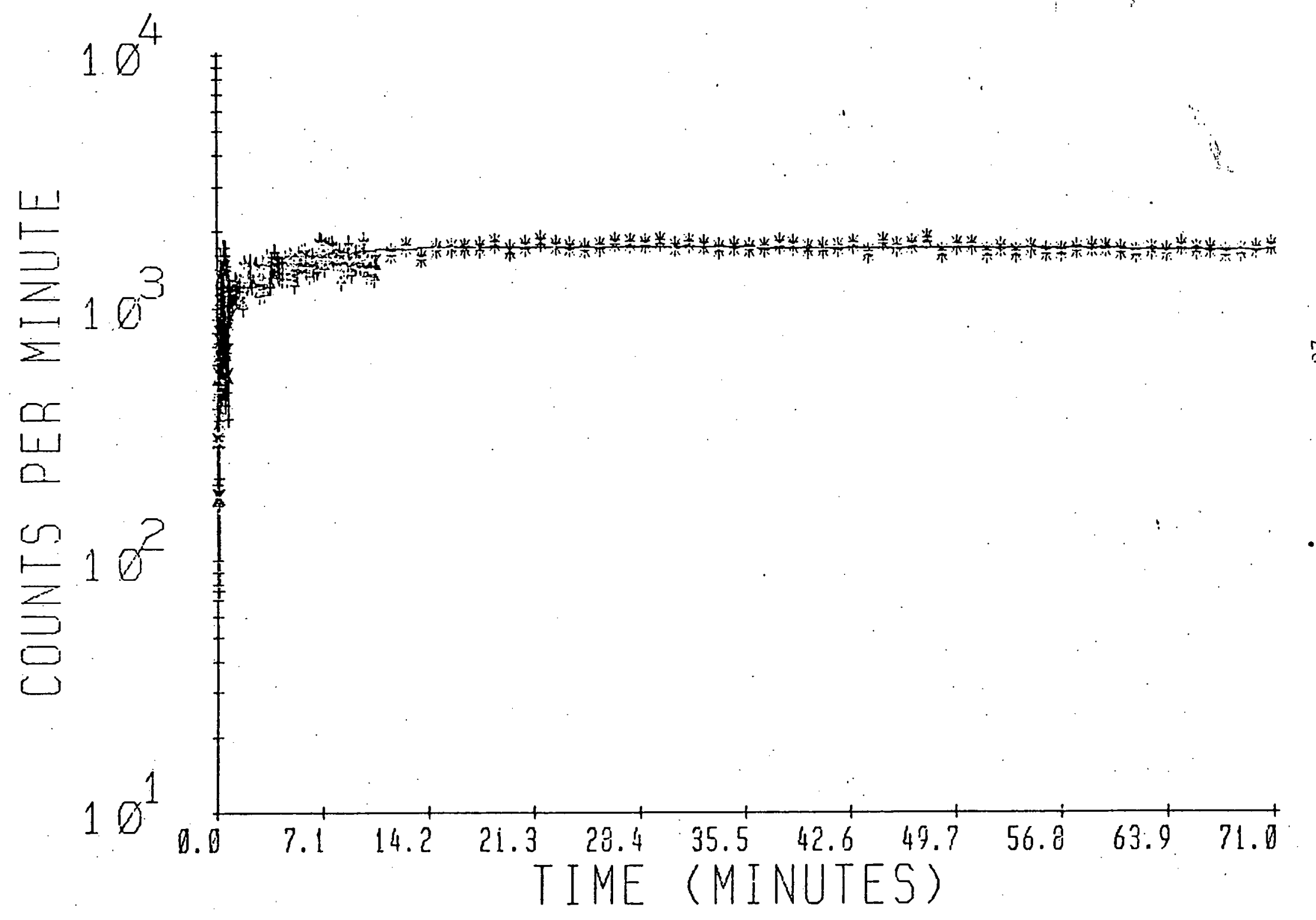




$$
\text { (18) }
$$



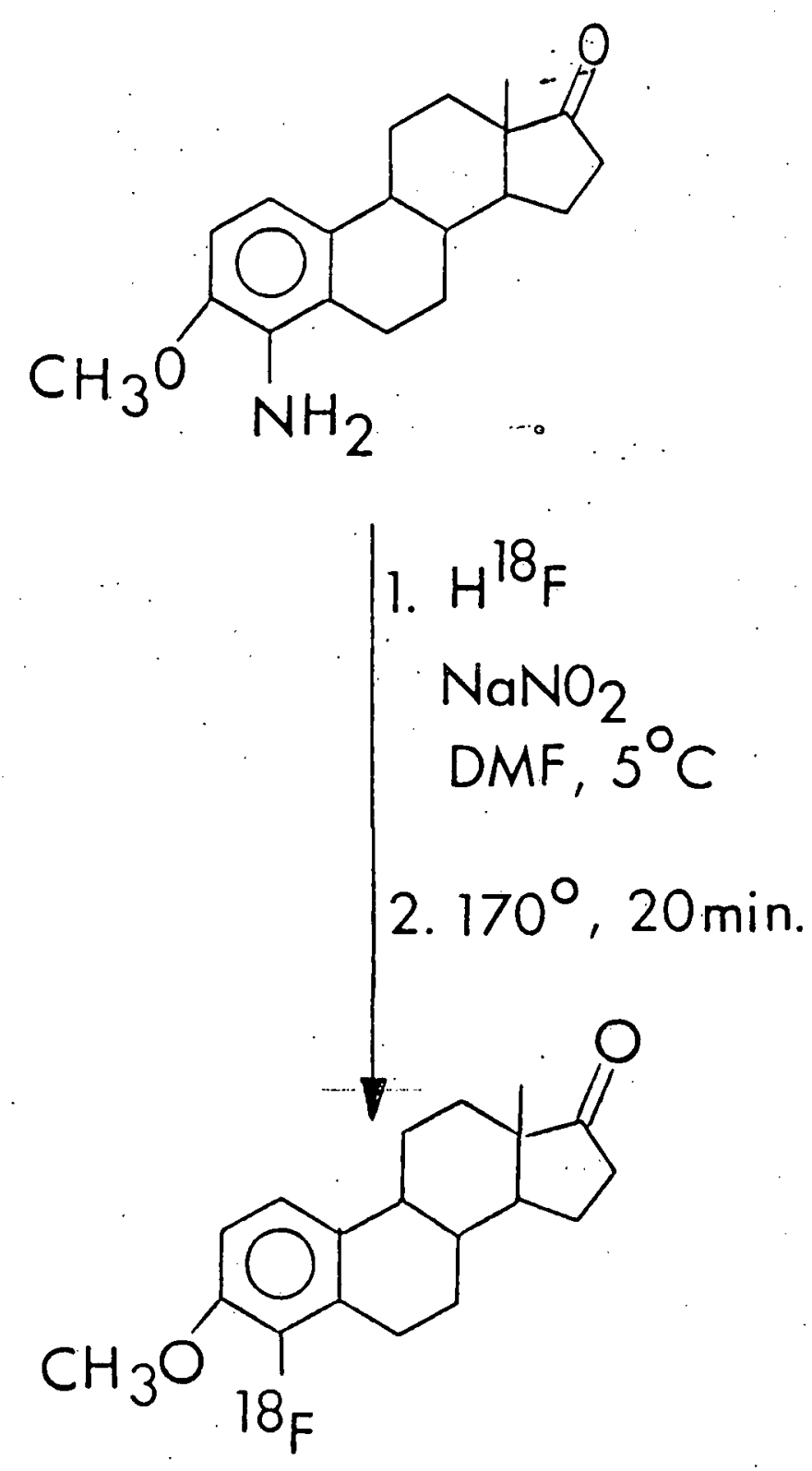


\section{REFERENCES}

1. Nisselbaum, J.S., et al. Estrogen receptors in human breast tissue. 65th Annual Meeting of the American Association for Cancer Research, March 27-30, 1974, Houston, Texas. (Abst)

2. Utne, T., Jobson, R.B., and Babson, R.D. The synthes is of 2and 4-fluoroestradiol. J. Org. Chem. 33: 2469-73, 1968.

3. Snyder, S.H. and Creese, I. Biochemical characterization of neurotransmitter receptors in the brain. In: A. Karlin, V.M. Tennyson, and H.J. Vogel (eds.) Neuronal Information Transfer, Academic Press, 1978 p. 74

4. Schmall, B., Tilbury, R.S., and Nisselbaum, J.S. The synthes is of 18F-labeled 4-fluoroestradiol and haloperidol for studies in nuclear medicine. American Chemical Society 4th Winter Fluorine Conference, January 29-February 2, 1979, Daytona Beach, Florida. (Abst)

5. Palmer, A.J. and Widdowson, D.A. The preparation of $18 \mathrm{~F}$-labeled 4-fluoroestrone and 4-fluoroestradiol. Second international symposium. on radiopharmaceutical chemistry. 0xford, England. pp. 14-16 July, 1978.

6. Kook, C.S., Reed, M.F., and Digenis, G.A. Preparation of 18F-haloperido7. J. Med. Chem. 18 533-535, 1975

7. Bigler, R.E. and Schma 11, B. Positron-electron transmutation (PET) tomography with the neuroleptic drug 18 F-haloperidol. The Radiological Society of North America Annual Meeting, Atlanta, November, 1979.

8. Ferm, R.L. and Vanderwerf, C.A. Synthesis of aromatic fluorides through diazotization in anhydrous hydrogen fluoride. J. Am. Chem. Soc. 72 4809-4810, 1950.

9. Hudlicky, M. Chemistry of Organic Fluorine Compounds. The Macmillan Co., New York, 1962, p. 114

10. Tewson, T. J. and Welch, M.J. A synthes is of carrier free fluorine-18 labeled aromatic compounds and its application to the preparation of the fluorine-18 labeled neuroleptic haloperidol. J. Nucl. Med. 20 671, 1979 (Abst).

11. Wallach, 0. Ann 235 233-255, 1886; ibid 235. 255-271, 1886.

12. Wallach, 0. and Hensler, F. Ann 243 219-244, 1888.

13. Saunders, K.H. The Aromatic Diazo-Compounds and Their Technical applications. Longmans, Green \& Co., New York, 1949, p̈p. 169, 284. 


\section{4}

STUDIES WITH POTASSIUM-38.

\section{OBJECTIVE}

To develop a method of production of potassium- 30 , to measure itss cross sections for formation by the nuclear reaction ${ }^{35} \mathrm{Cl}$ (4He,n) ${ }^{3} \mathrm{~K}$, and to use potassium-38 to assess myocardial function.

\section{SCOPE OF INVESTIGATION}

As previously reported $(1,2)$ we have developed a convenient method of producing 5 to $15 \mathrm{mCi}$ amounts of potassium-38 with no added potassium carrie $r$ in injectable saline. In this roport period we have measured the cross-segtions for the formation of ${ }^{38} \mathrm{~K}$ by the $\mathrm{He}, \mathrm{n}$ nuclear reaction on ${ }^{35} \mathrm{Cl}$. The stacked foil technique was used, covering the energy range 14.7 to $5 \mathrm{MeV}$. Plastic sheets of polyvinyl chloride interspersed with al uminum foil were used at beam curents of 0.1 uAmp or below.

Studies in dogs used ${ }^{38} \mathrm{~K}$ to measure the uptake of potassium in the heart before and after the administration of cardio-active drugs: dipyridamole, propanotol and digoxin.

\section{RESULTS AND CONCLUSIONS}

Excitation functions for the formatign of $30 \mathrm{P}$ and $38_{\mathrm{K}}$ from al pha particle induced reactions on ${ }^{2 \ell} \mathrm{Al}$ and $35 \mathrm{Gl}$ are repQged in 35 Tables 21 \& 22. The cross-sections for the ${ }^{29} \mathrm{Al}(\mathrm{a}, \mathrm{n}) \mathrm{PO}_{\mathrm{P}}$, and ${ }^{35} \mathrm{Cl}$ $(a, n) 38-k$ reactions are measured in the energy range of 5.7 to 14.7 $\mathrm{MeV}$. The zyerage croş-sectiggs over this energy range for the reactions ${ }^{27} \mathrm{Al}(a, n){ }_{P}$ and ${ }^{35} \mathrm{Cl}(a, n){ }_{K}$ are calculateg to be $3811+29$ and $37+14 \mathrm{mb}$, respectively. The thick target yields of $3 \mathrm{P}_{\mathrm{P}}$ and $38 \mathrm{~K}$ are detemined to be 6.6 and $1.1 \mathrm{mCi} / \mathrm{uA}$ for the respective reactions. The results of this work are compared with the previous measurements reported in the energy range of 4 to $10 \mathrm{MeV}$. A paper on this subject has been submitted for publication (2).

Potassium-38 in isotonic saline solution has been used to study the effect of cardio-active drugs, dipyridamole, propanolol and digoxin on the potassium uptake in the myocardium of dogs. The $38 \mathrm{KCl}$ without added carrier was injected intravenously at about $0,1,2$ and 3 hours after administration of the drug and the dog was scanned with a rectilinear scanner from 10-25 minutes after injection. The counts/sec/mCi corrected for decay were computed for a fixed number of scan elements and compared with controls. Dipyridamole produced a 
$50-80 \%$ increase in potassium uptake at 1 hour which returned to normal at 3 hours, Digoxin produced a 10-30\% increase, and propanolol produced a $25 \%$ decrease at 1 to 2 hours. Results are compared with studies of Hamilton using T1-201. Our results demonstrate that measurements of K-38 uptake can be made at hourly intervals to study the effects of cardio-active drugs.' A paper on this subject has been accepted for publication (3). 


\section{TABLE 21}

Cross-sections for the Reaction ${ }^{27} \mathrm{AI}(\alpha, n){ }^{30} \mathrm{P}$

Incident Energy

$E_{\alpha}(\mathrm{MeV})$

5.74

7.45

8.92

10.23

11.43

12.55

13.69

$14.70 \ldots$

$$
\text { Cross-section (milli barns) }
$$

This Work

Other Work (2)*

$16 \pm 9$
$58 \pm 16$
$100 \pm 18$
$137 \pm 27$
$155 \pm 27$
$184 \pm 51$
$142 \pm 26$
$108 \pm 22$

* The experimental cross-section values have an estimated uncertainty of $\pm 15 \%$ 


\section{TABLE 22}

Cross-section for the. Reaction $35 \mathrm{Cl}(\alpha, n)^{38} \mathrm{~K}$

\begin{tabular}{cc}
$\begin{array}{c}\text { Incident Energy } \\
\text { E (MeV) }\end{array}$ & $\begin{array}{c}\text { Cross-section (mili barns) } \\
\text { This Work }\end{array}$ \\
\hline 8.35 & $13 \pm 3$ \\
10.31 & $39 \pm 3$ \\
12.05 & $57 \pm 11$ \\
13.47 & $73 \pm 20$ \\
14.70 & $56 \pm 17$
\end{tabular}

* The experimental cross-section values have an estimated uncertainty $\pm 15 \%$ 


\section{REFERENCES}

1. Tilbury, R.S., Dahl, J.R., Chandra, R., McDonald, J.M., and Myers, W.G. Potassium-38 production with a cyclotron for medical use. J. Lab. Compds. \& Radiopharmaceuticals. Vo. XVI, no 1. 127-8, 1979.

2. Rao, S.A. Dahl, J.R Lee, R. \& Tilbury, R.S. Cross section for the reaction $27 \mathrm{Al}(\alpha, n) 30 \mathrm{p}$ and $35_{\mathrm{Cl}}(\alpha, n) 38_{K}$, submitted to $\mathrm{J}$. Applied Radiat. \& Isotopes.

3. Chandra, R, McDonald, J.M., Reiman, R.E., and Tilbury, R.S, K-38, a 7.6 minute half-lived radionuclide for assessment of myocardial function, proceedings of 2nd Interna tional Symposium on Radiopharmaceuticals, Society of Nuclear Medicine. 1979. 
3. DOSIMETRY FOR INTERNALLY DEPOSITED ISOTOPES IN ANIMALS AND MAN

\section{OBJECTIVE:}

To develop a compartmental model for estimating distributions of activity produced when ${ }^{5} \mathrm{O}_{2}$ and $\mathrm{C}^{15} \mathrm{O}_{2}$ are administered at a constant rate until a steady-state distribution is obtained. This kinetic model is not only useful for absorbed dose estimates, but al so contributes to our understanding of the biological and therefore medical significance of such measurements carried out using this methodology.

\section{SCOPE OF INVESTIGATION}

Since our introduction of the steady-state methodology, for imaging simple gases innaled and labeled witn $15 u$, empirical investigations have proceeded for tumor systems in our laboratory and brain studies at Mass. General Hospital in Boston and at Hammersmith Hospital in England. We recognized from the beginning that water of metabolism produced at the various body. sites wouldbe redistributed to a considerable extent, so a simple one compartment steady-state model to represent quantitatively the local rate of oxygen metabolism would not be adequate. In order to evaluate water redistribution, a multicompartmental model was nneded. The simulation, analys is and modeling program, SAHM- $\angle 7$, of Dr. Mones Berman was obtained from the Oak Ridge National Laooratory's Biomedical Computing Technology Information Center (BCTIC). This program substantially expands our modeling analysis capabilities.

Deuterium oxide data of Edelman (1) were used to establish a three compartmental model which lumps the rapid and slowly exchanging tissues into separate compartments. This model was expanded to include, explicitly, cerebral gray and white matter. using data from Ter-Pogossian et al. (2).

Cumulated activities for the organs which utilize the majority of the oxygen used by the body were derived from the model calculations and used to prepare radiation absorbed dose estimates according to the general methods developed largely by the Medical Internal Radiation Dose (MIRD) Committee of the Society of Nuclear Medicine. 


\section{RESULTS AND CONCLUSIONS:}

The possibility that measurements of the regional distribution of ${ }^{15} 0$ administered by inhalation to the steady-state could provide quantitative regional oxygen utilization information has received considerable attention. If water of metabolism produced by oxygen utilization were retained at the site of production for a time long. in comparison to the half-life of $15_{0}$. (123 sec), converting $15_{0}$ activity concentration measurements to absolute quantities of oxygen utilization would require simple multiplication of the ${ }^{15} 0$ decay constant. Unfortunately, this condition is not met throughout the body. So, correction for redistribution of water of metabolism are needed for all portions of the body.

a) Steady-state distribution of $\mathrm{C}^{15} \mathrm{O}_{2}$. The first step in analyzing the water distribution in the total-body is achieved by means of a multicompartmental model analysis of the data of Edelman (1). These data are the only known experimental studies in which a tracer for water, $\mathrm{O}_{2} \mathrm{O}$, was used to determine the arterial blood clearance as well as providing the total-body volume of distribution from equilibrium measurements. The subject population for the Edelman data included five nomal adult males. The charcteristics of this subject population are given in Table 23 . Figure 22 shows the threecompartmental model used. $D$ represents the dose of tracer administered as a bolus into the vascula $\bar{r}$ system of each patient. The model analysis provides for an evaluation of the rate constants, $K$ 's, interconnecting compartments. The rate constants can be expressed as clearance half-times by dividing them into the natural logarithm of two. Table 24 gives the deuterium arterial blood dissappearance parameters derived from the arterial analysis. The rapidly exchanging tissues, represented by compartment 2, have a clearance half-time of under two minutes, and the slowly exchanging tissues, represented by compartment 3 , have an average of about 14 minutes clearance half-time.

It is then possible to use the parameters derived from the analysis of the Edelman data to eval uate the relative distributions of $\mathrm{H}_{2}{ }^{15} \mathrm{O}$ when $\mathrm{C}^{15} \mathrm{O}_{2}$ is administered at a constant rate, $\mathrm{R}_{1}$ to the three-compartment model (See Fig 23). Lambda, $\lambda$, is the radioactive decay constant for ${ }^{15} 0$. Figure 24 shows the mean and standard deviations for the concentrations of activity in compartments 1,2 and 3 in $\mathrm{uCi} / \mathrm{g}$ of $\mathrm{H}_{2} \mathrm{O}$ when $1 \mathrm{mCi} / \mathrm{min}$ is administered to compartment 1 . Note that a condition substantially different from a one-compartment model is demonstrated. Only $34 \%$ of the activity concentration in compartment 1 is shown to be achieved in the rapidly exchanging compartment and 7\% for the slowly exchanging compartment. The standard deviation for this group is approximately $12 \%$ for all compartments. This result is particularly useful in evaluating one key parameter in using the steadystate method with $\mathrm{C}^{15} \mathrm{O}_{2}$ for measuring regional blood flow. It predicts 
the arterial blood concentration $\mathrm{f}_{2}{ }^{15} \mathrm{O}$ for any particular rate of administration of activity into compartment 1. A thorough evaluation of this method for measuring cerebral blood flow (CBF) has been carried out by a number of authors $(3,4)$.

In order to investigate the water exchange effects in tissues that turn over $\mathrm{H}_{2} \mathrm{O}$ very rapidly, data giving the water clearance half-times for gray and white matter in the brain (2) (see Table 25 ) and the water volumes of these tissues (5) were used. To keep the total volume of the system constant, the gray and white matter water volumes"were substracted from the rapidly exchanging compartment. Figure 25 shows the five-compartment steady-state model for $\mathrm{H}^{15} \mathrm{O}_{2}$ administered to the zero-time volume of distribution water compartment 1 with compartments 4 and 5 . respectively, representing gray and white matter. The concent $\bar{r}$ atjons provided by this five-compartment steadystate calculation for $\mathrm{H}^{15} \mathrm{O}_{2}$ are shown in $\mathrm{Fig} .26$. It should be noted that in this case the percent standard deviations shown for the concentrations in each compartment do not allow for variations in the water volume of white and gray matter, which were fixed in these calculations. Clearly, $\mathrm{H}^{13} \mathrm{O}_{2}$ does not distribute in direct proportion to the volume of water in each tissue and this model would not allow an estimate to better than $10 \%$ even in a group of individuals who closely approximate the Edelman group. The potential for flow measurement requires further development, but it can easily be shown that the activity present in each compartment is not directly proportional to blood flow, confirming a result found in other studies $(3,4)$.

b) Steady-State Distribution of ${ }^{15} \mathrm{O}_{2}$. Once a model has been developed for the distribution of water in the body, it is possible to change its input fungtions. In the particular case of $\mathrm{H}_{2}{ }^{15} \mathrm{O}$ of metabol ism derived from ${ }^{15} \mathrm{O}_{2}$ utilization, it is produced in the various tissues, compartments 2 and 3 , rather than in the central compartment 1. By making the reasonable assumption that the oxygen metabol ism of the brain, heart, kidney, liver, and lung can be described as a single compartment within compartment 2 which exchanges water rapidiy and that the rest of the body's oxygen metabolism in confined to the slowly exchanging tissues; it is possible to assign $79 \%$ of the total-body oxygen metabolism to compartment 2 and $21 \%$. to compartment 3 (6), i.e. $79 \%$ of $R_{1}$ equals $R_{2}$ and $21 \%$ of $R_{1}$ equals $R_{3} . R_{2}$ and $R_{3}$ are are then the constant rates at which oxygen is supplied to the tissues by the arterial blood system of the body. The total oxygen utilization used for these calculations is 22.13 liters of oxygen per hour in the resting state ( 7$)$ and the specific activity of the delivered oxygen is assumed to be $1 \mathrm{UCi} / \mathrm{ml}$ of oxygen gas. Figure 27 shows the model assumed for water of metabolism calculations. Figure 28 shows the distribution of total observed activity by the numbers at the left and the amount expected from metabolism al one without any redistribution as a percent of the total at the right of each vertical bar. The central 
compartment contains $0.2 \mathrm{mC} i$, where without redistribution of labeled water of distribution it would contain no activity. The fast compartment would contain an additional $35 \%$ and the slow compartment has an excess of $6 \%$. As expected the effects of redistribution are much greater in the rapidly exchanging compartment. With the aid of the model we can predict this effect to within about $\pm 3 \%$ for both the fast and the slow compartments. In order for such adjustments to the data to be possible we must know apriori what fraction of each compartment is within the portion of the body being analyzed.

Figure $29^{\circ}$ shows a breakdown of both the slow and the fast compartments into the percentages lost from and regained into these compartments relative to $100 \%$ observed. Whereas, rather large changes are seen for the fast-body compartment (46\% loss with $11 \%$ regained) much smaller changes are seen in the slowly exchanging tissues (7\% 1oss with $13 \%$ regained).

It is possible to determine how large a variation in the loss and gain percentages would result if this model were used to correct for changes in the slowly exchanging compartment 3 , by varying the clearance constants by $+10 \%$ while holding the remainder of the model constant. These result $\bar{s}$ are shown in Figure 30 . Apparently a $20 \%$ change in the clearance constant results in only a $1.5 \%$ change in the produced versus observed results. Measurements of regional oxygen metabolism in tumors currently underway in this laboratory are assumed to fall within the category of slow water-exchanging tissues.

A model for oxygen of metabolism including brain gray and white matter (compartments $4 \& 5$ ) is shown in Figure 31 . Results for white and gray matter showing losses and gains from these compartments due to recirculation are shown in Figure 32. White matter shows an $84 \%$ loss with an $8 \%$ gain and gray matter shows a $256 \% 1$ oss with a $28 \%$ gain. The standard deviations for the model are +4 and $+10 \%$, respectively, for white and gray matter. The size of these errors and corrections make it appear that absolute measurement of oxygen metabolism in the brain by the steady-state method will be more difficult than is now generally appreciated, even with the model provided corrections. This is especially true for the cases where some pathology in the brain is under study, since the kinetics would likely be modified in an unpredictable manner. Further, if the resolution of any quantitative imaging device were insufficient to resolve white and gray matter the correction appropriate would be uncertain by $150 \%$. The results given above were presented at the recent Society of Nuclear Medicine Meeting in Altanta (8). 
G. Radiation dose estimations. The results of the steady-state model calculations have been used to estrmate cumulated activities in the body during a constant administration of $15 \mathrm{U}_{2}$ at $1 \mathrm{mCi} / \mathrm{liter}$ of air for thirty minutes duration. The radiation dose estimates are given in Table 26 . Ihe radiation dose estimated for the lung is quite nign under these conditions. It is suggested that these radiation doses be reduced by a decrease in the rate of activity administration or a shorter period of inhalation or a combination of the two. These radiation dose estimates were prepared according to the general methods of the MIRD Committee of the society of Nuclear Medicine (9). The details will be prepared as a manuscript for publication. 
Table 23

\section{EDELMAN* DEUTERIUM OXIDE SUBJECT POPULATION}

5 NORMAL ADULT MALES

\begin{tabular}{|c|c|c|}
\hline $\begin{array}{l}\text { WEIGHT } \\
\text { AGE } \\
\text { TOTAL BODY WATER } \\
\% \text { BODY WEIGHT } \\
\text { ZERO-TIME VOLUME } \\
\% \text { BODY WEIGHT }\end{array}$ & OF DILUTION & $\begin{array}{l}70.8+5.8 \mathrm{~kg} \\
23.0 \pm 4.1 \mathrm{yrs} \\
42.0 \pm 2.6 \mathrm{l} \\
59.4 \pm 2.7 \\
10.3 \pm 7.2 \ell \\
14.6 \pm 1.7\end{array}$ \\
\hline$?$ & & \\
\hline
\end{tabular}




\section{Table 24}

\section{EDELMAN* DEUTERIUM OXIDE ARTERIAL DISAPPEARANCE PARAMETERS IN NORMAL ADULT MEN}

Fast Tissues

CLEARANCE HALF-TIMES (MIN.) HIGH

Slow Tissues

$\begin{array}{cccc}\text { LOW } & \text { HIGH } & \text { AVERAGE } & \% \text { SD } \\ 1.51 & 1.98 & 1.77 & 10.7 \\ 12.84 & 15.75 & 13.81 & 8.8\end{array}$

*AM. J. PHYSIOL. 171: 279-296, 1952. 


\section{Table 25}

TER-POGOSSIAN ET AL. * OXYGEN 15 REGIONAL CEREBRAL BLOOD FLOW PARAMETERS IN PATIENTS WITH BRAIN PATHOLOGY

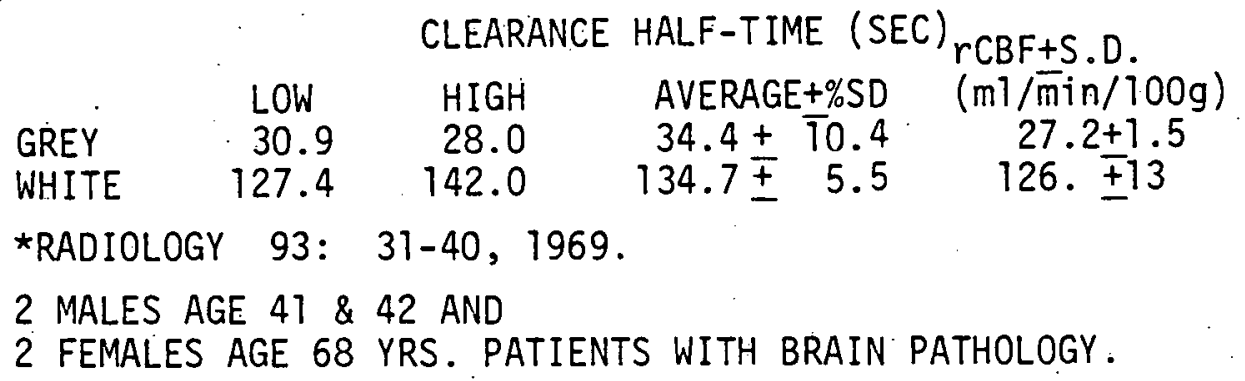


Table 26

HUMAN RADIATION DOSE ESTIMATES FOR INHALED

MOLECULAR OXYGEN-15 STEADY-STATE MEASUREMENTS

( $1 \mathrm{mCi} / 1 \mathrm{iter}$ of Air for 30 Minutes)

ORGAN

DOSE

(rad)

Lungs

Heart

Kidneys

Liver

2.8

1.7

1.2

Brain

1.0

Spleen

0.47

Total Body

0.43

0.040 


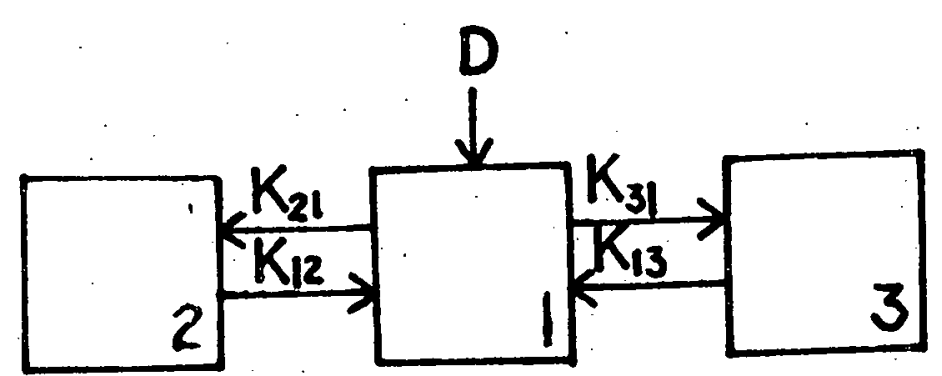

Figure . Three-compartment model representing the distribution of a bolus infusion $D$ of a tracer for water $\left(D_{2} O\right)$ in humans. 


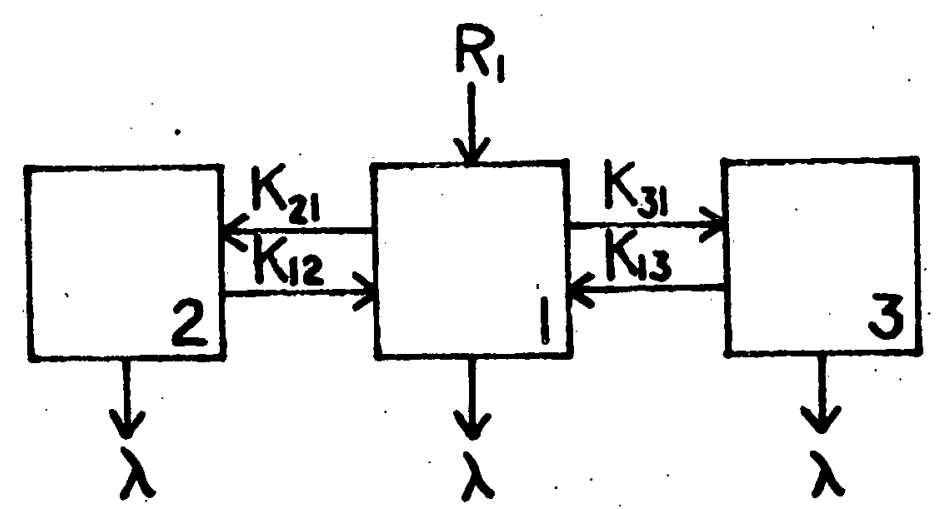

Figure. Three-compartment model used to evaluate the steady-state distribution for $\mathrm{H}^{75} \mathrm{O}_{2}$ delivered to compartment 1 at a constant rate $\mathrm{R} l$ in humans. Lambda, $\lambda$, is the radioactive decay constant for oxygen-15. 


\section{Figure 24}

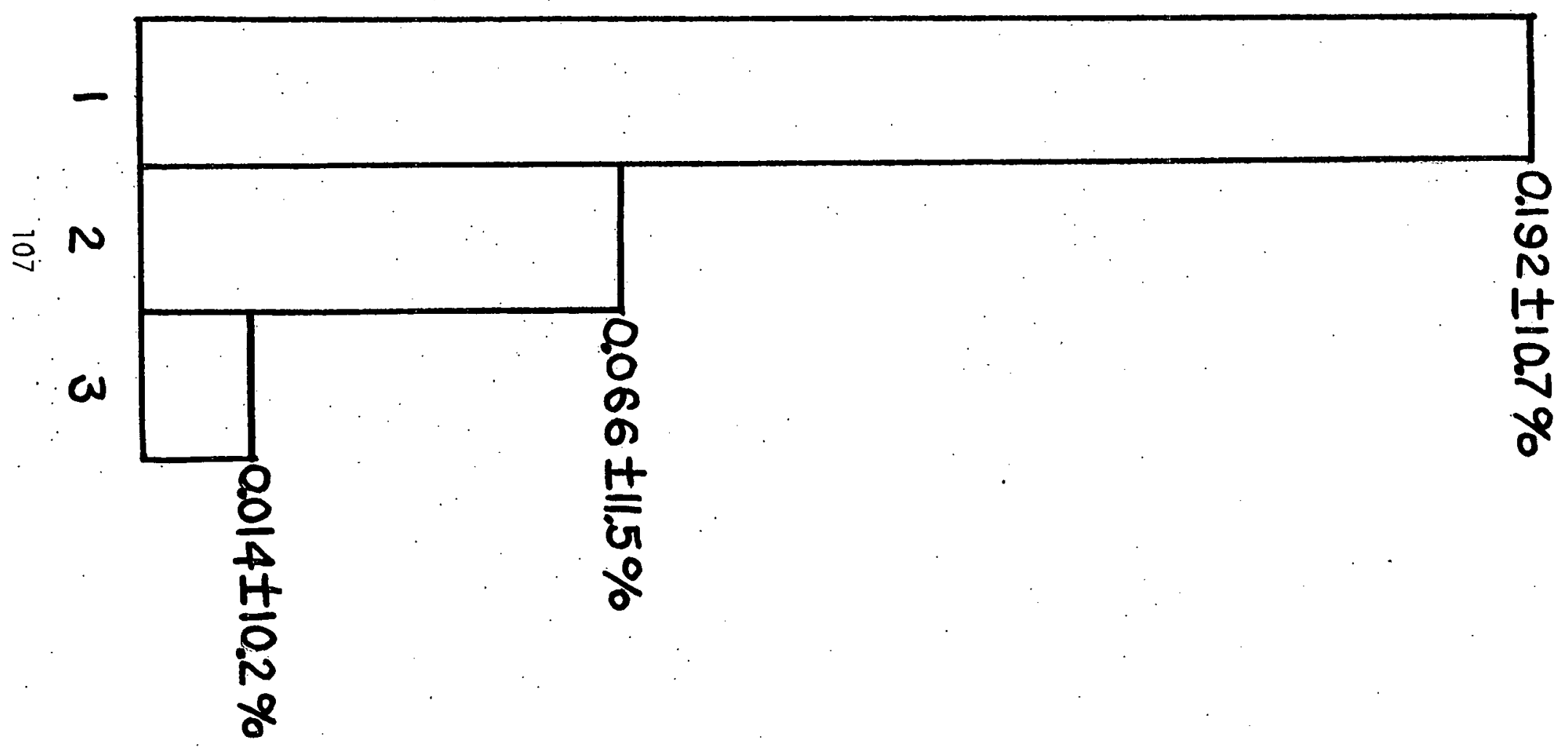

Figure Steady-state activity concentrations in $\mu \mathrm{Ci} / \mathrm{cc}$ of water in a three-compartmental model of the water distribution in humans. The H150 activity is administered to compartment 1. 


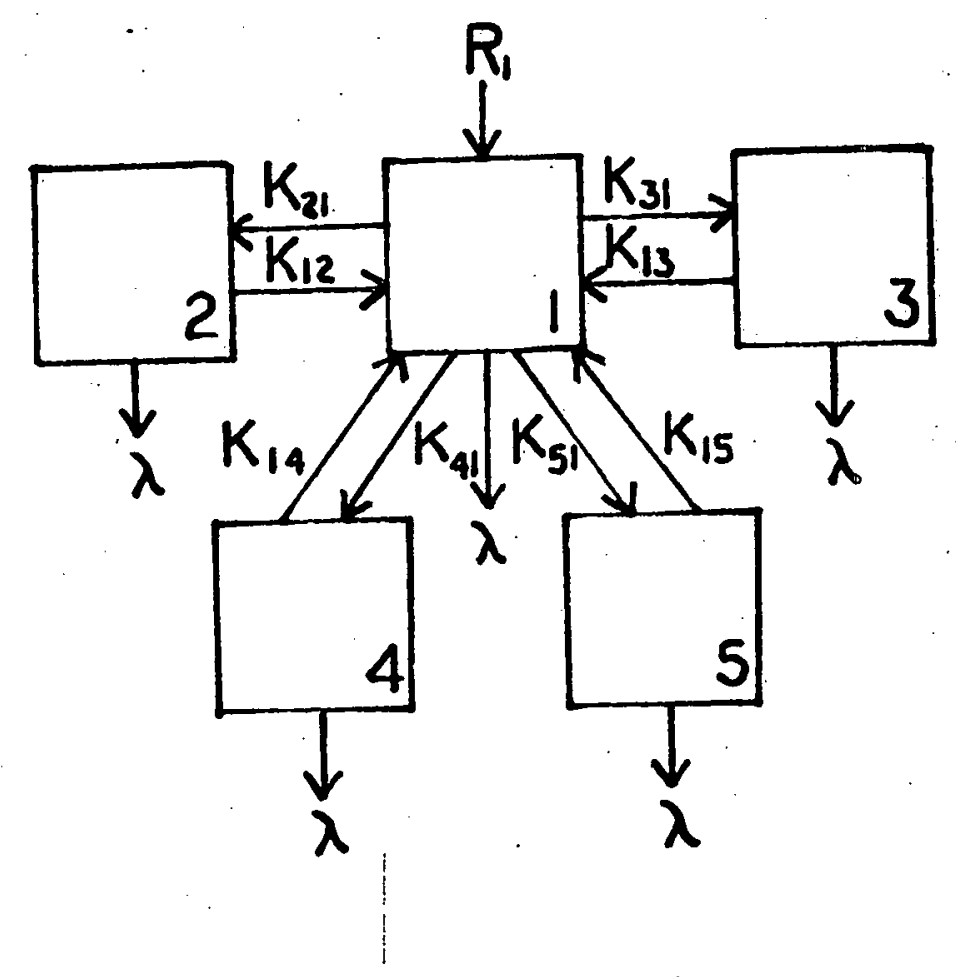

Figure . Five-compartment model used to calculate the steady-state distribution in humans of $\mathrm{H}_{2}{ }^{15} 0$ administered at a constant rate $R_{1}$ to compartment 1 . 
Figure 26

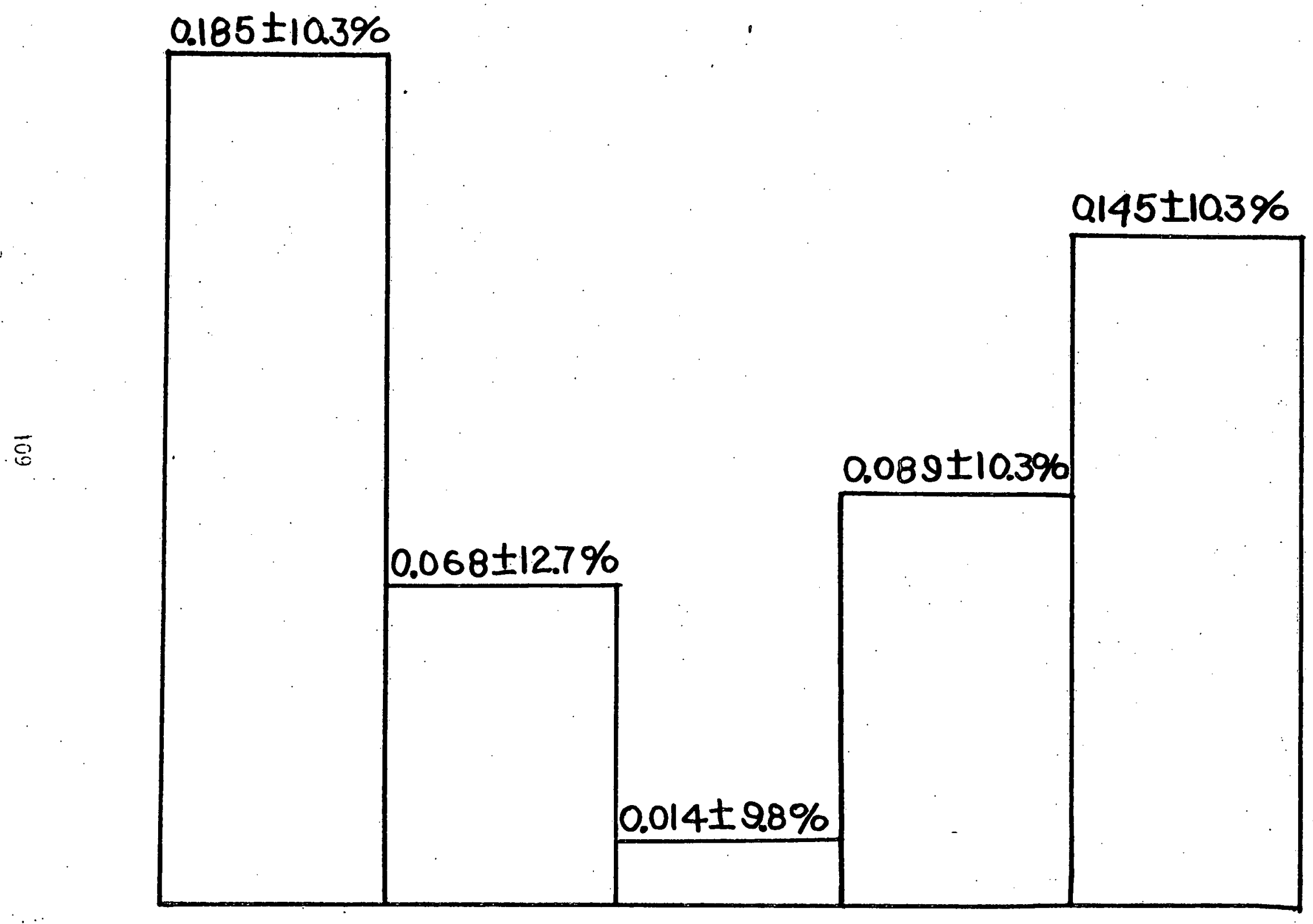

Figure $\because$ Steady-state activity concentrations in $\mu \mathrm{Ci} / \mathrm{cc}$ of water in a five-compartment model of the water distribution in humans. The $\mathrm{H}^{5} 5_{0}$ activity is administered to compartment 1 . 


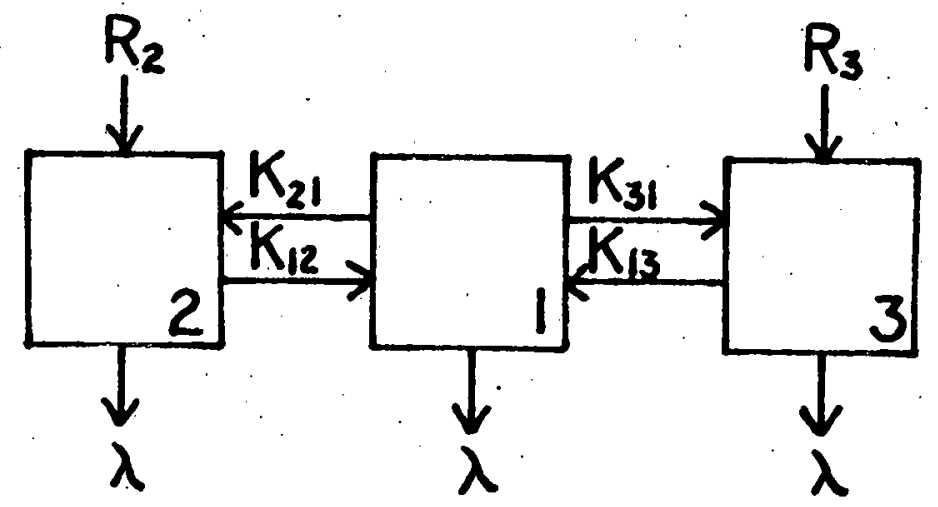

Figure . Three-compartment model for evaluation of the steady-state distribution of $\mathrm{H}_{2}{ }^{15} 0$ produced in compartments 2 and 3 by the metabolism of oxygen delivered at the rates it is utilized in those compartments ( $R 2$ and $R 3$ ).

\section{Figure 27}


150 DISTRIBUTION OF WATER OF METABOLISM IN mGi FOR A THREE COMPARTMENT STEADY STATE MODEL

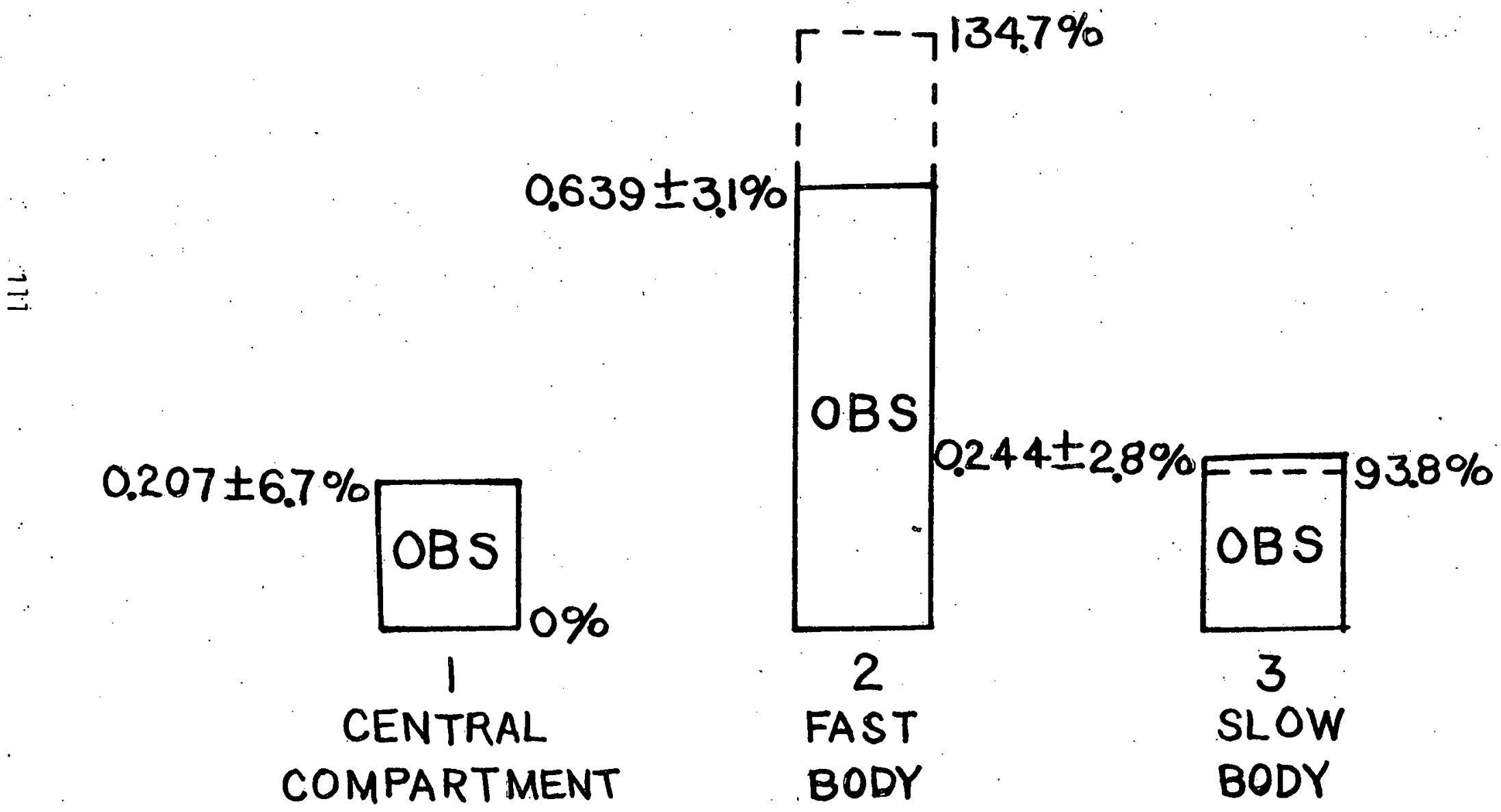

Figure 28. Steady-state activity concentrations of $\mathrm{H}^{15} 0$ of metabol ism produced in a three-compartment model of the distribution of oxygen metabolism in humans. Water of metabol ism is produced at a constant rate equal to the rate at which oxygen is metabolized in compartments 2 and 3 . 


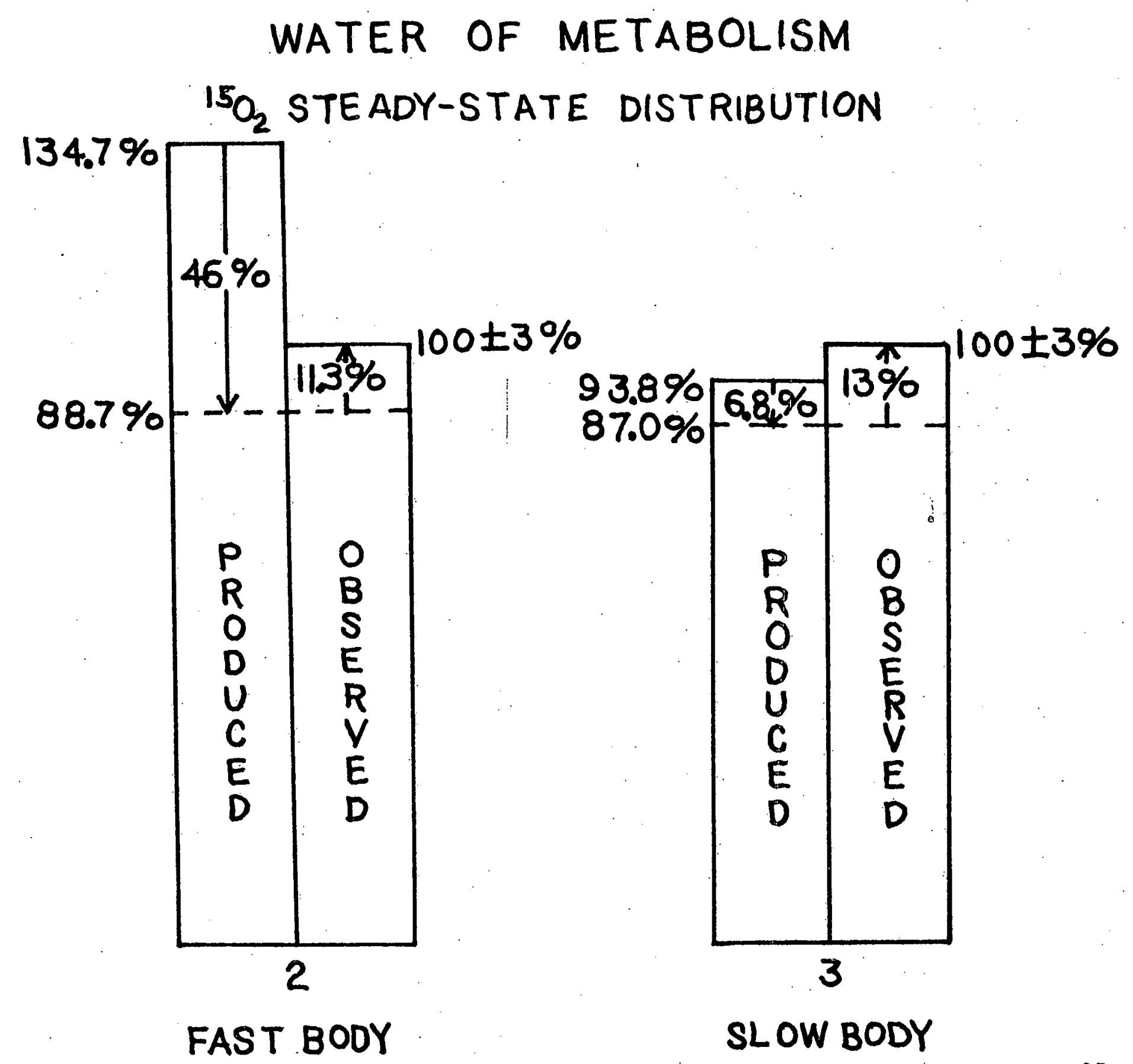

Figure 29. Water of oxygen metabolism redistribution analys is showing how the quantity of $\mathrm{H}_{2}{ }^{15}$ produced in each metabolic compartment is lost and regained from the human body by body water exchange processes at the steady-state to result in the observed quantities. 


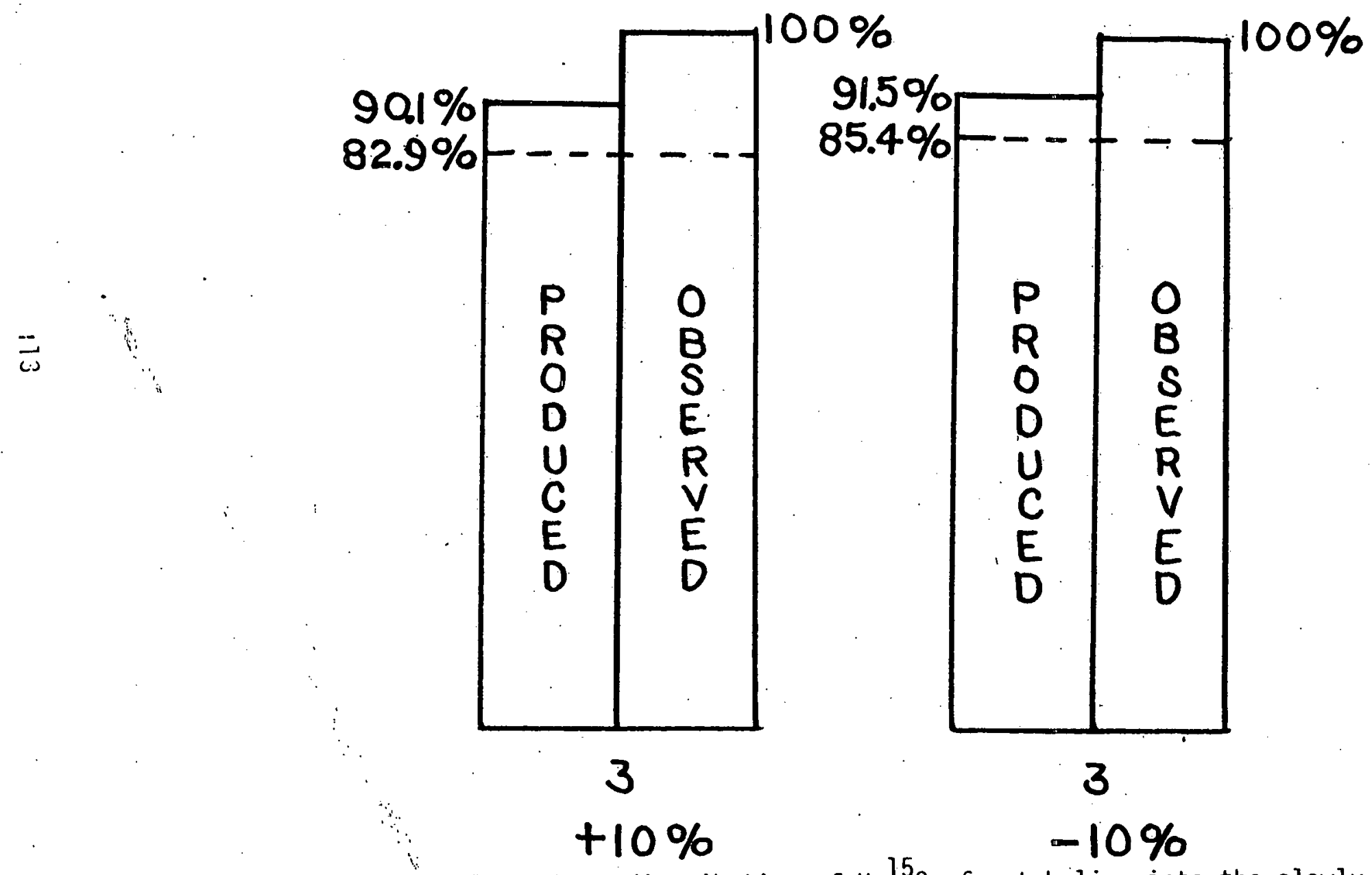

Figure 30 Changes observed in the redistribution of $\mathrm{H}_{2}{ }^{15} 0$ of metabolism into the slowly exchanging tissues, compartment 3 , where the compartment clearance half-time is changed by $+10 \%$ and $-10 \%$. 


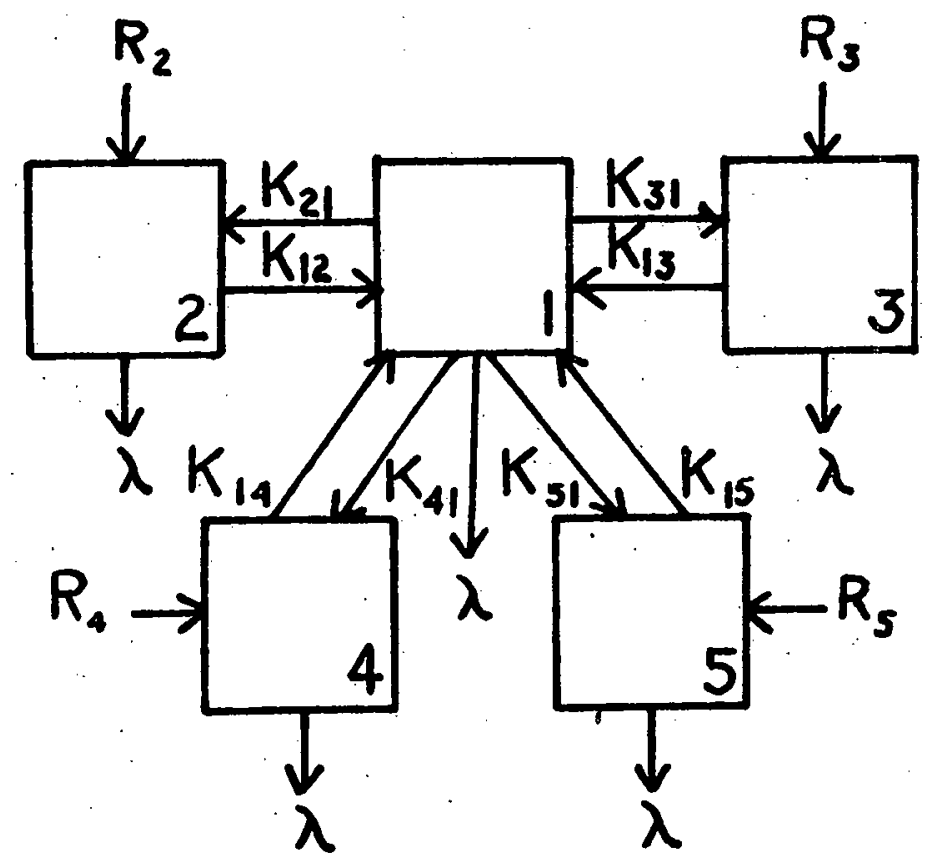

Figure 31. Five-compartmental model for evaluation of the steady-state distribution of $\mathrm{H}_{2} \mathrm{~T}_{0}$ produced in compartments $2,3,4$ and 5 by the metabolism of oxygen delivered at the rates it is utilized in those compartments $\left(R_{2}, R_{3}, R_{4}\right.$ and $\left.R_{5}\right)$. Compartments 4 and 5 represent grey and white matter, compartments 2 and 3 represent rapid and slow water exchanging tissues, and compartment 1 is the central arterial blood system. 
WATER OF METABOLISM IN BRAIN

\section{${ }^{15} \mathrm{O}_{2}$ STEADY-STATE DISTRIBUTION}
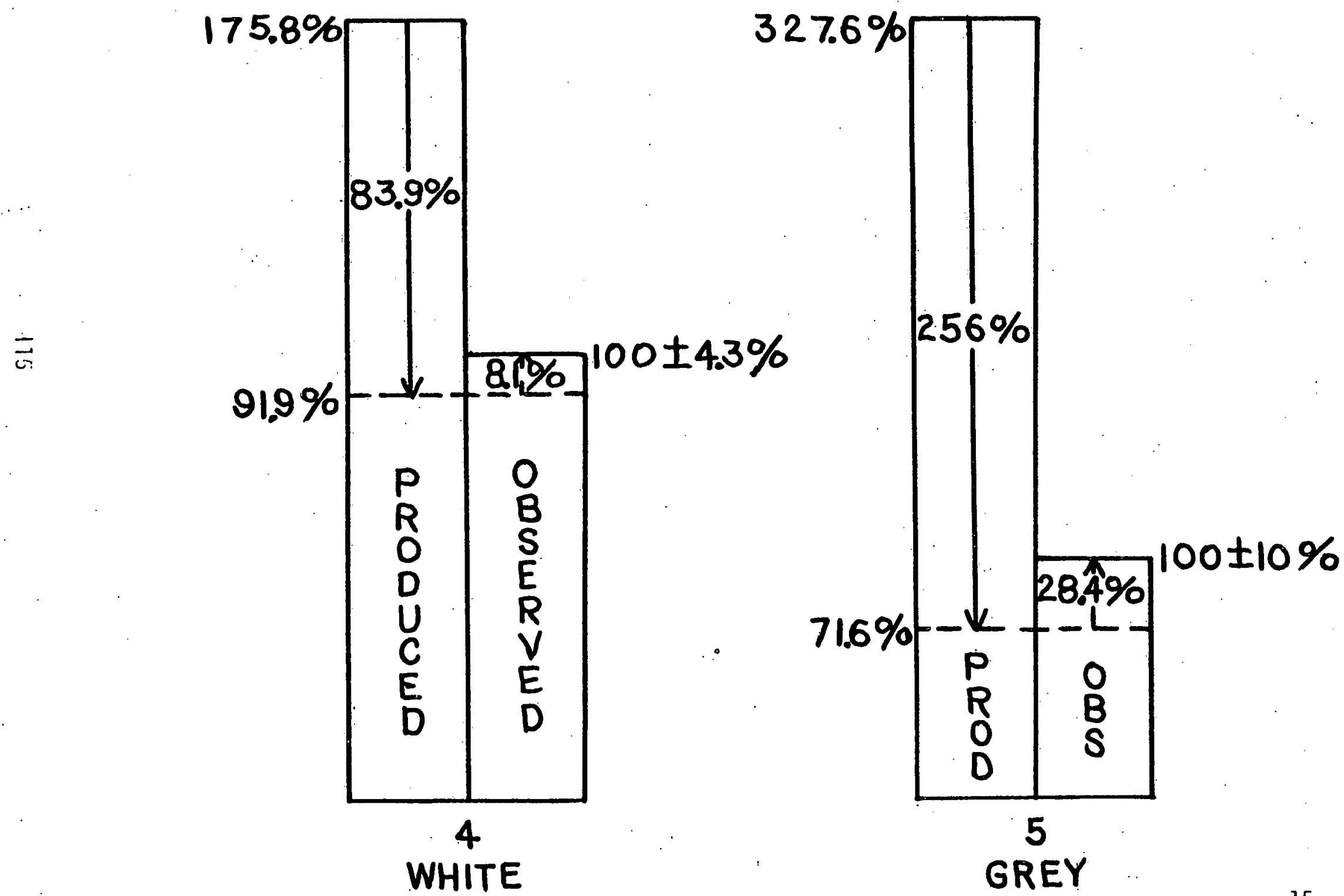

Figure 32 Water of oxygen metabolism redistribution analysis showing how the quantity of $\mathrm{H}_{2}{ }^{15} 0$ produced in the white and grey metabolic compartments is lost and regained from the human body by body water exchange processes at the steady-state to result in the observed quantities. 


\section{REFERENCES}

1. Edelman, I.S. Exchange of water between blood and tissues characteristics of deuterium oxide equilibration in body water. Am. J. Physiol. 171: 279$296,1952$.

2. Ter-Pogossian, M.M. The determination of regional cerebral blood flow by means of water labeled with radioactive oxygen-15. Radiology 93: 31-40, 1969.

3. Huang, S.C., Phelps, M.E., Hoffman, E.J. and Kuhl, D.E. A theoretical study of quantitative flow measurements with constant infusion of short lived isotopes. Phys. Med. Biol., 1979 (In Press).

4. Jones, S., Reivich, M. Greenberg, J.H. Error propagation in the determination of cerebral blood flow with the inhalation of $15 \mathrm{CO}_{2}$. J. Nucl. Med. 20: 606, 1979. (Abstract)

5. Rasmussen, K.H., Skinhoj, E. In vivo measurements of the relative weights of grey and white matter in the human brain. Neurology 16:515-520, 1966.

6. Holliday, M.A., Potter, D., Jarrah, A., and Bearg, S. The relation of metabolic rate to body weight and organ size.

7. Biology Data Bood Vo1. III Ed. Altman and Dittmer. Maryland; Federation of American Societies for Experimental Biology, 2nd Edition, 1527, 1974.

8. Bigler, R.E., Kostick, J.A., Gillespie, J.R. and Laughl in, J.S. Compartmental analysis of the steady-state distribution of oxygen-15 labeled oxygen and water. J. Nucl. Med 20: 606, 1979. (Abstract).

9. Loevinger, R. and Berman, M. MIRD Pamphlet No. 1, Revised, Society of Nuclear Medicine, New York, 1976. 
4. INSTRUMENTATION AND ANALYTICAL PROCEDURES

4.1 CYCLOTRON RESEARCH AND DEVELOPMENT

OBJECTIVE

To maintain and improve cyclotron operating efficiency and reliability, to improve personnel and equipment safety and protection and to simplify and standardize cyclotron operation.

\section{SCOPE OF INVESTIGATION}

The research programs utilizing the Sloan-Kettering cyclotron demand a high degree of cyclotron reliability and versatility, especially when patient scheduling is involved.

Cyclotron scheduling normally requires daily particle changeovers, and frequently twice daily or tri-daily changeovers, followed by cyclotron retuning at a different beam current. The limited particle energy of our cyclotron requires long term stable high and low beam currents for production of some isotopes and neutrons. To meet these demands we have concentrated on developing simple and standard cyclotron operation and maintenance methods, stable and reproducible beam currents, optimum extraction efficiencies and extended life times for perishable components.

\section{RESULTS AND CONCLUSIONS}

A. - The following projects, described in our 1978 Report, have been completed.

1. A Carbon Puller Modification to Reduce Replacement Cost: A modified carbon puller arrangement has been tested in routine use since Nov. T978 in the cyclotron (Fig. 33 ). The "plug" portion is eroded by the ions emerging from the ion source and needs replacement once a month at a cost of $6 \varnothing$. By comparison, 6 pullers were replaced between Nov. 1977 and Nov. 1978 at a cost of $\$ 675$. The plug is cut from stock rod and enough material is on hand for 77 years.

This modification has resulted in an unanticipated benefit. The ion source anode is also eroded by the ions emerging from it and needs replacement twice a year. Resistance to heat conduction across the mating surfaces of the plug and puller body causes the plug to erode about twice as fast as the corresponding portion of the old puller. Some of this material is deposited on the face of the source anode where the ions emerge, coating it with a heat resistant carbon surface. The anode, normally eroded by the emerging ions and needing replacement about twice a year, has not been replaced since March 1979 and shows little wear at present.

\section{Rebuilding Our Damaged Ion Source}

The inoperative ion source, part of the original equipment of our cyclotron, has been rebuilt and tested. After some initial problems with clogged water lines and vacuum leaks, the ion source was put into service and has 
has been in routine use since March 1979.

Being water-cooled in a vacuum, this type of ion source is difficult to repair, thus having a spare on hand assures us of continued operation should one ion source fail.

3. New Internal Probe for Beam Monitoring: Assembly, testing, installation and troubleshooting our new internal probe has been completed. Parts for this project have been available for some time, but other duties and projects had deferred its completion. This probe was designed to replace the original equipment for two reasons:

a. Increased internal beam currents due to improvements in cyclotron performance made here exceeded the cooling capacity of the original probe. The evaporated or sputtered copper generated by overheating caused vacuum problems and RF shorting in the dee box.

b. A set of adapters was needed when using the original probe since the probe transport equipment had previously been modified to accept the larger diameter of our internal target probe.

Due to these difficulties, the internal target probe was routinely used as a beam current monitor by installing a blank copper target disc, designed here by us to dissipate the heat caused by high beam currents. However, the internal target probe became moderately radioactive due to continual use and exposed personnel mounting the target to a $200 \mathrm{mR} / \mathrm{hr}$ field 6 in. from the probe: head and at least $2,000 \mathrm{mR} / \mathrm{hr}$ for $30 \mathrm{sec}$. When remounting the blank.

The new probe has been in routine use since March 1979. The internal target probe is being used only for internal targets which are run no more than once a week, permitting the probe to "cool off" substantially between runs.

The new probe has been designed to map the beam orbit pattern using a second monitoring terminal that will accept fine pickup wires.

4. Internal Probe Carriage Extension: A radiation hazard was created when our internal target probe was built. The range of the mechanism which moves the probe in and out of the dee box was extended, but only enough to drive the probe into the dee box one inch less than extraction radius if the probe was to be withdrawn completely from the dee box, as when retrieving an irradiated internal target. . Eor purposes of RF system troubleshooting the vaul.t door interlock can be bypassed with a special key, if the probe is at its "in" limit, and the cyclotron turned on. The rationale was that the probe would stop the beam at low energy orbits if the ion source was also on, greatly reducing the severity of an accidental radiation exposure. Until now, the beam was stopped at high energy orbits. Extending the carriage a second time provides enough travel so that the probe can be sent in $7.9^{\prime \prime}$ less than extraction radius, where the beam is $275 \%$ of maximum energy for any particle.

5. Operator Training: Personnel changes and the increased need for coordination of the cyclotron schedule with patient availability has placed 
heavy emphasis on training additional cyclotron operators from our staff. We have completed the training of five operators, which is sufficient to meet our immediate needs.

B. The following project is currently being pursued:

1. Inner Orbits Correction: The quality and quantity of the internal beam and its effect on extraction efficiency and external beam depends on the configuration of the first turn and subsequent inner orbits, which in turn depend heavily on the positioning of components of the central region: the ion source, puller, first turn shield and dees. These parameters are a compromise between those necessary for maximum proton, $\mathrm{He}-3$, He-4, and deuteron operation. A system of harmonic coil magnets are used to alter the phase space of the beam entering the deflector and are an important component of the external beam extraction system. Similar sets of coils installed close to the inner orbits of our cyclotron will increase extraction efficiency substantially by providing "tuning" ability of the inner orbits, thereby alleviating the negative effects of. the compromise central region setup. Increased extraction efficiency will also lessen deflector loading, lengthening the period between servicings and thus reducing cyclotron staff radiation exposure levels. We have completed the design, fabrication and installation of three sets of inner coils and have purchased the necessary power supplies. The control circuit for this project is currently being built (see Fig. 34) and completion of the project is expected within six months.

C. The following projects have not been completed for the reasons stated.

1. Magnetic Channels Limiter: Installation of electromagnetic limiting devices on each end of our movable magnetic channels to prevent their damage and loss of calibration will be made after the Inner Orbit coils Project is completed.

2. Target Current Limiter: An adjustable target current limiter interlocked with our cyclotron power to prevent target destruction will be installed upon completion of our Inner Orbit Coils Project.

3. Modification of Spare Deflector: Our second deflector needs to be modified so that the deflector gap can be adjusted remotely. This would allow our present deflector to "cool off" for a year before servicing, greatly reducing personnel radiation exposure. We lack the necessary funds to complete this project. 


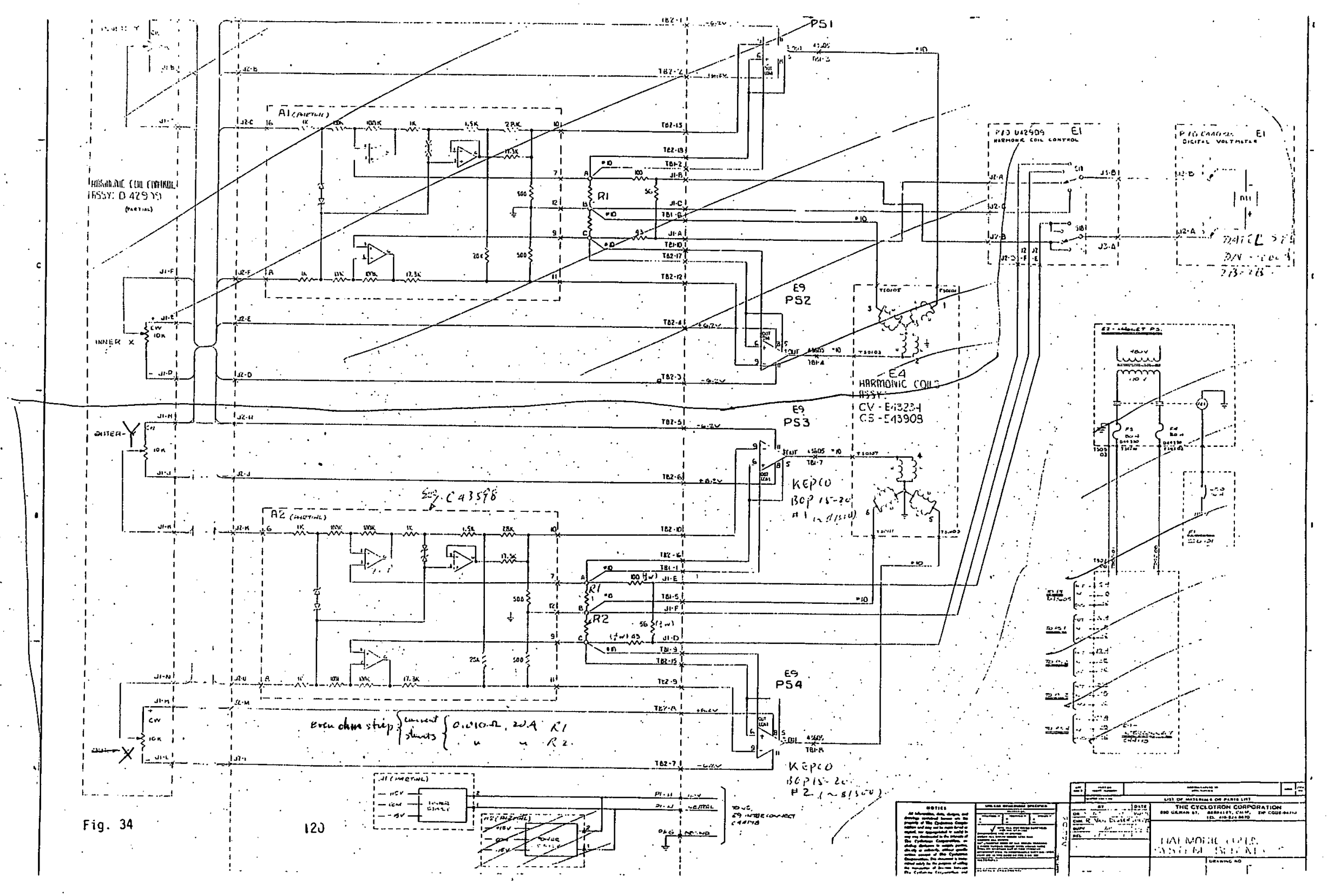




\section{OBJECTIVE}

1) To design and construct new phantoms for the quantitative calibration of scan data obtained under the new patient research protocols; for example, with $13 \mathrm{~N}$-glutamate in patients with osteogenic sarcoma.

2) To determine the quantitative characteristics of the PC-4200 and to compare them with the characteristics of the HEG system.

3) To continue the development of software for the TOKIM system.

\section{SCOPE OF INVESTIGATION}

Fulfilling the objectives of this investigation was partly contingent on the addition of technical staff, which was not forthcoming during the contract period. Hence the scope of the investigation was reduced, and priorties were redirected toward projects that he]d the greatest immediate potential for supporting the quantitation of $13 \mathrm{~N}$ and $\mathrm{T} \mathrm{I}_{\mathrm{C}}$ in-vivo in human cancer patients using the HEG and TOKIM systems. Detailed phantmm studies on the PC-4200 position tomograph were not carried out due to the formidable amount of data acquisition, analysis and software development necessary, and considering the uncertainty of the residence time of the machine here.

\section{RESULTS AND CONCLUSIONS}

A review of the course of the clinical studies with $13 \mathrm{~N}-\mathrm{glutamate}$ as a chemotherapy monitor (section 1.1.2). showed that an absolute determination (percent dose) of tumor uptake may not be as important as an accurate serial assessment of tumor uptake in arbitrary units (counts/second/millicurie injected) which included correction for variations in tissue thickness between scans (due to changes in edema or positioning) or between individuals. The use of transmission scans to provide a point-by-point map of equivalent tissue thicknesses in a body region, which could be used to orrect emission images for attenuation, was investigated. A transmission source was designed which could be mounted on the lower detector of the $\mathrm{HEG}$ system and filled with $99 \mathrm{~m}_{\mathrm{TCO}}=$ solution. $A$ collimated beam of $140 \mathrm{KeV}$ gamma rays approximately one $\mathrm{cm}$. in diameter was directed to the upper detector (fitted with the long focal length dual focus collimator used in the quantitative emission studies\%. The scanner was then used in its usual rectilinear mode, with the resuiting image reflecting attenuation of the gamma rays in the subject. The linear absorbtion coefficient for water at $140 \mathrm{KeV}$ was measured with the system and found to be identical to published values. Software was written to convert the transmission image into a "thickness image"; studies with a normal volunteer showed excellent correlation between thickness values derived from the transmission scan and true geometric thicknesses in peripheral body regions devoid of air cavities. The linear absorbtion coefficient for water was used in the computations, since the differential attenuation of adipose tissue and bone at $140 \mathrm{KeV}$ would result in only a small error in calculated thickness. The HEG system software was modified to permit the use of the thickness image in performing a point-bypoint attentuation correction of a given emission image. Transmission 
images have been obtained in conjunction with $1713 \mathrm{~N}$-glutamate tumor studies and 11 M-carbon monoxide lung studies in patients. The point-by-point correction will undoubtedly provide a more accurate assessment of $13 \mathrm{~N}-\mathrm{glutamate}$ uptake in tumors than the old "single-number" correction; the clinical impact of the technique is still being evaluated. In the case of $11 \mathrm{co}$, it has proved very useful in outlining the region of the air space in the lungs and therby providing important anatomical landmarks for the analysis of changes in the emmission images.

Software was developed for the TOKIM gamma camera system and implemented on the Core Computer Laboratory's PDP-11/70 (Digital Equipment Corporation). An easy-to-use interactive acquisition program was developed to replace the. cumbersome thumbwheel and interupt button system used with the IBM 1800. A fast, flexible command-line system, which was modeled after that used by the $11 / 70$ 's system utilities, was written in Fortran IV. This command structure, which can be learned easily by anyone familiar with the standard system utilities, permits multiple operations on images within a single command 1 ine. Operations such as thresholding, rotation, filtering, constant arithmetic, spatial shifting and display can be performed in any combination; region of interest definition, dynamic analysis and tape-handiing utilities can be invoked as separate functions. Series of command strings can be stored on disk and executed automatically.

A dot-density display was developed for use with the Gould electrostatic printer/plotter, which permits the production of inexpensive hard-copy images in either equally or logarithmically-spaced level formats. The new system has been used to acqujre, display and analyze the data from a variety of animal studies and three $13 \mathrm{~N}$-glutamate clinical studies; we conclude that the initial investment in developing an easy-to-use, flexible acquisition/ analysis system was worthwhile considering the time saved during data analysis and user training. 


\section{OBJECTIVE}

Facilitate the work of investigators in the Biophysics Laboratory by maintaining and upgrading existing instrumentation and implementing new instrumentation to increase the reliability and facility with which data may be acquired, retrieved, processed and displayed.

\section{SCOPE OF INVESTIGATION}

The responsibility of the Electronics lab can be divided into two sections 1) maintenance and 2) design and development. The principal task is the maintenance and upgrading of electronic instrumentation in the Biophysics Laboratory. Responsibilities include the maintenance of the following electronic equipment:

1) A Positron Emission Tomograph (PET) was installed in August of 1978. The PCS 4200 (here for evaluation), built by the Cyclotron Corporation, is capable of tomographically reconstructing 23 cross sectional slices and displaying this data on a color graphics display. The system uses a Digital Equipment Corporation (DEC) PDP $11 / 34$ computer with modified Gamma-11 software for all processing and displays.

2) A dual-headed High Energy Gamma (HEG) rectilinear scanner with 4" $\times$ 4" $\mathrm{Nal}$ (11) crystals, with 9-track magnetic tape storage of digital data from 8 scalers, plus detector $x-y$ position, patient scan ID and time.

3) An Anger-type gamma camera system, designed and constructed inhouse, incorporating two opposed 13-1/2" diameter by $1 / 2^{\prime \prime}$ thick Nal crystals (Total Organ Kinetic Imaging Monitor) with associated electronics for coincidence counting. The TOKIM system has recently been interfaced to our DEC PDP $11 / 70$ computer.

4) An Osteodensitometer, a scanning device used to measure bone mineral content, stores information on a digital cassette recorder for later transfer to a PDP $11 / 70$ computer for analysis and plotting of data.

5) A Cyclotron Corp. CS-15 cyclotron, capable of accelerating protons and alpha particles to $15 \mathrm{MeV}$, deuterons to $7.8 \mathrm{MeV}$ and $\mathrm{He}-3$ particles to $23 \mathrm{MeV}$.

6) Four multichannel analyzers (MCA's) are used in the Biophysics Laboratory: One RIDL 400-channel a Northern-Scientific 512 channel with magnetic tape storage, an Hewlett Packard 1024 channel MCA with a GeLi detector, and a Packard autogramma counter with a 1024 channel MCA unit.

7) A Packard liquid scintillation detector with sample changer.

8) Numerous NIM modules, e.g., linear amplifiers, standard and constant fraction timing single channel analyzers, counters, coincidence units, nuclear pulse generators, etc. 
In the area of design and development the first goal was to transfer data acquisition equipment, displays and controls from an IBM 1800 computer (phased out of operation) onto a newly acquired DEC PDP 11/70 computer. The PDP 11/70, running under an RSX-11M operating system, will support real-time data acquisition (e.g., TOKIM gamma camera) and multiuser operation. The system includes $25 \overline{6 \mathrm{~K}}$ bytes of memory, an 88 Megabyte disk drive, two 9 track magnetic tapes, Texas Instrument (TI) compatible cassette unit, (enables data entry from numerous labs throughout the Institute), paper tape reader, Gould electrostatic printer/plotter, several digital and analog 1/0 interfaces, and communication interfaces capable of supporting up to 16 users. We are currently using 6 local and 3 remote CRT and hard-copy terminals, 4 dialup, and 2 dedicated phone 1 ines, (used for remote data entry and CRI/hardcopy terminals) and an MFE microprocessor controlled cassette unit.

Another important project was the interfacing of a high speed matrix printer ontu a Packard Auto Gamma spectrometer with a 1024 channel MCA.

We are currently completing an in-house microprocessor development system that will enable efficient implementation of microprocessor based instrumentation (see Figure 35). Part of the system includes a PDP 8 minicomputer running under an OS8 operating system with a 2.4 Megabyte RK05 disk. The computer is used for microprocessor program storage and micro-code assembly (conversion of a microprocessor symbolic language into microporcessor code or micro-code).

\section{RESULTS AND CONCLUSIONS}

The interface of an Anger-type gamma camera system (TOKIM) to a PDP 11/70 computer was completed. This system allows on-line magnetic tape storage of TOKIM data with immediate analys is and (16 gray scale) hard-copy output on a Gould printer/plotter. All functions are controlled through a video terminal tied to the PDP $11 / 70$ computer. In the near future a video graphics display system with $256 \times 256$ pixal resolution and a gray scale of 64 level will be installed on the PDP 11/70, allowing more sophisticated data analysis.

Other instrumentation interfaced to the PDP $11 / 70$ include:

1) A Tektronix type 611 storage scope with $1000 \times 1000$ dot resolution to allow viewing of data before outputing onto a hard-copy device.

2) $x-y$ joystick

3) 16 indicator Tights

4) 16 control switches and analysis.

The last 3 devices can be used for interactive control of data input/output

The interfacing of a high speed printer onto our Packard Auto-Gamma 
Spectrometer allows researchers to rapidly count short half-lived radiolabeled samples, and simultaneously obtain a hard-copy printout of data. Previously data had to be copied manually because of a slow teletype printout.

Microprocessor developments include the implementation of a serial input/output line on a PDP 8 minicomputer used to assemble microprocessor code. This allows micro-code to be transmitted over a standard RS-232 serial line to an intelligent device "Smart EPROM Blaster/Simulator;" now being. completed. This device (see Fig. 35 ) will be capable of a number of functions required to develop a microprocessor instrument:

1) accepting assembled micro-code transmitted from the PDP 8

2) running a microprocessor controlled instrument (under development) from this micro-code.

3) allowing modifications to be made to the micro-code to facilitate debugging and

4) after verifying program operation, "blasting" the micro-code into an EPROM for permanent storage.

The EPROM is then plugged into the instrument to provide the program on which the instrument will run. The "Smart EPROM BIaster/Stimulator" will also provide a printer output allowing hard-copy output of program listings. 


\section{SKI LABORATORY MICPOPROCESSOR DEVELOPPIENT SYSTEM (BLOCK DIAGRAM)}

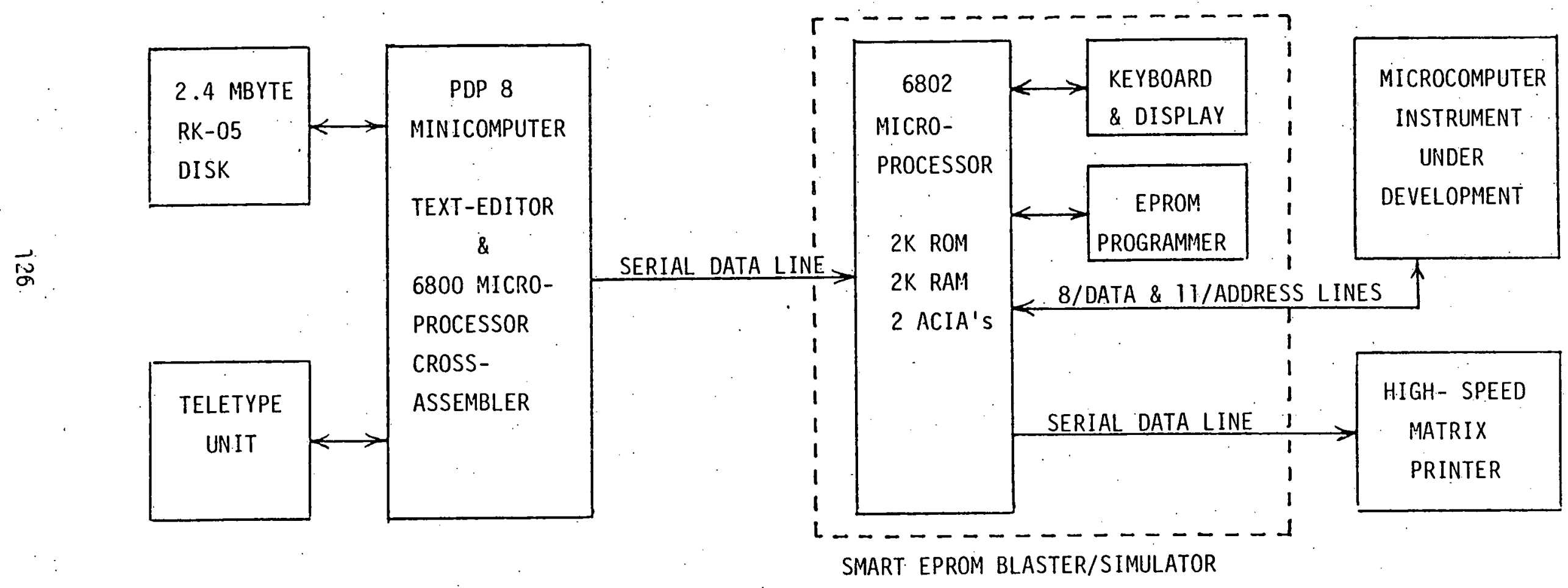

FIG. 35 


\subsubsection{SUMMARY EVALUATION OF PC 4200 TOMOGRAPHIC CAMERA.}

\section{OBJECTIVE}

To carry out a clinical evaluation of the Model 4200 Positron Camera. Tomograph, and to perform clinical and animal in vivo biochemistry and physiology, research studies, and instrumentation development integrated into our current research program which also provides critical evaluation information for the Model $4200 \mathrm{PC} \cdot \mathrm{T}$.

\section{SCOPE OF INVESTIGATION}

1. Clinical evaluation and research studies:

a. ${ }^{18} \mathrm{~F}$ Sodium fluoride: The extent to which tomographic iamges enhanced routine bone imaging with $\mathrm{Na} 78 \mathrm{~F}$. was investigated in a series of patient studies. A report of this work follows this section.

b. 11.C-Carbon monoxide: A number of patient studies were initiated to investigate the capability of the PC.T 4200 in various body regions; e.g., head, thorax, and limbs, for quantitative 2-and 3-dimensional static and 2dimensional dynamic imaging procedures. The general clinical purposes of these studies include patient selection for chemical therapy (amount of circulating hemoglobin as a selection parameter) and for detection of tumor recurrence by means of serial studies in which changes in tissue vascularity are noted. These studies are supported in part by a grant from the National Heart, Lung and Blood Institute (ROI HL22371, Principal Investigator: Dr. Rodney E. Bigler).

c. ${ }^{13} \mathrm{~N}$-L-Glutamate: Patient and human volunteers were studied to evaluate the normal and tumor-modified distribution of this agent. Of particular interest is myocardial and pancreatic uptake which can be simultaneously studied using the multiple slice ( 23 covering $33.6 \mathrm{~cm}$ of $z$ axis) capability of the PC.T 4200 . evaluation purposed.

d. ${ }^{13} \mathrm{~N}$-Ammonia: A human volunteer was planned for instrument

2. Animal Research:

a. ${ }^{38}$ K-Potassium chloride: A substantial effort was planned to evaluate the imaging and distribtution characteristics of potassium chioride labeled with $38_{\mathrm{K}}\left(\mathrm{T}_{\frac{1}{2}}=7.6 \mathrm{~min}\right.$.). Of particular interest is its value for evaluating kideny function in the camera dynamic imaging mode, the heart transaxial tomographic images obtained from 3 to 18 minutes after IV administration, and the early images and kinetics in a variety of tumors.

b. ${ }^{11}$ C-AIB: Carbon-11 labeled alpha-aminoisobutyric acid has been synthesized for the first time (see Sect. 2 .1.1) and a series of imaging studies initiated in dogs bearing spontaneous tumors. This agent has potential for imaging primary and metastatic brain tumors due to a blood-brain barrier restriction of AIB into normal brain $(1-3)$. In regions where the blood-brain barrier is broken down, viable cells, including normal brain cells, accumulate and concentrate AIB. The agents curretnly used in Nuclear Medicine for brain 
scans, e.g., ${ }^{99 m}$ Tc-pertectnetate, do not enter cells once having passed the bloodbrain barrier. The additional distribution space provided by cell entry and concentration, should provide extremely high brain to tumor activity concentration ratios. The ratio expected from $14 \mathrm{C}$-autoradiographic studies in mice will likely result in brain imaging with this agent becoming the method of choice for early detection of brain tumors.

AIB is transported with the general characteristics of a small neutral amino acid (e.g., glycine, alanine, serine and proline) and therefore we expect it will be found of utility for in vivo studies of amino acid transport. The special transport characteristics into tumors may prove useful for diagnosis, and further changes brought about by means of chemical therapies may prove useful as monitors for the effects of therapy upon tumors and normal tissues. The nonmetabolized characteristic of this agent will aid in the understanding of its in vivo distribution.

c. $H^{11} \mathrm{CN}$ : Carbon-11 labeled hydrogen cyanide is being used to investigate its potential as a tumor localizing agent. It has been reported that $\mathrm{H}^{\mathrm{T}} \mathrm{CN}$ may reflect gradients of oxygen consumption and energy expenditure in various physiological states, as well as in deviations induced by disease or drugs, and thus may be useful in assessing tumor metabolism.

d. ${ }^{15} 0$ Steady-state inhalation of $\mathrm{O}_{2}, \mathrm{CO}_{2}$ and $\mathrm{CO}$ : The value of serial studies of circulating red cells $(15 \mathrm{CO})$, rapidly exchangeable water space $\left(1 \mathrm{O}_{2} \rightarrow \mathrm{H}_{2} 15_{0}\right)$, and molecular oxygen consumption $\left(150_{2}\right)$ through and subsequent to radiation therapy treatment is being investigated in order to evaluate it as a monitor of the effectiveness of the therapy. These studied also provide a particularly good opportunity for an in vivo demonstration of the quantitative capability of the Model 4200.

e. ${ }^{18}$ F-Haloperidol: Because changes in the concentration of receptors are known to be brought about by disease in some in vivo receptor systems we feel an agent known to bind to dopamine receptors may be valuable for study of receptor alterations associated with brain functions including control of movement, autonomic function and mental and emotional status. A first step in this direction was to carry out a dynamic and transaxial study with this agent in a dog to. test various aspects of the feasibility of such studies in humans.

Progress toward the preparation of haloperidol, spiroperidol, and other compounds in the butyrophenone series of sufficiently high specific activity for the in vivo measurement of high affinity receptors is given in Section 2.3.2.

\section{Instrumentation Investigation:}

We were concerned with the capability of the PC.T 4200 to produce quantitative images of the distribution of a positron-emitting radionuclide when in-coincidence gamma-rays other than the back-to-back 0.511 MeV positron annihilation gammas were emitted during the decay. Potassium-38 decays by $100 \%$ psoitron emission with a $99.8 \% 2.168 \mathrm{MeV}$ gamma-ray in coincidence. Two kinds of backgrounds would be provided by the high energy gamma-ray:

a. True coincidence events not properly located, one $0.511 \mathrm{MeV}$ and one $2.2 \mathrm{MeV}$ gamma ray interactions providing the coincident events, similar to scatter events observed as a background in the usual operation of positron 
coincidence imaging instrumentation;

b. Events produced by detection of annihilation radiation derived from positron-electron pair production by the high energy gamma-ray in its interaction with the object being imaged as well as the shielding materials which are part of the positron imaging system.

\section{RESULTS AND CONCLUSIONS}

The number and a brief description of the studies carried out using the Model 4200 Positron Camera. Tomograph are presented in Table 27. There were 49 patient studies, 35 animal studies, 7 instrument evaluation, and 1 gas transfer system test study carried out for a total of 86 multiple image studies. Most studies included one transaxial tomographic measurement which provided 23 slice images and a variety of dynamic focal plane tomographic camera images of the isotope distribution within the subject:

1. Clinical evaluation and research studies:

a. ${ }^{18}$ F-Sodium fluoride: The results of a 29 patient clinical evaluation study are presented in the next section.

b. ${ }^{11}$ C-Carbon monoxide: The tomograph protion of this study has included 1 dog, 1 human volunteer and 12 patients. All results achieved so far are very preliminary. A head study where the patient had a tumor previously subjected to a variety of therap ies was imaged before and after antifibrinogen treatment to see if the treatment improved the vascular volume of the tumor. There was no evidence of any vascular volume improvement provided by the treatment. An interesting result of the study was that the tumor displaced the carotid artery and jugular vein. The relocation and narrowing of the artery and vein were readily observable and gave a quantitative measurement of the degree of stenosis $(50 \%)$. This study suggests a simple and noninvasive test which can be used to evaluate major vein and artery stenosis brought about by disease processes, e.g., phlebitis and atherosclerosis.

One untreated osteogenic sarcoma showed a high blood volume compared to the contralateral region in the opposite leg. An extrapulmonary tumor within the thorax showed a very small tumor blood volume and greatly enhanced blood volume in the lung on the same side as the tumor. The reduced blood volume may be an effect of the chemical therapy upon the relatively undeveloped tumor vascular system. A series of patients exhibiting a variety of responses to therapy will be needed in order to show the diagnostic merits of serial tumor vascular volume measurements.

Our study of the response of lung tissue to a radiation therapy protocol, designed to produce lung fibrosis, is in progress. A considerable period of followup and a more extensive patient group will be required in order to determine its usefulness. A more complete report of the current status of this study, including the two-dimensional quantitative HEG imaging studies, is contained within the 1980 Proposal for this contract. 
c. ${ }^{13} \mathrm{~N}-\mathrm{L}-\mathrm{G}$ Tutamate: We have carried out three normal volunteer and three patient studies with $13 \mathrm{~N}-\mathrm{L}$-glutamate where the heart and pancreas were observed. Both 2-dimensional focal plane and 3-dimensional transaxial tomographic studies produced fine quality images of the heart and pancreas. There is insufficient data to determine the value of these scans for disease of the pancreas. This will be an important goal of our continuing studies. Figure 36 shows a focal plane image of one of our volunteer subjects. Figure 37 shows a transaxial tomographic slice through the head of the pancreas and Figure 38 shows a slice through the heart.

2. Animal research:

a. ${ }^{38}$ K-Potassium chloride: Five dogs and two rhesus monkey tomographic and dynamic studies were carried out using $38 \mathrm{KCl}$ to evaluate its value as an imaging agent for the heart. An abstract covering this work was accepted for presentation at the most recent American Society of Therapeutic Radiologists Annual Meeting (4), and a paper covering this material is in preparation.

In one rehsus monkey dynamic study it was possible to observe within the same series of images the bolus injection of $38 \mathrm{KCl}$ in an arm vein, the appearance of the bolus in the heart, the lungs, and the subsequent appearance in kidneys and bladder. Within a few minutes a functional image of the kidneys and ureters was obtained. The possibility that this may prove of clinical utility will be explored further.

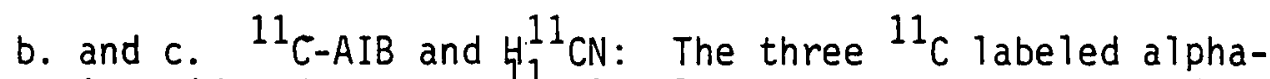
aminoisobutyric acid and the two ${ }^{1} \mathrm{C}_{1}$ jabeled hydrogen cyanide studies are reported in Section 1.1.2." The 11 -AIB work has been accepted for presentation at the forthcoming annual meeting of the Radiological Society of North America (5).

d. ${ }^{15} 0$ steady-state tumor studies: Two dogs, one with fipfosarcoma and one with hemangiopericytoma, were imaged using the steady-state ${ }^{15} 0$ technique. Af each 15 ession images were obtained when continuous inhalation of the gases ${ }^{15} \mathrm{O}_{2},{ }^{15} \mathrm{CO}_{2}$ and $\mathrm{C}^{15}$ resulted in a static, steady-state distribution within the body. Two sets of three images were obtained for the dog with fibrosarcoma, with a 100 rad single fraction of radiation being administered immediately after the first set of studies. The second set of studies was done one week later. This tumor showed low uptake of the tracers indicating a small blood volume, tissue water volume space and rate of oxygen metabolism. Analys is of this study is in progress.

The dog with hemangiopericytoma has tumor located of the metatarsus of the left foot. It was selected as potentially curable by ${ }^{60}$ co radiation treatment and thus given six fractions of 700 rads each at a rate of two per week, Monday and Firday. Steady-state imaging studies were carried out pretherapy, at one week (before the 3rd fraction) and at two weeks (before the 5 th fraction). The next imaging study is scheduled for August 27 and additional studies will be scheduled according to the condition of the tumor. Hopefully, the study will progress to the point of total tumor destruction. The tomographic slices proximal to the tumor show quantatively the excess. vascular supply, compared to the normal leg. Figure 39 shows a typical focal plane image of the dog's hind legs with the tumor bearing leg at the top, the normal leg at the bottom and the animal's body $t_{9}$ the left of the image. The image is of the steady-state distribution of $\mathrm{H}_{3}{ }^{{ }^{2}}{ }_{0}$ taken at two weeks following initiation of treatment and after four 760 rad fractions. Data 
taking and analysis of this study are in progress.

e. ${ }^{18} \mathrm{~F}-\mathrm{Haloperidol:}$ There is currently considerable interest in the possibility of measuring the number and distribution of neurotransmitter receptors in the brains of humans by a noninvasive and low hazard method. According to a model by Snyder and co-workers haloperidol binds selectively to the antagonist state and dopamine to the agonist state of the same receptors. We have synthesized haloperidol labeled with fluorine-18 by a Schiemann type reaction in sufficient quantity $(0.2 \mathrm{mCi})$ and specific activity $(0.8 \mathrm{mCi} / \mathrm{mg})$ to carry out a focal plane and transaxial tomographic measurements of its biological distribution in the head of ahealthy dog, using the PC.T4200. The camera mode was used to observe the dynamics of uptake during the first 70 minutes after IV administration of the labeled haloperidol. High uptakes were observed for the brain and salivary glands that reached a. plateau in under one minute. Twenty-three tranxaxial tomographic slice images one cm FWHM thick and spaced at $1.4 \mathrm{~cm}$ were taken, which verified the presence of activity within the brain and salivary gland regions. According to our estimates based upon mouse brain data of Hollt et al. (6), it will be necessary to develop synthesis for this compound where in the specific activity is improved to at least $30 \mathrm{mCi} / \mathrm{mg}$ in order to attempt dopamine receptor measurements in humans. These studies are in progress. An abstract of this work was submitted and accepted for presentation at the forthcoming annual meeting of the Radiological Society of North America (7).

\section{Instrumentation Investigation:}

A series of measurements have been carried out to evaluate flo comparative quantitative characteristics of a pure positron emitter ( ${ }^{18} \mathrm{~F}$ ) and one that emits in addition a high ${ }^{2}$ nergy gamma-ray in coincidence with the positron annihilation radiation $\left({ }^{3}\right)$. Three phantom arrangements were compared: first, a line phantom for resolution and uniformity measurements; second, a ratio phantom in which activities in measured amounts in approximate ratios of 10:5:4:3:1 were placed in a $2.6 \mathrm{~cm}$ diameter cylinders within a 20 $\mathrm{cm}$ diameter lucite cylinder; and a third phantom, designed to approximate the situation of high heart uptake within the body. A bottle containing $\mathrm{Na}{ }^{18} \mathrm{~F}$ and then ${ }^{38} \mathrm{KCl}$ in water solution was placed within a $35 \times 35 \times 20 \mathrm{~cm}$ rectangular water filled tank. In thebeart phantom $18 \%$ greater coincidence counts were observed for ${ }^{38} \mathrm{~K}$ than for ${ }^{18} \mathrm{~F}$. In the region of the phantom outside (with a $2 \mathrm{~cm}$ margin) the heart activity, a $260 \%$ increase in the average background was observed. The resolution degregation abserved in the i ine phantom was $14 \%$. This is shown in Figure 40 for ${ }^{18} F$ and ${ }^{38} K$ in a $20 \mathrm{~cm}$ diameter lucite phantom. The results of the above described measurements are currently being prepared for inclusion in a presentation and a manuscript to be submitted at the time of the presentation to the American society of Therapeutic Radiologists in Atlanta, October 23-28, 1979 (4).

A study designed to investigate the physical imaging characteristics of a Baird Atomic System Seventy-Seven for dynamic and statis imaging of the distribution of positron-emitting radionuclides and labeled compounds in humans was carried out with the collaboration of Dr. S. Cochavi, Dr. S. Goidsmith and Mr. A.M. Strashun of the Mt. Sinai Medical center, New York. Resolution was evaluated by imaging a three line source in the 16 step mode at $1,6,11$, and $16 \mathrm{~cm}$ from the collimator surface using a 235-670 keV window (see Fig. 41). Full-width-half-maximum of line spread function response was $5,8,14$, and $18 \mathrm{~mm}$, respectively. The sensitivity was $1800 \mathrm{cps}$ per $\mathrm{mCi}$; maximum count rate caparility was 200,000 cps (see Fig.42). A thyroid phantom filled with $2 \mathrm{mCi}$ of ${ }^{18} \mathrm{~F}$ clearly showed a cold nodule of $6 \mathrm{~mm}$ in diameter; also larger hot and cold spots and variations in thickness activity were observed. Preliminary results of bone imaging of a rabbit and patients present high quality images. 
Bone images of ${ }^{18} \mathrm{~F}$ were taken also with a conventional scanner and the $P C \cdot T-4200$ for comparison purposes. The results of this study were presented at the most recent meeting of the American Association of Physicists in Medicine (8). 
TABLE 27

Studies Aided by the Model 4200

Positron Camera Tomograph

\begin{tabular}{|c|c|c|}
\hline ISOTOPE & PURPOSE & NUMBEF \\
\hline $\mathrm{Na}{ }^{18} \mathrm{~F}$ & Patient evaluation & 29 \\
\hline \multirow{4}{*}{${ }^{11} \mathrm{CO}$} & Instrumentation evaluation & 4 \\
\hline & Patient treatment evaluation & 13 \\
\hline & Animal distribution & 1 \\
\hline & Gas Transfer System Test & 1 \\
\hline${ }^{13} \mathrm{~N}$-glutamate & Patient evaluation & 6 \\
\hline \multirow[t]{2}{*}{${ }^{38} \mathrm{KCl}$} & Animal distribution & 7 \\
\hline & Instrument evaluation & 3 \\
\hline $18 \mathrm{~F}$-haloperidol & Animal distribution & 1 \\
\hline${ }^{15} \mathrm{O}_{2}$ & Therapy evaluation (Animal) & 5 \\
\hline $\mathrm{C}^{15} \mathrm{O}_{2}$ & Therapy evaluation (Animal) & 5 \\
\hline$c^{15} 0$ & Therapy evaluation (Animal) & 5 \\
\hline $\mathrm{H}^{11} \mathrm{CN}$ & Animal distribution w/tumor & 2 \\
\hline${ }^{11}$ C-AIB & Animal distribution w/tumior & 3 \\
\hline${ }^{13} \mathrm{NH}_{4}$ & Patient evaluation & $\frac{1}{86}$ \\
\hline
\end{tabular}

TOTAL 
36. Focal plane image of the distribution of $13_{N-L}-g l$ tamate in a heal thy human subject showing the heart (upper right), the paricreas (lower right) and the liver (left).

37. Transaxial tomographic slice image of the head. of the pancreas seen in a healthy human subject.

38. Transaxial tomographic slice image through the heart (left) and liver (right). The left ventrical shows prominently.

39. Focal plane image of the hind. legs of a dog with a hemangiopericytama on the metatarsus of one foot (top). This image shows the steagy-state distribution of $\mathrm{H}_{2}{ }^{15} \mathrm{O}$ at two weeks following initiation of ca radiotherapy treatment (after four 700 rad fractions).

40. Comparative line spread functions for ${ }^{18} F$ and ${ }^{38} K$ using the PC.T 4200 Positron Tomograph.

41. (given on graph) ${ }^{18} \mathrm{~F}-1$ ine source study-resolution vs. distance $4 \mathrm{~cm}$ line spacing. .

42. Positron activity vs. count rate observed for the Baird Atomic System Seventy-Seven imaging instrument. The systemis shown linear to above $100,000 \mathrm{cps}$. 


$$
\beta^{0}
$$


$\delta$ 


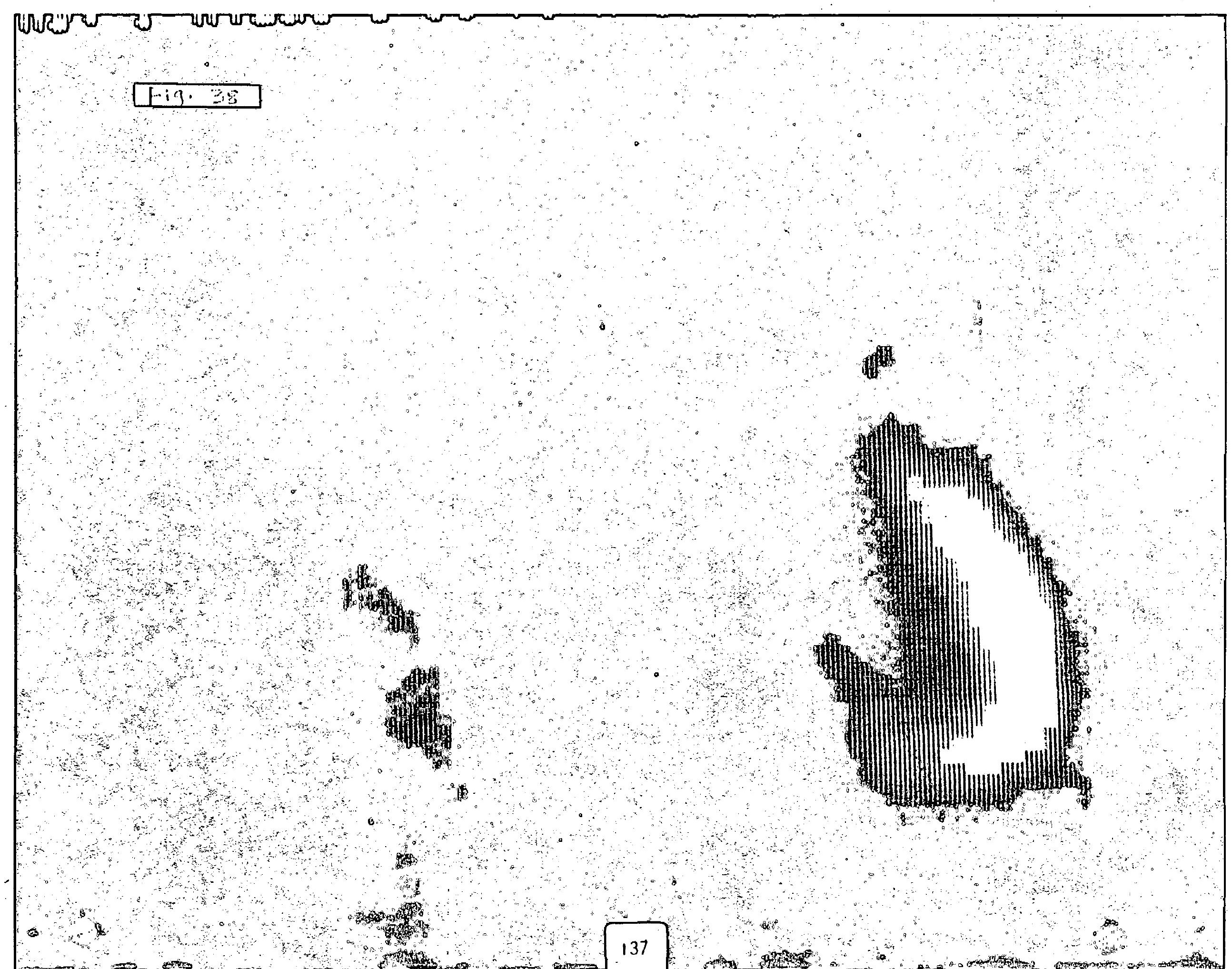




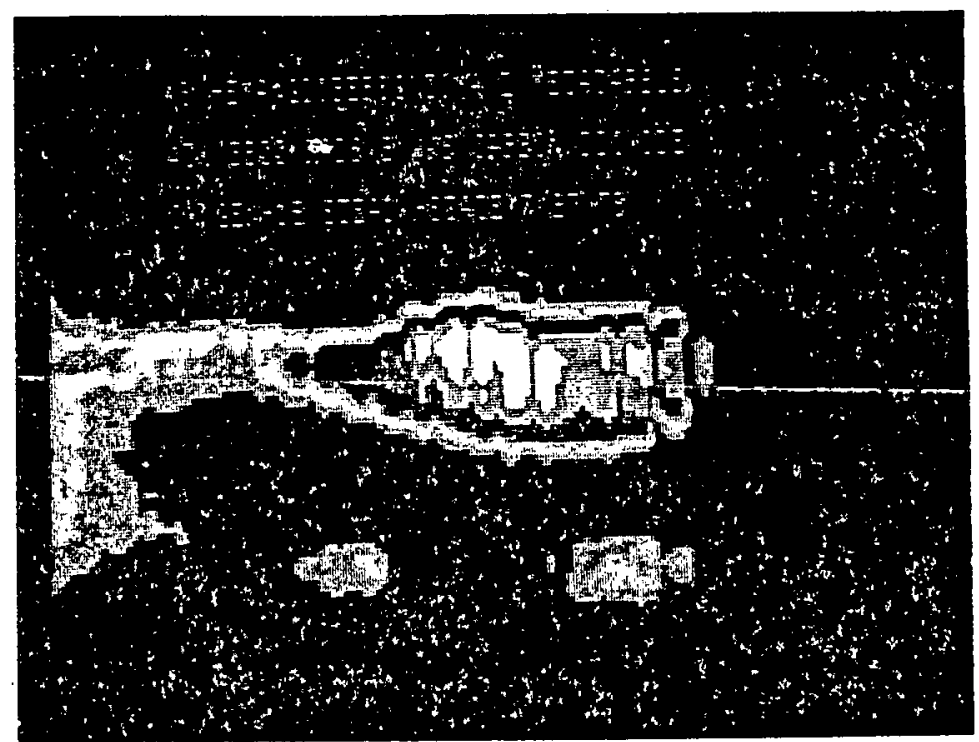

FIGURE 39 


\section{$18_{F^{-}}$LINE SOURCE STUDY}

RESOLUTION vS. DISTANCE

4 cm LINE SPACING

$\mathrm{d}=1 \mathrm{~cm}$.

$R=5 m m$

$\mathrm{d}=6 \mathrm{~cm}$

$R=8 \mathrm{~mm}$

$\mathrm{d}=11 \mathrm{~cm}$

$R=14 \mathrm{~mm}$
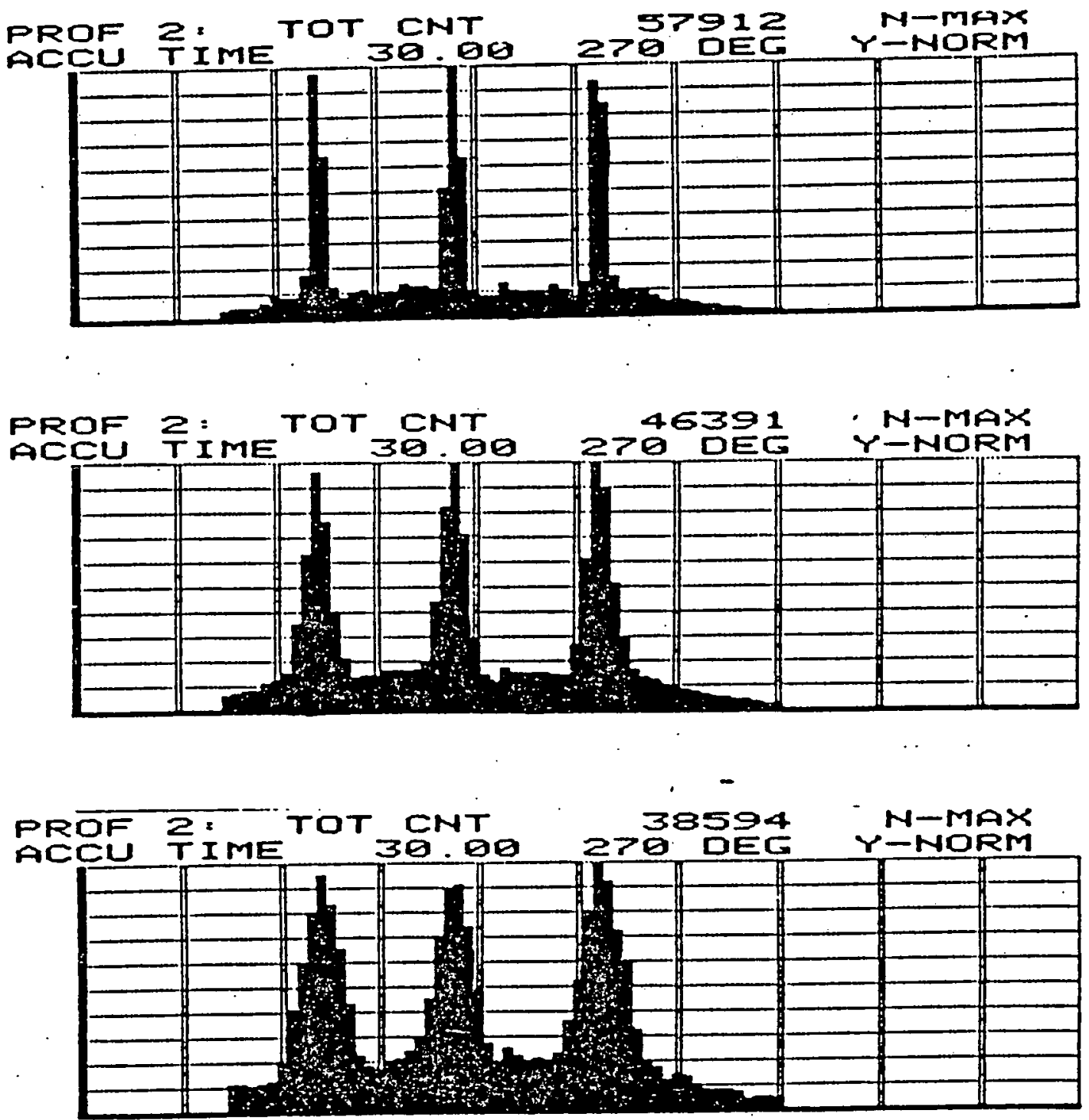

$d^{\circ}=16 \mathrm{~cm}$

$R=18 \mathrm{~mm}$.

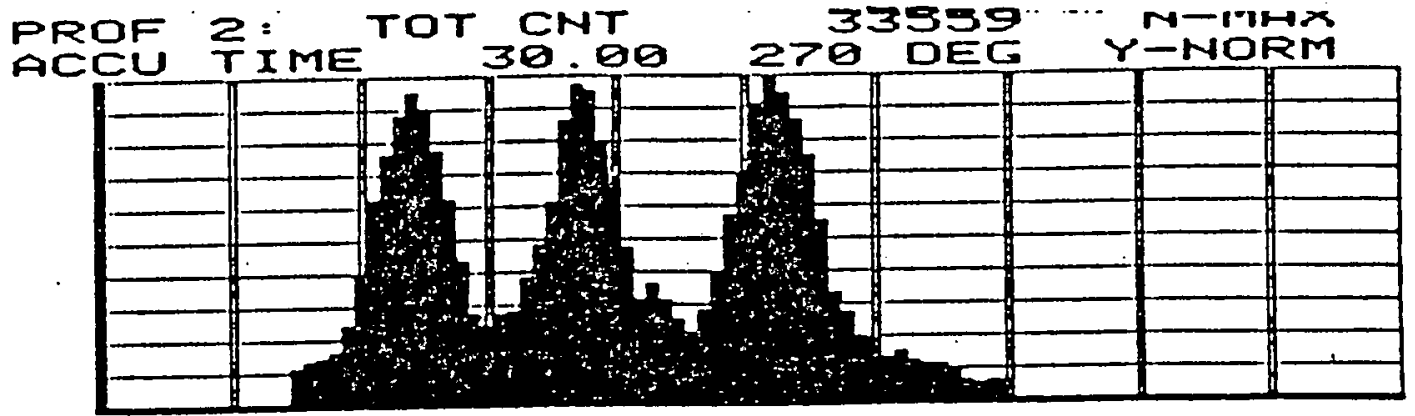

FIbURt 41 


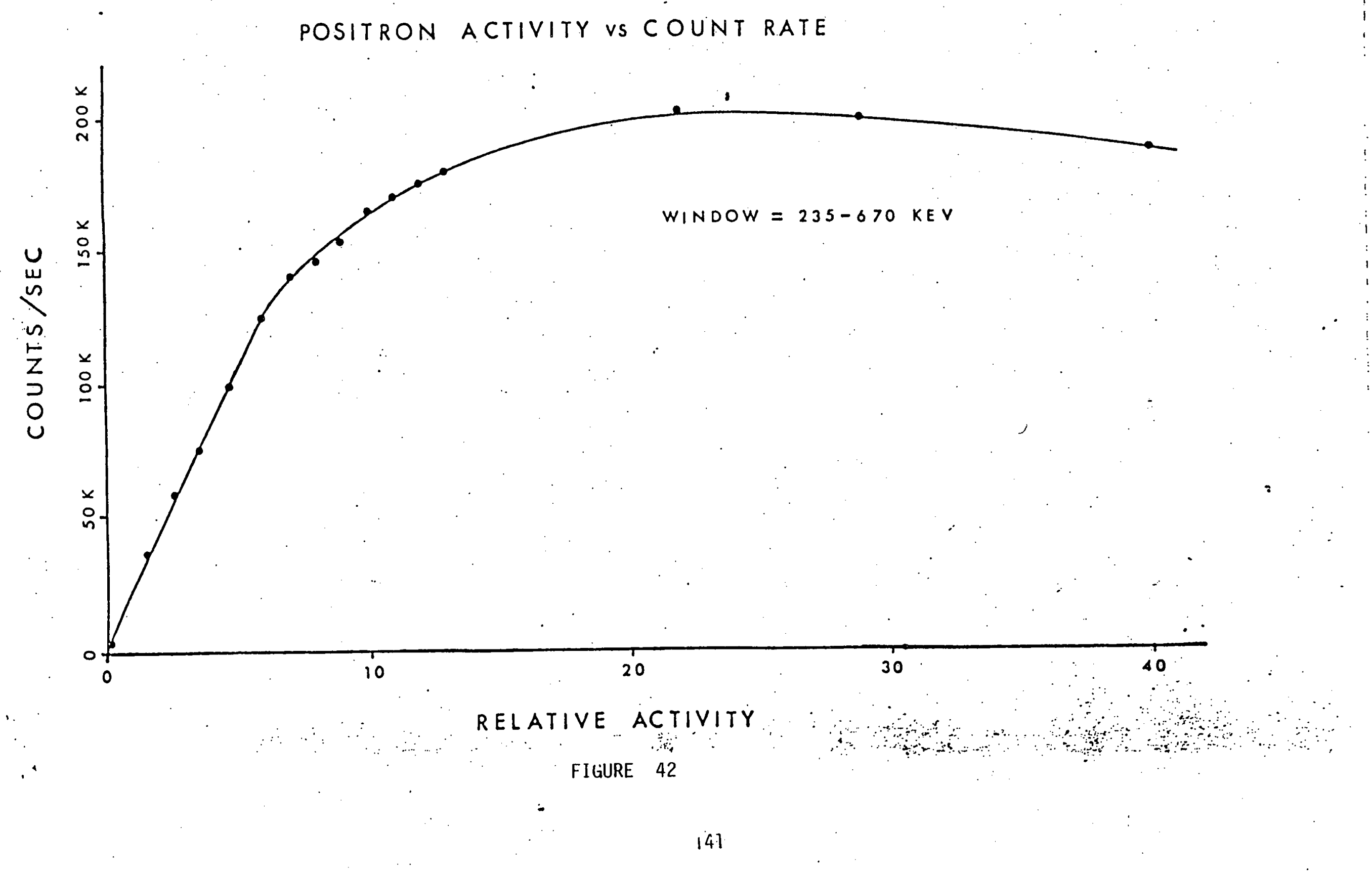




\section{REFERENCES}

1. 0ldendorf, W.H. Brain uptake of radiolabeled amini acids, amines and hexoses after arterial injection. Am. J. Physiol. 221; 1629-1639, 1971 .

2. Bl asberg, R., Patlak, O.C.A., Jehle, J.W., and Fenstermacker, J.D. An autoradiographic technique to measure the permeability of normal and abnormal brain capillaries. Neurology 23; 363, 1978.

3. Blasberg, R., Patlak, C., Shapiro, W. and Fenstemacher, J. Metastatic brain tumors: Local blood flow and capillary permeability. Neurology 29; 547, 1979.

4. Myers, W.G., Bigler, R.E. and Graham, M.C. Studies on the distribution of potassium-38 in vivo by means of positron-electron transmutation tomogrraphy. American Society of Therapeutic Radiologists, 21st Annual Meeting, New Orleans, Oct. 23-28, 1979.

5. Bigler, R.E., Schmal 1, B, Andrews, L.K. and Kostick, J.A. Lymphosarcoma uptake of ${ }^{11} \mathrm{C}$-al pha-aminoi sobutyric acid. The Radiological Society of North America, 65th Scientific Assembly and Annual Meeting, Nov. 25-30, 1979.

6. Hollt, V., Czlonkowski, A. and Herz, A. The demonstration in vivo of specific binding sites for neuroleptic drugs in mouse brain. Brain Research 130:176-183, 1977.

7. Bigler, R.E. and Schmall, B. Positrongelectron transmutation (PET) tomography. with the neuroleptic drug ${ }^{8} F$-haloperidol. The Radiological Society of North America, 65 th Scientific Assembly and Annual Meeting, Atlanta, Nov. 25-30, 1979.

8. Cochavi, S. Strashun, A.M., Goldsmith, S.J., Bigler, R.E. and Benua, R.S. Planar imaging of positron emitting radionuclides (PIPER) with a multi-crystal camera. American Association of Physicists in Medicine, Twenty-first Annual Meeting, New Orleans, Oct. 23-28, 1979. 


\subsubsection{TOMOGRAPHIC BONE SCANS WITH F-18}

\section{OBJECTIVE}

The purpose of this study is to evaluate the usefulness of PC.T4200 Positron Camera. Tomograph in detecting bony involvement with F-18 sodium fluoride.

\section{SCOPE OF INVESTIGATION}

A commercial version of the Positron Camera II developed at the Massachusetts General Hospital recently became available to us. As part of our evaluation of this new tomographic camera, we decided to image selected bone lesions of the thorax or pelvis during our routine F-18 bone scanning. A dose of $12 \mathrm{mCi}$ of $\mathrm{F}-18$ sodium fluoride was given for $65 \mathrm{~kg}$ patients. Images were obtained one hour after injection. Comparison was made with other radiographic or radionuclide studies.

Totally, 31 studies were made in 11 patients suffering from osteogenic sarcoma, 6 patients with carcinoma of the breast, 4 patients with carcinoma of the prostate, and 10 with other diagnoses. Fourteen examinations were made of the thorax, 16 studies were made of the pelvis and one study was limited to the lower extremity. Reconstruction was not possible in three studies, nine studies were definitely superior, 11 were helpful or confirmatory, only eight studies were not helpful.

\section{RESULTS AND CONCLUSIONS}

In conclusion, tomographic bone scans can provide additional information about bony involvement in primary and secondary bone tumors. It is useful in determining the precise location of the intrathoracic and pelvic lesions. 
4.5 REVIEW OF POSITRON COMPUTED TRANSAXIAL TOMOGRAPHIC INSTRUMENTS

\section{OBJECTIVE}

The objective of this section is to review the design details for two commercially available proposed positron-emission transmutation (PET) tomographic designs: : ORTEC ECAT with a multi-slice option, and The Cyclotron Corporation $P C \cdot T 4500$.

\section{SCOPE OF INVESTIGATION}

Both proposed instruments are multiple-slice imaging units and can be used for any body region. Two other companies have expressed to us their interest in designing and building total-body units according to our needs, but at the moment only have advanced designs. for neurology units available. These companies are Scanditronix in Uppsala, Sweden and Atomic Energy of Canada Limited (AECL). our continuing review of available total-body tomographs will include a close analys is of all available comercial units as well as continuing analysis of the design characteristics of units built and developed by various non-commercial laboratories (e.g. Donner Labs, U.C. Berkeley; Montreal Neurological Institute; and Washington University, St. Louis).

ORTEC has been manufacturing nuclear instrumentation modules and systems for over 20 years. Their experience in analyzing state-of-the-art electronics for nuclear research is extensive. As a basis for the ECAT, ORTEC started by using a proven PETT III design developed by the St. Louis group. They upgraded the computer configuration to a standard well-defined multi-user system, upgraded the mechanical design, and developed a standard modular electronic package. The proposed multislice ECAT will consist of one additional plane of detectors using the same basic electronic hardware, computer configuration, and software as the single slice version. The additional detector plane will enable the reconstruction of three slices, the center slice of which includes cross coincidences between detector planes. Projected resolution specifications of this device are essentially those of the single slice device.

The basis for the first Cyclotron Corporation positron camera tomograph was the prototype PC II developed by Dr. Gordon Brownell at the Massachusetts General Hospital. The PC 4200 uses the original PC II design with improvements and modifications in the mechanical design of the gantry, the electronic hardware, and the computer system (the PC 4200 is currently on loan to MSKCC for evaluation and testing). The PC 4500 proposed design as currently designated consists of four circular planes of 128 detectors each. The computer central processor will be a Digital Equipment Corporation (DEC) model PDP 11/60 with 67 Mbyte disk and an array processor for rapid image reconstruction.

\section{RESULTS AND CONCLUSIONS}

The comparative technical specifications of the two currently available total-body transaxial computer tomographic instruments are summarized in Table 28. 
SUMMARY OF CURRENTLY AVAILABLE POSITRON TOMOGRAPH SPECIFICATIONS

SPECIFICATION

ORTEC: MULTISLICE ECAT II

(measured specifications)

Number and arrangement of scintillation detectors

Crystal dimensions

Intercrystal spacing

Interplane shielding

Number of planes along $z$ axis

Provisions for changing shielding configuration

Field of view

Patient opening

Detector motion

Angular measurements
Two banks of $66 \mathrm{NaI}(\mathrm{Tl})$ detectors arranged hexagonally

Each crystal cylindrical, $3.8 \mathrm{~cm}$ wide $\times 7.5 \mathrm{~cm}$ deep

Crystals are $45.7 \mathrm{~mm}$ apart center to center, therefore $7.6 \mathrm{~mm}$ separate adjacent crystals

1.5 inch of lead outside of planes with a lead septum used to separate planes

Three slices will be imaged simultaneously

Shadow shields, which define the spatial resolution are changeable

$50 \mathrm{~cm}$ field of view, with detector faces $100 \mathrm{~cm}$ apart

$50 \mathrm{~cm}$ patient opening

Detector bänks translate in 8 steps of $0.57 \mathrm{~cm}$ or 4 steps of $1.14 \mathrm{~cm}$ and rotate in $5^{\circ}$, or $10^{\circ}$ steps

Angular samplings are made in $2.5^{\circ}$ segments
CYCLOTRON CORPORATION: PC 4500 (design specifications)

Four rings of 128 Bismuth Germanate crystal detectors

Unspecified

$2.2 \mathrm{~cm}$ center to center

$6 \mathrm{~mm}$ thick $\times 19 \mathrm{~cm}$ deep lead septa $2.5 \mathrm{~cm}$. lead collars, front \& back.

Four straight across, 3 cross plane, total

Shielding could be optimized for head only, or head and body applications

$43 \mathrm{~cm}$ diameter without "wobble", 45 with "wobble"

$50 \mathrm{~cm}$ wide $\times 40 \mathrm{~cm}$ high

16 point wobble on $20 \mathrm{~mm}$ diameter circle; rotation; $z$ axis sampling by computer control couch motion

Fully programmable 
Minimum time required for complete scan

Resolution characteristics (in the plane)

Sensitivity characteristics

$Z$ axis resolution

Count rate capability
10 seconds live time (minimum)

$17.0+1.0 \mathrm{~mm}$ without shadow shields

$13.5 \mp 7.0 \mathrm{~mm}$ with standard shadow shield

$11.0+1.5 \mathrm{~mm}$ with high resolution shadow shields

Slices number 1 and 2 have efficiency of $>8,000 \mathrm{c} / \mathrm{sec} / \mu \mathrm{Ci} / \mathrm{ml}$ a $\mathrm{High} \mathrm{re}$ solution shields; $>12,500 \mathrm{c} / \mathrm{sec} / \mu \mathrm{Ci}$ $\mathrm{m} 1$ a medium resolution shields; $>25,000 \mathrm{c} / \mathrm{sec} / \mu \mathrm{Ci} / \mathrm{ml}$ o Shields removed.

Center projected to have

approximately 1.7 times these efficiencies

Without shadow shields, $18,5 \mathrm{~mm} \pm 1.0$

Standard shadow shields, $19.5 \mathrm{~mm}+1.0$

High resolution shadow shields; $20.5 \mathrm{~mm}+1.0$

The measured nonuniformity of slice thickness across the transaxial plance is $\leq 1.0 \mathrm{~mm}$.

Measured $90,000 \mathrm{cts} / \mathrm{sec}$ where $24 \%$ are randoms for one straight across silice at low resolution with $2-3 / 4 \mu \mathrm{Ci} / \mathrm{cm}^{3}$. a. Full sampling, $1 \mathrm{~cm}$ FWHM, $30 \mathrm{sec}$.

b. "on the fly", $1.4 \mathrm{~cm}$ FWHM, $5 \mathrm{sec}$.

c. rotate only, $1.1 \mathrm{~cm}, 1 \mathrm{sec}$.

d. stationary cross plane only, $2.2 \mathrm{~cm}$, $0.25 \mathrm{sec}$.

High resolution: $1.0 \mathrm{~cm}$ FWHM on axis, increasing to $1.5 \mathrm{~cm}$ FWHM at $22.5 \mathrm{~cm}$ radius.

Medium resolution: $1.4 \mathrm{~cm}$ FWHM on axis, increasing to $1.9 \mathrm{~cm}$ FWHM at $28.5 \mathrm{~cm}$

radius. $16,000 \mathrm{CPS} / \mu \mathrm{Ci} / \mathrm{cm}^{3}$ (straight across plane) $22,000 \mathrm{CPS} / \mu \mathrm{Ci} / \mathrm{cm}^{3}$ (cross plane)

/ $1.3 \times 10^{5} \mathrm{CPS} / \mu \mathrm{Ci} / \mathrm{cm}^{3}$ (total system) with $20 \mathrm{~cm}$ diameter water filled phantom

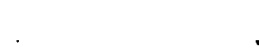


Resolution in 2 dimensional rectilinear mode

Coincidence time resolution

Random coincidence correction

Type of discriminator

Computer manufacturer/model No.

Special processor

Memory

Mass Memory

Price (Estimate)

Delivery Time (Estimate)
ORTEC: MULTISLICE ECAT II

With standard shields and high

resolution reconstruction approximately $15 \mathrm{~mm}$, other choices at user's option

\section{$2=12.5$ nanoseconds}

Three modes, operator electable:

A) Increment totals, ignore randoms.

B) Increment totals, decrement randsom

C) Increment totals, route randoms to separate memory

Constrant fraction

DEC PDP $11 / 60$, RSX-11M

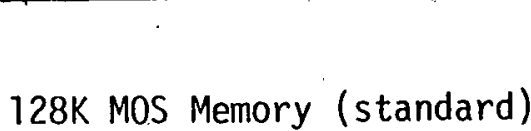

$\$ 650,000$ F.0.B. Oak Ridge, Tenn.

9-11 Months AR0
CYCLOTRON CORPORATION: PC 4500

$1 \mathrm{~cm}$ FWHM

25 nanosec timing

Singles counting and delayed coincidence decrement

Leading edge type with built-in noise rejection

DEC PDP $11 / 60$, RSX-11M

Array processor for rapid C.T. reconstruction

$128 \mathrm{~K}$ bytes MOS memory $67 M$ byte drive and controller for data acquisition

TJE 169 track magnetic tape \& controller

$\$ 1,200,000$

1 Year ARO 
5. RADIOACTIVE MATERIAL TRANSFER SYSTEM

OBJECTIVE

To provide rapid, reliable transport of cyclotron produced radioactive materials to three remote clinical sites.

\section{SCOPE OF INVESTIGATION}

As originally built in 1967, the SKI Cyclotron facility could deliver radioactive gases to the scanning facility on the floor above and 150 feet laterally distant from the cyclotron. Labeled material in liquid form, such as injectable solutions, had to be hand carried to the place of use. Planned clinical investigations and the loan by the Cyclotron Corporation of a PC 4200 Positron Camera Tomograph for installation in the Memorial Hospital Nuclear Medicine Service required a system for rapid delivery of short-lived positron emitting radioisotopes.

A radioactive materials transfer system (RMTS) was designed to transport radioisotope preparations in solid, liquid or gaseous form from the cyclotron to the scanning facility at the cellar level of Kettering Laboratory to the Diagnostic Radiology Suite on the second floor of the Clinical Office Building and to the Nuclear Medicine Suite on the second floor of Howard Laboratory. The last two locations are on the opposite side of East 68th Street from the Kettering Laboratory where the cyclotron is located. A tunnel under East 68th Street connects Kettering Laboratory to the Clinical office Building. The RM S consists of two major units, the gas transfer tube (GTT) and the pneumatic transfer system ( $P$-Tube). A Drawing (figure 43 ) shows the location of the areas involved and the route of the RMTS. The GTT connects to the radioactive gas processing system in the cyclotron "Hot Lab" and is led up to the cellar level of the Kettering Lab where it branches to the SKI scanning facility. Paralleling the route of the P-tube, the GTT passes through the tunnel under 68th Street to a shaft rising to the second floor. A branch is led into the neuro-angiographic suite. The GTT then passes directly to the Positron Tomograph Room of the Nuclear Medicine Suite. The total run of the pipe is 170 meters of 316 stainless steel tube, $3 \mathrm{~mm}$ ID, $4.75 \mathrm{mm0D}$, inside a $3.8 \mathrm{~cm}$ OD PVC plastic pipe. The inner steel tube is joined with 316 steel Swagelok connectors throughout. Inspection ports were installed at appropriate points to allow any maintenance which might be required. . Each terminal consists of a locking stainless steel box with a quick-disconnect and flow control valve.

The $P$-tube is a commercially supplied system specially modified for use here. Four inch (nominal) welded galvanized pipe connects each terminal directly with the sending station in the cyclotron facility counting area. A standard transmission cannister, called a "Rabbit," is blown through the pipe by air supplied from blowers in each station. Installing. individual blowers in each station is less costly and easier to service than a central supply with diverter valves and return pipe. Prior to construction there was some worry that a rabbit may be jammed in the system in an unknown location. An electronic tracking system at the cyclotron terminal monitors the progress of the rabbit in transit.

RESULTS AND CONCLUSIONS

The GTT was designed to operate at a concentration of $10 \mathrm{mCi}$ of 
a pure positron decay radionuclide per liter of gas. The closest proximity to the line an individual will pass is the tunnel under East 68th Street. Figure 44 shows a cross section of the tunnel and the dose rates at one foot and one meter from the GTT; with $10 \mathrm{mCI}$. 150/1 flowing. A "worst case" calculation assuming that the system were operating 8 hour/day, 200 days/yr., an individual making thirty-two leisurely 12 second trips through the tunnel every day would accumulate $2.7 \mathrm{mR} / \mathrm{yr}$. from this source.

The GTT was subjected to two pressure tests. The stainiess steel transport tube withstood 60 PSIG Helium pressure for 72 hours with no measurable pressure loss. The plastic outer tube was pressure-tight at 10 PSIG, with a leak of $\sim 75 \mathrm{ml} /$ minute mostly attributed to the testing apparatus.

Selected to provide flow rates of 2 to $4 \frac{1}{1}$ min at pressure differentials of 5 to 10 PSIG, the tubing diameter allowed for many bends and some possible restriction or flow which would result if any joints were left with flashing or the tube were crimped. Table 29 shows the measured values of flow at various pressure differentials with a 15 PSIG input. The system volume is estimated at $1550 \mathrm{ml}$. For steady-state 150 studies the usual primary gas flow rate is one 1/min, at a pressure drop of $22-3$ PSI. The average transit time at these conditions is 93 seconds, or just slightly iess than the half life of 150 . Higher flow rates and shorter transit times are possible. It is also possible at the cyclotron hot lab to pre-mix the gas with other gases to make an inhalation mixture. The increased delivery volume will decrease transit times even further.

Transit times for the P-tube are: 1) to the scanning facility, $\sim 5$ seconds, 2) to the Diagnostic Radiology Suite, 220 seconds, 3) to the Nuclear Medicine Suite, 245 seconds. This compares to walking times of 15-30 seconds, 45 to 60 seconds, and 90 to 120 seconds, respectively. 


\section{TABLE 29}

Flow Vs $\triangle P$ at 15PSIG input
Flow $(1 / \mathrm{min})$
4.35
4.80
5.30
5.85 


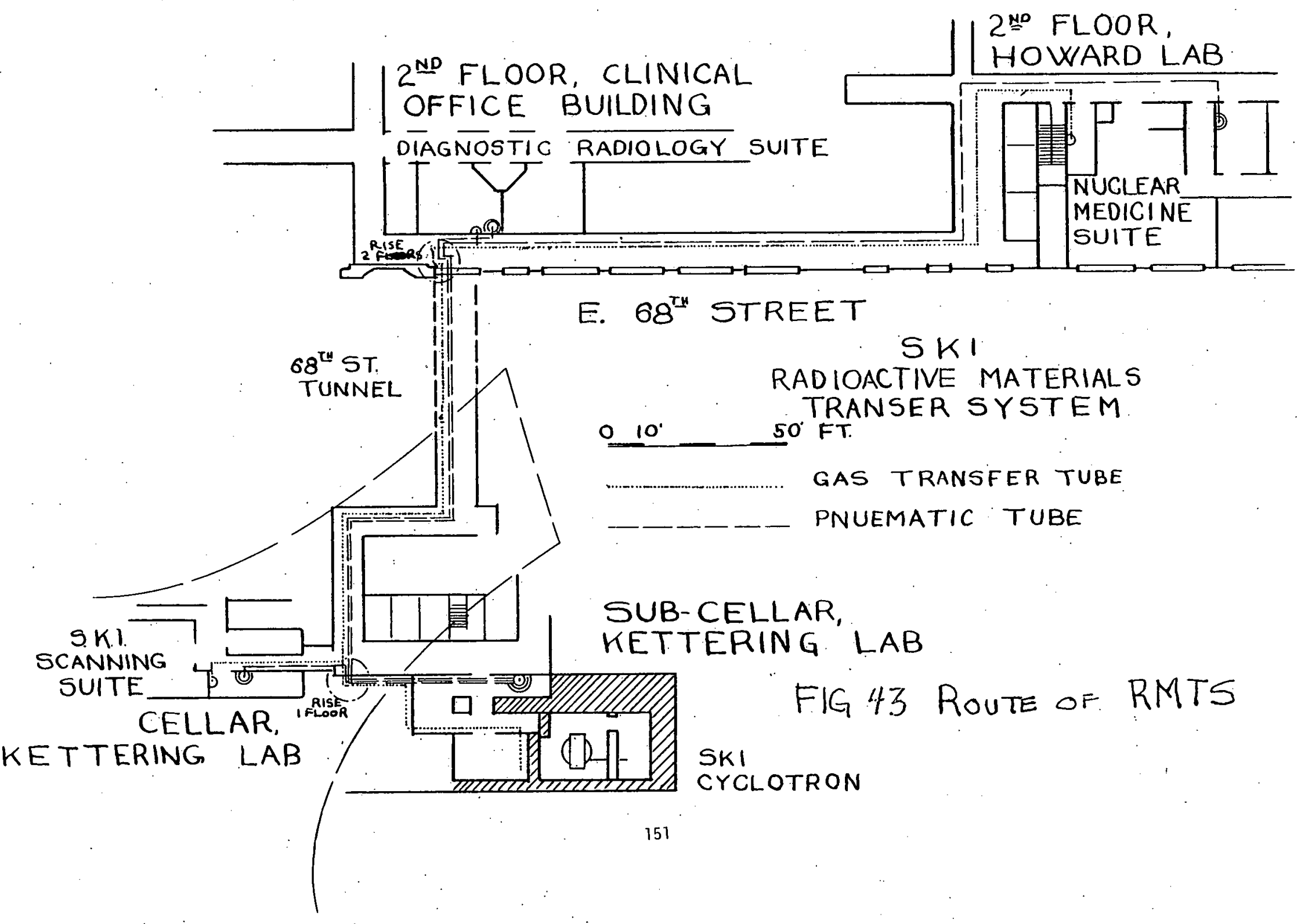




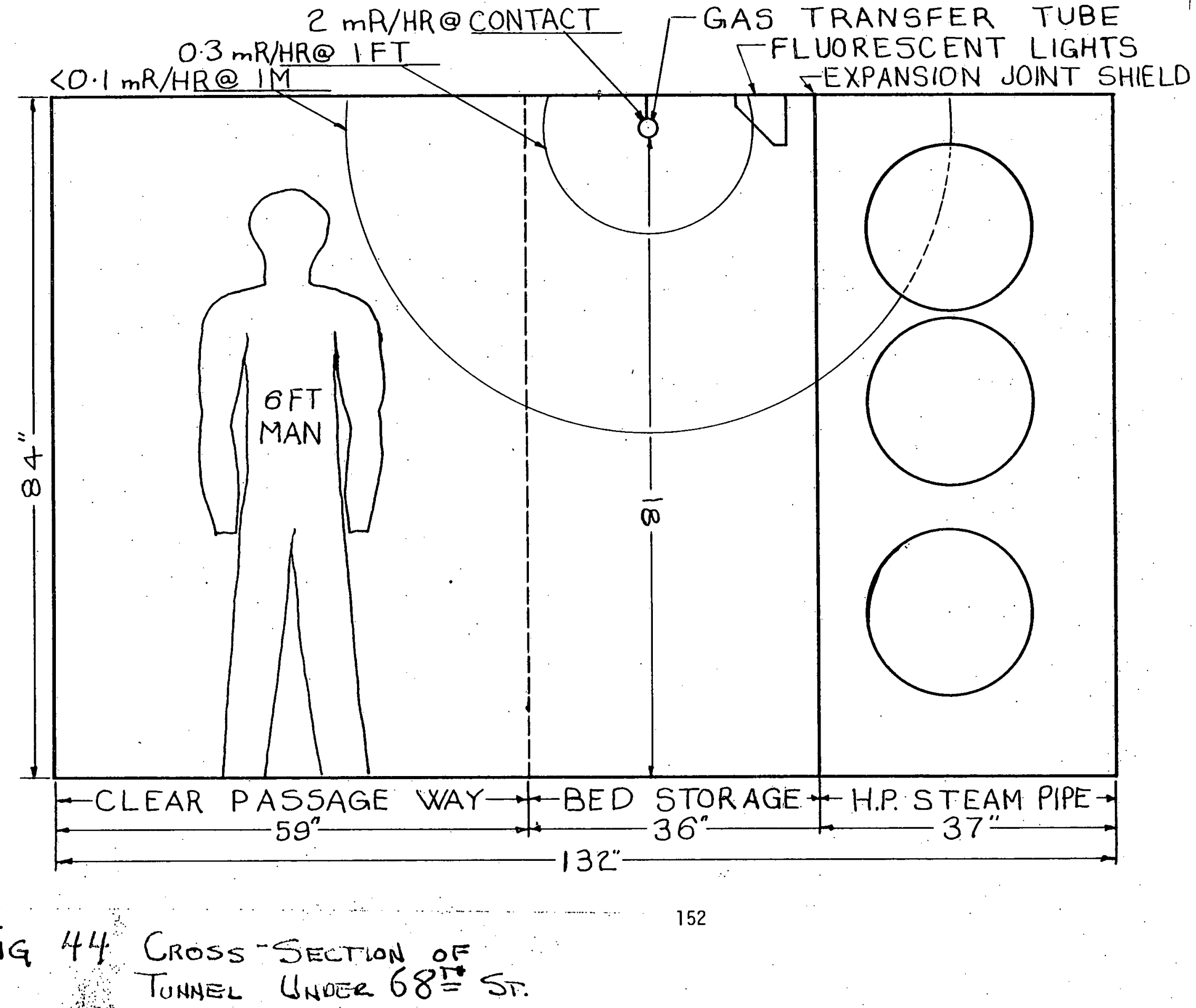




\section{PUBLICATIONS}

1. Chandra, R. and Freed, B.R., Tissue distribution of DL-lactin-acid- $1\left({ }^{14} \mathrm{C}\right)$ in tumor-bearing rats. Int. J. of Nuc. Med. and Biol., In Press.

2. Chandra, R., McDonald, J.M., Reiman, R.E., and Tilbury, R.S. Potassium-38, a 7.6 minute half-lived radionuclide for assessment of myocardial function. (in) Proceedings of Second International Symposium on Radiopharmaceuticals, Soc. of Nuc. Med., New York, 1979.

3. Cooper, A.J.L., McDonald, J.M., Gelbard, A.S., Gledhill, R.F. and Duffy, T.E. The metabolic fate of $13 \mathrm{~N}-1$ abeled ammonia in rat brain. J. Biol. Chem., 254, $4982-4992,1979$.

4. Gelbard, A.S., Benua, R.S., Laughlin, J.S., Rosen, G., Reiman, R.E. and McDonald, J.M. Quantitative scanning of osteogenic sarcoma with nitrogen-13 labeled L-glutamate, J. Nucl. Med., 20, 782-784, 1979.

5. Lockwood, A.H., McDonald, J.M., Reiman, R.E., Gelbard, A.S., Laughlin, J.S., Duffy, T.E. and Plum, F: The dynamics of ammonia metabolism in man. Effects of liver disease and hyperammonemia. J. Clin. Invest., 63,.449-460, 1979.

6. Rao, S.A., Dahl, J.R. Lee, R and Tilbury, R.S. Cross section for the

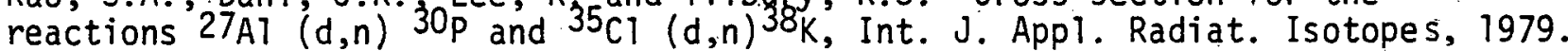

7. Stavchansky, S.A., Tilbury, R.S., McDona.ld, J.M., Ting, C.T., and Kostenbauder, H.B. In-vivo distribution of carbon-11 phenytoin and its major metabolite, and their use in scintigraphic imaging. J. Nucl. Med.; 19, 936-941, 1978.

8. Tilbury, R.S., Dahl, J.R., Chandra, R., McDonald, J.M., Reiman, R.E. and Myers, W.G. Potassium-38 production with a cyclotron for medical use. J. Labe1. Compds. and Radiopharm., 16, 127-128, 1979.

9. Tilbury, R.S., Gelbard, A.S., McDonald, J.M., Benua, R.S., and Laughlin, J.S. A compact in-house multi particle cyclotron for production of radionuclides and labelled compounds for medical use. IEEE Trans. on Nuc. Sci.; 26, 1.729-1732, 1979.

10. Tilbury, R.S., Dahl, J.R., N-13 species formed by proton irradiation of water. Radiat. Res., 79, 22-33, 1979.

11. Tilbury, R.S., Myers, W.G., Chandra, R., Dah1, J.R. and Lee, R. Production of 7.6 minute potassium-38 for medical use., J. Nucl. Med., In Press.

12. Zeitz; $L$. and McDonald, J.M. Pitfalls in the use of in vitro survival curves for the determination of tumor cell survival with fractionated doses. Brit. $J$. Radiology, 51, 637-639, 1978. 


\section{ABSTRACTS}

1. Bigler, R.E., Kostick, J.A., Gillespie, J.R., and Laughlin, J.S. Compartmental analysis of the steady-state distribution of oxygen-15 labeled oxygen and water. J. Nucl. Med., 20, 606, 1979.

2. Bigler, R.E., Schma11, B. Andrews, L.K. and Kostick, J.A., Lymphosarcoma uptake of Iic-alpha-amminoisobutyric. The Radiological Society of North America, 65th Scientific Assembly and Annual Meeting, Nov. 25-30, 1979.

3. Bigler, R.E. and Schmall, B. Positron-electron transmutation (PET) tomography with the neuroleptic drug I8F-haloperidol. The Radiological Society of North America, 65th Scientific Assembly and Annual Meeting, Nov. 25-30, 1979.

4. Cochavi, S., Strashun, A.M., Goldsmith, S.J., Bigler, R.E. and Benua, R.S. Planar imaging of positron emitting radionuclides (PIPER) with a multi-crystal camera. American Association of Physicists in Medicine, Twenty-first Annual Meeting, Atlanta, Georgia, July 29-Aug. 2, 1979.

5. Cooper, A.J.L., McDonald, J.M., Gelbard, A.S. and Duffy, T.E., Metabolism of $13 \mathrm{NH}_{3}$ in brain. Amer. Chem. Soc. Book of Abstracts, 198th National Meeting, Washington, D.C., Sept. 9-14, 1979.

6. Gelbard, A.S., N-13-L-amino acids synthesized enzymatically for in vivo metabolic studies. 2nd Int. Congress, World Fed. Nucl. Med. \& Biol., Sept. 17-21, 1978, Washington, D.C.

7. Gelbard, A.S., Benua, R.S., McDonald, J.M., Reiman, R.E., Vomero, J.J. and Laughlin, J.S. Organ imaging with N-13-L-glutamate. J. Nucl. Med., 20, 663, 1979.

8. Gelbard, A.S. - and Cooper, A.J.L., Synthesis of ${ }^{13} \mathrm{~N}$-labeled arometic L-amino acids by enzymatic transamination of $13 \mathrm{~N}-\mathrm{L}-\mathrm{g}$ lutamic acid. J. Label Compound Radiopharm, 16, 92, 1979.

9. Gelbard, A.S., Freed, B.R., Cooper, A.J.L., McDonald, J.M., Reiman, R.E., and Vomero, J.J., L(N-13) amino acids: enzymatic syntheses and metabolic studies. Amer. Chem. Soc., 1978th National Meeting, Washington, D.C. . Sept. 9-14, 1979.

10. Myers, W.G., Bigler, R.E., Graham, M.C. Studies on the distribution of potassium-38 in vivo by means of positron-electron transmutation tomography. The American Society of Therapeutic Radiologists, Joint Meeting with the Radiat. Res. Soc. and the AAPM, Oct. 23-27, New Orleans, 1979.

11. Rosen, G., Gelbard, A.S., Benua, R.S., Laughlin, J.S., Reiman, R.E., and McDonald, J.M. N-i3 glutamate scanning to detect the early response of primary bone tumors to chemotherapy. Am. Assoc. Ca. Res., 20, 1979.

12. Russ, G.A. and Baronfsky, D.R., Selective radiation of osseous tumors with 32p-HEDP. Proc. Conf. Combined Modalities: Chemother. Radiother., 115, 1979.

13. Russ, G.A., Woodard, H.O, Baronofsky, D.R. and Tobin; M.A., Long term retention of hydroxy-ethylidine diphosphonate-32p (HEDP) in Fractured and intact rat tibias. Health Physics, 1979. 


\section{ABSTRACTS (Continued)}

14. Schmall, B., Dahl, J.R., and Bigler, R.E. Synthes is of C-11 labeled alphaaminoisobutyric acid as a potential agent for tumor visualization. Amer. Chem. Soc., 114th National Meeting, Washington, D.C., Sept. 10-14, 1979.

15. Schmal1, B., Tilbury, R.S., and Nisselbaum, J.S. The synthes is of $18_{F-}$ labeled 4-fluorestradiol and haloperidol for studies in nuclear medicine. Amer. Chem. Soc. 4th Winter Fluorine Conference, Daytona Beach, Fla., Jan. 29-Feb. 2, 1979. 


\section{PRESENTATIONS:}

1. Bigler, R.E. The use of $\mathrm{C}^{15} \mathrm{O}$ and $15_{2}$ steady-state imiaging to monitor radiation treatment of cancer. University of Illinois, College of Veterinary Medicine and Bioengineering, Urbana-Champaign, I1linois, 1978 .

2. Bigler, R.E. A survey of current positron emission tomographs. Hemorial Hospital Nuclear Medicine Seminar, New York, N.Y., October 16, 1978.

3. Bigler, R.E. Recent experiences with the PC4200 positron canera. The Mount Sinai Medical Center, New York, N.Y., January 4, 1979.

4. Bigler, R.E. and Graham, H. Recent developments in positron enission tomography. Radiological and liedical Physics Suciety of Rew York, American Association of Phy'sicists in Medicine, New York, N.Y., January 24, 1979.

5. Bigler, R.E., Grahan, M.C., Kostick, J.A. and Laughlin, J.S. Phantom measurement intercomparison of current pos tron coincidence tomographs. The Radiological Society of North America, 64th Scientific Assembly and Annual Meeting, Chicago, Inlinois, Nov. 6-llec. 1, 1978. 